\title{
Feeling the Fear and Doing It Anyway: \\ A Case Study of CHRS-City, an Intervention for Adolescent Mental Health
}

\section{Lisa Thompson}

A three paper thesis submitted in partial fulfillment of the requirements of the Master of Education

Victoria University of Wellington 2011 


\section{Acknowledgements}

This thesis has been a long time in the making, and its final completion is due to the support, advice and encouragement of numerous people.

I am forever grateful to my supervisor, Dr. Catherine Savage for her encouragement to embark on this journey in the first place. I would like to thank Cath for her patience, and her valuable advice and guidance which supported the development of this thesis.

There are many others who have made the completion of this thesis possible. I would like to acknowledge and express my sincere gratitude to the participants, all of whom had experienced challenging journeys, but gave their time willingly to share their experiences. Without them this research would not have been possible. It was their journeys of transition that inspired this research. I would also like to acknowledge the other students who have attended CRHS-City and experienced the challenge of transitioning back to school or further education.

I would particularly like to thank my Principal, Ken McIntosh and the Board of Trustees of the Central Regional Health School, for providing me with the time and assistance to complete this project. I would also like to thank my colleagues who have not only been instrumental in supporting the development of CRHSCity, but also managed with an absent team leader at times.

Finally, I want to thank my family, husband Terence and my parents Walter and Pauline, who have provided their love and support throughout. I would particularly like to thank my daughter Emilie who put up with a busy and sometimes unavailable Mum. I am looking forward to being able to watch you surf Emilie!

It is to Emilie that I dedicate this work. 


\begin{abstract}
Provision for adolescent mental health in New Zealand is in its infancy. CRHSCity is the first Ministry of Education funded initiative that addresses adolescent mental health and transition back to school in New Zealand. This thesis examines the experiences of students and their families attending CRHS-City and how they were supported to transition back to school or further education. This research is important as it focuses on a growing need and documents Central Regional Health School's attempt to address it.
\end{abstract}

The methodological approach was a multiple case study underpinned by a constructivist paradigm. A qualitative approach was appropriate for this study as the research wanted to capture the impact attending CRHS-City had on a specific group of students and their transition back to a regular school or further education. Three students and their families identified they would be willing to be interviewed as part of this study. Eight overarching themes emerged from the research.

Participants described positive outcomes from their experience of attending CRHS-City. This study has found being at CRHS-City helped the participants explore different ways of managing their mental health condition and gain confidence in their abilities to do so, which in turn supported the overall goal of a return to school or further education. However this was not an easy process for either the students or their parents.

The findings from this research identified recommendations specific to CRHSCity and for the education sector in general to support students who have a mental health condition continue with their education goals. Support for the student's family and the regular school is an essential part of this process. Research into effective interventions within mainstream schools to support students who have mental health needs is seen as a logical next step. 


\section{Table of Contents}

Acknowledgements

Abstract ii

Chapter 1: Introduction 1

1.1 Child and adolescent mental health in New Zealand 2

1.2 Background to CRHS-City 3

1.3 The setting 5

1.4 The programme 6

$\begin{array}{lll}1.5 & \text { Admission and review process } & 7\end{array}$

1.6 Transition process 8

1.7 The researcher's role within CRHS-City 9

$\begin{array}{lll}1.8 & \text { Overview of the thesis } & 10\end{array}$

\section{Chapter 2: Literature Review}

2.1 Introduction 11

2.2 Special Education in New Zealand 12

$\begin{array}{lll}2.3 & \text { Adolescents and mental health } & 14\end{array}$

2.4 International research on mental health programmes 16

2.5 Anxiety and school refusal 18

2.6 Transition planning 21

2.7 School connectedness 24

$\begin{array}{lll}2.8 & \text { Family involvement } & 27\end{array}$

2.9 Summary 28 


\section{Chapter 3: Methodology}

3.1 Introduction

3.2 Part A - Research

3.2.1 Aims

3.2.2 Case study research

3.2.3 Theoretical perspective

3.2.4 Tasks and procedures

3.2.5 Validity

3.2.6 Ethical consideration

3.3 Part B - Researcher role

3.3.1 The role of the researcher

3.3.2 Researcher bias

3.4 Summary of methodology

\section{Chapter 4: Findings}

4.1 Introduction

4.2 Part A - Case stories

4.2.1 Data sources from the students files 49

4.2.2 Natasha 49

4.2.3 Jimmy 54

4.2.4 Anna 60

4.3 Part B - Themes 65

4.3.1 Theme A 65

4.3.2 Theme B 69

4.3.3 Theme C 72

4.3.4 Theme D 74

4.3.5 Theme E 77

4.3.6 Theme $F \quad 80$

4.3.7 Theme G 81

4.3.8 Theme $\mathrm{H}$ 
4:4 Issues for future consideration $\quad 85$

4:5 Conclusion 86

\section{Chapter 5: Discussion}

5:1 Introduction 88

5:2 Significance of context 89

5:3 Issue of inclusion 93

5:4 Value of learning skills to manage mental health 96

5:5 Implication of establishing school connectedness 98

5:6 Importance of family 101

5:7 Limitations 103

5:8 Summary 104

5:9 Recommendations 104

5:10 Conclusion 108

$\begin{array}{ll}\text { References } & 111\end{array}$

\section{Appendices}

Appendix A: Parent expression of interest 117

Appendix B: Student expression of interest 118

Appendix C: Parent information 119

Appendix D: Student information 121

Appendix E: Invitation to parents 123

Appendix F: Invitation to students 125

Appendix G: Informed consent for parents 127

Appendix H: Informed consent for students 129

Appendix I: Interview schedule 131

Appendix J: Content units of themes 134

Appendix K: Approval memo 137

Appendix L: Principal consent 138

Appendix M: Transcriber's confidentiality agreement 140 


\section{List of Tables}

Table 1:1 Admissions at CRHS 3

Table 3:2 Description of participants 38

Table 3:3 Example of coded transcript 42

\section{List of Figures}

Figure 3:1 Overview of tasks and procedures 


\section{CHAPTER 1}

\section{Introduction}

"When you want something to change, you must change something"

(Molnar \& Lindquist, 1990) ${ }^{1}$

The prevalence of emotional health problems, including depression, eating disorders and suicidal behaviours with New Zealand youth are of serious concern (Adolescent Health Research Group, 2003). This research centred on three students' experiences of attending Central Regional Health School City (CRHSCity), a stand alone school developed to meet the needs of adolescents with a mental health condition and their families' experiences too. A distinguishing feature of students attending CRHS-City is their current inability to attend a mainstream school because of a mental health condition. Attending CRHS-City is intended to support students return to school or transition to further education or employment.

The purpose of this research was to investigate the experiences both of students attending CRHS-City and of their families and how attendance at this school supported transition back to school or further education. Further, the research aimed to ascertain to what extent attending CRHS-City and the programme at CRHS-City met the needs of the students specific to supporting the student to manage their mental health condition.

The following section provides a rationale for the research, situating the study in the current schooling context and providing a brief overview of provision of mental health services for students in NZ schools. This is followed with an overview of the background to CRHS-City including a description of CRHS-City. The chapter concludes by identifying the role of the researcher within CRHS-City.

\footnotetext{
1. Molnar, A., and Lindquist, B. (1990). Changing problem behavior in schools. San Francisco: JosseyBass.
} 


\subsection{Child and Adolescent Mental Health in New Zealand}

The mental well-being of school age students is of increasing concern in New Zealand, in particular the ability of schools to be able to manage the needs of these students within the school environment. The New Zealand Mental Health Survey (2006) reports half of all cases of people who have experienced a mental health disorder experience this before age eighteen. This survey claims that the median onset of an anxiety disorder is thirteen years. Furthermore the prevalence of a mental health disorder and particularly a serious disorder is higher for younger people and people with less education (Oakley Browne, Scott, Wells, 2006). The report Te Tahuhu - Improving Mental Health 2005 - 2015 states that better outcomes are achieved for children and young people when the intervention occurs early and state services work together to effectively address the needs of children and young people who have mental health conditions (Minister of Health, 2005).

In 2003 a health profile of New Zealand youth who attended secondary school identified that the rates of mental health problems in school age students in New Zealand are up to twice those found in a national mental health survey of young people in Australia. Clearly mental wellbeing should be a priority for health

promotion for young New Zealanders (Adolescent Health Research Group, 2003). However, according to Eggleston and Watkins (2008) who conducted an analysis of mental health outcome measures for children and adolescents, mental health services in New Zealand remain significantly underfunded. In 2008, the rate of suicide amongst youth aged fifteen to twenty four years (1524yrs) decreased by 35.4 percent since the peak in 1995, however the female youth suicide rate of 11.1 per 100,000 population was the highest since 1999 . When ranked alongside other OECD countries, the New Zealand suicide rate for males aged fifteen to twenty four years in 2008 was higher than that in any other country except Iceland (2007) and Finland (2007). Furthermore the New Zealand female youth suicide rate in 2008 was higher than that of any other country (Ministry of Health, 2010). Mental illness and exposure to stress and 
adversity are identified as the largest precipitants to suicidal behaviour. Protective factors that have been found to alleviate suicidal behaviour include having social support and social networks, as well as positive school experiences (Beautrais, 2003).

Over the last five years an increasing number of students have been admitted to the Central Regional Health School as a result of a mental health condition that impacts upon the student's ability to be able to attend school. This admission rate has risen steadily since 2007 reaching forty four percent (44\%) of all admissions in 2010. Table 1:1 below shows the admission rates at Central Regional Health School over the last five years.

Table 1:1 Admissions at CRHS

\begin{tabular}{|c|c|c|c|}
\hline Year & Total Admissions & $\begin{array}{c}\text { Mental Health } \\
\text { Admissions }\end{array}$ & $\begin{array}{c}\text { Percentage of Mental } \\
\text { Health Admissions }\end{array}$ \\
\hline 2007 & 386 & 120 & $31 \%$ \\
\hline 2008 & 384 & 117 & $30 \%$ \\
\hline 2009 & 368 & 120 & $33 \%$ \\
\hline 2010 & 442 & 194 & $44 \%$ \\
\hline 2011 (Feb-May) & 267 & 127 & $48 \%$ \\
\hline
\end{tabular}

Despite these alarming statistics, research on interventions within the education system that support young people with a mental health condition appears to be non-existent in New Zealand.

\subsection{Background to CRHS-City}

In 2000 three regional Health Schools were established as part of the Special Education 2000 (SE 2000) policy to provide education for students with high health needs. The Central Regional Health School based in Wellington is one of these schools. The school delivers education to a variety of students across the lower North Island who experience high health needs. These services include health school teachers who work with individual students in hospital or at home and a school based at the Regional Rangatahi Adolescent In-patient Service 
(RRAIS) at Porirua Hospital for students with a mental illness. In 2002 a Lower North Youth Justice facility at Palmerston North was established and its education services provided by Central Regional Health School.

In 2008, Central Regional Health School in conjunction with the Capital and Coast District Health Board (CCDHB) established Central Regional Health School-City (CRHS-City), a stand alone school to meet the needs of adolescents with mental health conditions. The decision to establish this school within the Central Regional Health School was made in response to the increasing numbers of students admitted as a result of a mental illness over the years. Up until then these students, due to a lack of facilities within their schools remained in their homes accessing education through individual health teachers. Due to the nature of mental illness this was unsatisfactory in part because the ensuing isolation became a major barrier to students returning to school. In many cases students with social phobias became more reclusive. The establishment of CRHS-City was not to act as a separate special school but to provide a vehicle through which students would access therapy and make the transition back to their original school.

The Principal of Central Regional Health School first approached Ministry of Education (MoE) in 2007 with the idea of establishing a site specific to supporting students with mental health needs. This was as a result of a conversation with a CCDHB clinician regarding two students who were clients of CCDHB and were admitted with Central Regional Health School and being taught at home by a regular health school teacher. The two students were not able to manage a return to a large mainstream school but it was thought they would be able to manage a smaller environment geared specifically to supporting them to manage their mental health condition while maintaining their education. The idea that CRHS-City would provide a smaller environment that enabled students to access both their educational and therapeutic needs emerged from this conversation. MoE agreed to a two year pilot to determine if CRHS-City did meet a need for 
these students. The focus of the intervention was an eventual transition back to a regular school or on to further education and/or employment.

At the start of 2008 I became involved as the team leader of CRHS-City and worked with the Principal to determine what a school like this would look like and the type of programme it would offer. This included consultation meetings with health and education professionals. The team leader and staff employed to work at CRHS-City met regularly over the first two years to evaluate and adapt the programme, protocols and interventions that are now a part of the CRHS-City school culture. In December 2010 MoE approved CRHS-City for permanent funding as an on-going school within the Central Regional Health School.

\subsection{The setting}

CRHS-City is located in central Wellington with easy access to public transport and community facilities. The school consists of a large open plan space, with two meeting rooms, office space and a "chill out" room. Students that attend can expect:

- a locker to place their belongings

- kitchen facilities to prepare their lunch

- access to music as negotiated with staff to meet their needs

- to-date equipment and resources to meet their educational goals

- quiet spaces that enable students to meet with their support staff

- to feel included, supported, accepted and valued.

CRHS-City provides an integrated programme that enables students to access both education and mental health services as part of a multi-disciplinary process. The aim of the programme is to reduce the time students spend out of school by providing quality teaching and learning combined with active therapeutic interventions to support students with their transition plans. Both students and schools require time and support to put in place effective strategies and supports to enable a successful transition back to school. Students initially attend CRHS- 
City each day to enable them to establish routines, engage in learning and identify and practise purposeful coping strategies to assist them to remain within a school setting. Once ready, a plan is put in place to support their return to regular school. This process is monitored and adjusted with the goal being to spend decreasing time at CRHS-City and increasing time at their regular school. This transition process generally takes two to three terms and involves CRHSCity staff working as a team with the student, their family, the student's regular school staff and mental health case managers.

CRHS-City takes up to fifteen students at one time. The daily roll varies depending on the number of students being admitted and the number transitioning to their regular school. The staff at CRHS-City includes a team leader, two full-time teachers, one part-time teacher, a support worker, and a CCDHB employed occupational therapist who provides clinical support and therapeutic interventions. For students to meet the criteria for an admission to CRHS-City they need to be enrolled in a regular school but currently not attending that school as a result of their mental health condition. Students must also be in a mental health funded programme and have a DHB case manager. Furthermore the student's regular school and family must support their admission.

\subsection{The programme}

All students admitted to CRHS-City have an individual plan (IP) which identifies both educational and therapeutic goals which actively are in turn supported by an individual education plan (IEP) and an individual therapeutic plan (ITP). The IEP's include transition goals, curriculum goals and key competency goals ${ }^{2}$.

\footnotetext{
${ }^{2}$. The Key Competencies listed in the New Zealand Curriculum are conceptualised as the capabilities needed to undertake a task or meet a demand. The five key competencies identified in the New Zealand Curriculum are: Managing self; Relating to others; Participating and contributing; Thinking; Using language, symbols, and texts (Ministry of Education, 2007).
} 
Curriculum goals generally include two to four subject areas determined with the student and their regular school. The student's individual plans are broken down into a weekly plan the student works toward. The individual key competencies and therapeutic goals are also reinforced during specifically designed group and school wide programmes.

The programme includes:

Curriculum studies/workshops

Co-operative group work focusing on social skills and life skills

Career and vocational programmes

Physical education programmes

Adventure based programmes

Creative activities including drama

Therapeutic groups

Active transition plans

The programme and timetable are evaluated regularly and modified to suit student needs at that time.

\subsection{Admission and review process}

On admission to CRHS-City a meeting is held for the student, their family, a representative from the student's regular school, the mental health case manager, relevant CRHS-City staff and other agencies that may be involved such as Special Education and Care and Protection Services. This meeting enables a team approach to be established from the outset and provides an opportunity for shared understanding, clarification of issues, and a chance to agree to initial goals in a collaborative way.

Following this meeting a three-weekly review process takes place involving the same team. Each review process provides an opportunity for feedback to be 
given, strategies to be agreed and reinforced and further plans to be put in place. The review process is seen as integral to the success of a student's transition.

An issue that has become apparent is a significant component of the work at CRHS-City is work with the family. Families require support and guidance specific to their responses to and management of their child. Such support takes time and a coordinated and consistent approach from all involved. A further issue that has arisen on several occasions is regular schools' reluctance to receive a student back. In some cases students may have presented with either behavioural problems or risky behaviour that has impacted on the school in some way. From experience, regular schools require support and guidance specific to their context and capability to manage the student's return.

The review process enables all involved to meet regularly to identify issues as they arise and to discuss and own together how to support a student. The outcomes of each meeting are reviewed at the next to ensure accountability. It is acknowledged transition to school works better when all services work together and the student and family are fully included in the planning and decision making process. These meetings take significant time and co-ordination. They demonstrate the need for clear and frequent communication to be in place to ensure issues are able to be addressed and planned for as they arise.

\subsection{Transition process}

Establishing regular attendance is the primary goal when a student is admitted to CRHS-City. Achieving it enables a student to develop a consistent routine of attending school as well as providing an opportunity for staff to become familiar with the strengths and needs of the student. As time progresses and as determined by the team, transition back to school begins. This is progressive and staged to meet the student's needs. Once a student has successfully transitioned back to school, CRHS-City remains involved for six to eight weeks in order to monitor and provide support as required. This involves a staff member 
having regular contact with the student, their regular school, and family as well as the review meeting process.

\subsection{The researcher's role within CRHS-City}

My teaching career began as a primary school teacher at a regular mainstream school. Prior to my current position as team leader of CRHS-City I worked as a health school teacher for seven years at the Regional Rangatahi Adolescent Inpatient Service (RRAIS). RRAIS is an acute psychiatric adolescent in-patient and day programme service. Adolescents are admitted if they have an acute mental illness such as: schizo-effective disorder; depression; psychosis; anorexia. The hospital is both an in-patient and day programme service. The inpatient service provides thirteen beds for adolescents thirteen to eighteen years from a wide geographical area with an acute mental illness. The day programme enables six local adolescents not requiring admission or in the process of transitioning back to the community to attend the therapeutic day programme operating at the hospital. The health school is a component of the therapeutic day programme for both in-patient and day patients.

Improving the process within a clinical setting for determining the readiness for a student to return to school followed by a carefully planned transition is vital for a student to be able to re-integrate back in to school successfully. A common dilemma when adolescents are discharged from an acute psychiatric hospital is they may not be ready to return to school or in some cases the school is not ready to accept the student back. This often results in CRHS and RRAIS staff taking on an advocacy role for the students concerned. My interest in supporting the students I worked with at RRAIS to transition successfully back to school led to my role as team leader at CRHS-City.

As the team leader for CRHS-City, my interest in carrying out this research comes from a desire to understand the experiences of students who have had time away from school as a result of a mental health condition and are returning 
to school. As the stated purpose of CRHS-City is to provide a transition service, understanding more about the transition experience for these students may enable the school to make adaptations to programmes to meet the needs of students more efficiently and effectively. More specifically, I would like to identify what challenges and supports, if any, the students and their families encountered so that CRHS-City might anticipate these challenges and optimise support for students. As I work in the areas of both education and mental health, I have opinions regarding the issues facing schools, students and their families. Therefore, I will share my experiences within the study and acknowledge how the findings may be influenced by my interpretations and point of view as part of the discussion in chapter 5.

Provision for adolescent mental health in New Zealand is in its infancy. CRHSCity is the first Ministry of Education funded initiative that addresses adolescent mental health and transition back to school in New Zealand. Therefore research is important as it focuses on a growing need and documents Central Regional Health School's attempt to address it.

\subsection{Overview of the thesis}

This first chapter has outlined the background, purpose and the structure of CRHS-City and why students attend. Chapter 2 reviews literature that relates to adolescents and mental health and their education with a particular emphasis on the challenges for students, their families and schools. Chapter 3 discusses the research methodology including data collection and analysis. Chapter 4 presents three case stories, and describes and interprets the students' experiences of attending CRHS-City and their families' experiences too. In Chapter 5, five key areas highlighted from the findings are discussed as well as limitations of the study and suggestions for further research. 


\section{CHAPTER 2 \\ Literature review}

We worry about what a child will become tomorrow, yet we forget that he is someone today.

(Stacia Tauscher) $^{3}$

\subsection{Introduction}

In this chapter I review literature and research specific to adolescents and mental health, international mental health programmes, inclusive education and transition planning. These areas were selected as they are reflective of the intentions of the establishment of CRHS-City. Further areas that became apparent from the literature and the research undertaken that are significant to this study are; anxiety and school refusal, school connectedness, and family involvement. Due to the nature of the research there was intersection between education and health literature.

This review presented a challenge as it became apparent for students with mental health conditions there was a lack of literature specifically related to school transition while concurrently enrolled in a specialist school. Furthermore adolescent mental health was not identified specifically in New Zealand Education policy. This provided a challenge as the area is noticeably nonexistent in literature around Special Education. As CRHS-City is a new initiative in New Zealand and one of the first interventions to address adolescent mental health in a secondary school context, the review was extended internationally to examine relevant areas. Before the literature in the area of mental health is reviewed, it is important to acknowledge the Special Education context in New Zealand in which this study is situated.

\footnotetext{
${ }^{3}$.http://thinkexist.com/quotation/we_worry_about_what_a_child_will_become_tomorrow/219120.html
} 


\subsection{Special Education in New Zealand}

The Government's Special Education policy affirms the right of every student to learn in accordance with the principles and values of the Education Act 1989 Special Education Policy (Ministry of Education, 1996). According to Davies (2000) Special Education in New Zealand has been subject to a number of reviews over the last twenty years. Davies (2000) identified the Special Education 2000 policy aimed to provide a level of resource for the purpose of meeting student's special educational needs. This involved targeted resourcing for students with high or very high special education needs and a mixture or resourcing mechanisms for students with moderate to high special education needs such as learning and behaviour difficulties.

More recently The Review of Special Education - Recommendations for Change, a cabinet report in 2010, sets out changes that are to be made over four years to ensure children with special needs get a fair deal, along with ensuring schools are ready to meet students' needs (Minister of Education, 2010). This report highlights the need for teachers to be better trained to meet the needs of students with special needs and emphasises the importance of agencies working more effectively together. Although the overall vision is to create a fully inclusive education system, the report also acknowledges the need for special schools. Further, while the report discusses broad concepts, meeting the needs of students who have a mental health condition is not specifically mentioned.

Since the 1980's, a focus on including students with disabilities in their regular school setting has been at the forefront of special education practice. This began with the integration of students with special needs from separate special schools into general mainstream education. However as students with special needs were mainstreamed, it became apparent placement in general education did not necessarily ensure students had access to positive learning opportunities or were included in the classroom and school activities. In fact for some, particularly students with high health needs, attending school was impossible. For this 
reason the Ministry of Education established the three regional Health Schools as part of SE 2000. The intention of the Health Schools was and still is not to act as a permanent placement but as a specialist service to support students' return to their regular school.

Working in an inclusive paradigm requires a fundamental shift in thinking, moving educators away from explanations of educational failure that concentrate on the characteristics of individual children and their families, towards an analysis of the barriers to participation and learning experienced by students within school systems (Ainscow, 1994, Booth \& Ainscow, 2002). In this respect special education is now recognised as a point on a continuum of instruction rather than a separate body of instruction for learners who are identified to fit into categories of disability and deficit. The intention of specialist schools like CRHS-City is to work within an inclusive ideology seeking to address exclusionary practices that have seen many students out of school and return them with support and success to their mainstream school or if old enough onto further education. Significant to this research is the daunting experience school can often be for students with a mental health condition, accompanied often with the inability of schools to manage these students. Eccles (as cited by McInerney \& Mclnerney, 2002) suggests there can often be a mismatch between what a school can offer in terms of a supportive social and intellectual environment for adolescents and what they might actually need. Although attendance at CRHS-City may appear to take students out of the mainstream setting, their very attendance at CRHSCity begins the process of establishing school connectedness. As the focus of CRHS-City is to establish and maintain links with their regular school, students attend CRHS-City with the knowledge they will be working towards a return to school and are constantly focused on this goal. For some students who are learning to manage a mental health condition attending a large mainstream school will continue to be difficult. 
As stated previously this review will cover literature in several areas: firstly, adolescents and mental health; secondly, international research on mental health interventions; thirdly, anxiety and school refusal; fourthly, transition planning; fifthly, school connectedness, and finally it will conclude with a review of family involvement in intervention.

\subsection{Adolescents and mental health}

The Human Rights status report in Aotearoa reports 'young people who have mental health problems are less able to fully realise their human rights than other social groups' (as cited by Bennyworth, 2006, p.15). Mental illness is a highly complex issue and can include a variety of diagnoses and disorders that may occur in isolation or as a set of disorders that reduce an individual's ability to access education and normal social activities. These conditions can range from anxiety disorders, depression, bipolar disorder, eating disorders, obsessive compulsive disorders and schizophrenia. For young people these conditions are accompanied with the adolescence developmental period which in itself can be a turbulent experience as they deal with the transition to adulthood.

It is not uncommon for adolescents to experience difficulties during this time, however most pass through puberty and adolescence without significant psychological or emotional difficulties (McInerney \& McInerney, 2002). Erikson (as cited by Smith, 1998) identifies adolescence as a crucial stage in the development of an individual's identity. This is a time young people move from being family focused to peer focused with a common concern being social success. Adolescence is a time of personal change on a number of levels which also coincides with changes within the educational environment, moving into college. Fuller (1998, p.9) describes adolescents as having 'a desperate, and uncontrollable air about them' leading adults to restrict and contain their ways. This information has relevance for this research in that a student may find school to be too constraining and/or not experience a social connectedness with their school leading them to disengage from education. Often what needs to be 
identified is normal adolescent behaviour as opposed to behaviour that is a component of a mental health condition. De-Hayes, Gradison and Thambirajah (2008) note there are significant differences between students who are not able to attend school as a result of a mental health disorder and those who are truanting.

The New Zealand Mental Health Survey which was designed to gauge the frequency of mental illness amongst New Zealanders indicated that most people experience their first disorder early in their lives. In fact half of all mental health cases have started by age eighteen and for anxiety disorders the median onset was found to be age thirteen. Along with other factors, the prevalence of a disorder and a serious disorder is higher for younger people and people with less education (Oakley Browne et al, 2006). These findings indicate serious mental health issues often begin in adolescence, highlighting we need to be investigating ways in which to support vulnerable and at-risk students in our schools.

Atkins, Hoagwood, Kutash and Seidman (2010) prepared a paper for the 2009 Child and Adolescent Mental Health Services conference held in Nashville, U.S.A addressing the need for further research in the area of integration of education and mental health in schools. Their paper highlights this is an area vastly in need of research as there is a weak research base supporting effective interventions. Their work suggests with recent national reform efforts in education and mental health, an opportunity exists for re-examining models to better integrate mental health and education. Atkins et al (2010) recognise schools represent the most influential context on children's cognitive and social development. Therefore they suggest an ecological model conducive to students learning not only academic skills but competencies specific to functioning and managing their mental health within the school context. Along with addressing classroom strategies for teachers, they suggest mental health staff working within schools rather than superimposing a new set of programs on already busy teachers. Current models 
of practice tend to focus on crisis intervention, however Atkins et al (2010) suggest sustained supports are more beneficial for students. Examples provided include the use of natural resources within the school to implement and sustain effective supports for students; integrated models to enhance learning and promote health; and strengthening family involvement. Their paper reiterates ideas are plentiful, however there is very little research to support effective interventions and theoretical models.

\subsection{International research on mental health programmes}

Although New Zealand is in its infancy in providing for students with mental health needs, international initiatives have been in place and have been the subject of research for sometime. These initiatives vary in construction from inschool withdrawal units to stand alone clinical sites. Henderson, Langman and White (2006) describe a withdrawal school based programme set up in Brookline, Massachusetts for adolescents returning to the community following a mental health crisis. The programme provided intensive school based support and care coordination during the first six to ten weeks following discharge from hospital. Clinicians and a classroom aide worked within a 'home base' set up specifically within the school in order to support transition. An intensive plan was put in place to assist with the reintegration of students back into the classroom. The service offered assessment, counselling, family support, case management, care coordination and educational planning. Henderson et al (2006) identified following this programme eighty-eight percent (88\%) of students were attending school regularly and from the programme reported other significant functional gains. The programme recognised the need for students, families and schools to work together to assist the transition process. However Henderson et al (2006) also emphasised the lack of intensive aftercare resources and the impact of a fragmented service system on student success. Their study has implications for this research as it identifies the need for the student, family and services to work together including services remaining involved long enough to ensure the student and family are able to independently maintain transition outcomes. 
In the United States several states run comprehensive mental health care progammes such as the programme 'Expanded School Mental Health' (ESMH) which is designed to include mental health services offering evaluation, therapy and case management. Nabors, Reynolds, and Weist (2000) used focus group interviews to evaluate the ESMH programmes in high schools. To gather data ten focus groups were conducted with adolescents aged thirteen to nineteen years and nine focus groups with adult professionals as well as individual parent interviews. The students and adults represented three school communities with the majority being African American from low income families. The mental health condition of the student was not identified in the study however most students involved in the study were not receiving current mental health treatment outside of the programme. Significant outcomes of the ESMH programme were increased academic attendance and improved grades, improved self-esteem, social and coping skills, and reductions in aggressive behaviour and peer conflict. The study reported this programme served as a protective factor enhancing positive mental health and reducing risk. Although it was recognised some students did not readily access these services, the researchers argued if the services were promoted the associated stigma may be reduced.

A review was undertaken in England which sought to bring together findings from recent systematic reviews and individual evaluation studies to determine the effectiveness of programmes that support emotional wellbeing and mental health in schools. The review conducted by Aggleton, Hill, Maxwell, Mehmedbegovic, Warwick and Yankah (2008), aimed to make information available to policy makers and practitioners to support young people's emotional wellbeing and mental health. Five search strategies were utilized: a search of four on-line bibliographic databases; a manual search of nineteen international journals; eighteen websites relevant to the nature of the study; e-mail and telephone contact with mental health professionals; and literature not otherwise identifiable using the previous strategies. The criteria for the data collected included; 
publication dates, a target age range of between three to eighteen years, concerned with emotional well being and mental health, and focused on research or programmes taking place in schools and/or mental health services. The reviews and studies were limited to those that had been formally evaluated. Findings were categorised into three areas; supporting emotional wellbeing and mental health in schools, early assessment and support, and working with parents. The results indicate that school-based programmes sustained over one year were effective through the modification of the environment as well as the development of cognitive and behaviour strategies. Early and brief intervention programmes delivered through mental health services were found to reduce the time students remained with the service. Finally the review found that working with parents could not only substantially complement work undertaken with the young people, but altering parental perceptions and improving parents skills to cope with their children's needs could in itself be a stand-alone intervention.

Findings significant to this research is the recognition that 'intervention' is most effective when not completed with the student in isolation and it involves a team of people supporting the student including adapting the environment where necessary. Family are seen as a vital part of the process especially family being supported to develop skills to support their child during intervention and having skills to provide support post intervention. Further the earlier intervention takes place reduces the likelihood of young people becoming long term users of mental health services. It appears earlier intervention may reduce the likelihood of students developing unhelpful avoidant behaviours and is relevant to this research.

\subsection{Anxiety and school refusal}

Many of the students attending CRHS-City have presented with anxiety and school refusal (CRHS-City admission data 2008-2010). Therefore this was an area in need of further investigation. A review by Heyne, King, and Ollendick (2005) of cognitive-behavioural treatments (CBT) for anxiety and phobic disorder 
in children and adolescents indicate CBT strategies to be useful for addressing child-anxiety problems. The review identifies anxiety related problems act as barriers within an educational setting and can be experienced in differing ways. For example, students with performance anxiety encounter difficulty being ontask during social evaluative situations in a social setting. Students with internalising difficulties may experience problems forming or maintaining friendships resulting in becoming socially isolated from their peers. The review identified that such problems can lead to school refusal.

A twenty one year longitudinal study of the relationship between adolescent anxiety disorder and later mental health, educational and social functioning of New Zealand children indicates there are significant associations between anxiety disorders experienced in childhood and adverse outcomes in early adulthood. Significant associations were found between anxiety disorders experienced in adolescence and later risks of anxiety disorders, depression, illicit drug dependence and educational under-achievement. Of the nine hundred and sixty four (964) participants in the study $29.9 \%$ met criteria for at least one anxiety disorder, $9 \%$ for two or more disorders and $2.7 \%$ for three or more anxiety disorders (Fergusson \& Woodward, 2001).

Heyne et al (2005) identified a range of studies including clinic based studies and school-based studies where a CBT approach was used to treat childhood anxiety disorders, phobic disorders and school refusal. Common CBT strategies included relaxation training, cognitive restructuring, systematic and graded exposure to anxiety provoking situations, social skills training, contingency management and training in relapse prevention. Their review identified the need to be flexible with the approaches and exposure being a critical component of intervention programmes. A group format was found particularly useful as it created opportunities for peer modelling and further social exposure. Further they identified the role of parents as co-therapists responsible for the implementation of procedures was significant, along with the role of the school. The review 
confirmed behavioural and cognitive procedures are effective in the treatment of childhood anxiety disorders, phobic disorders and school refusal and emphasised the need for exposure and caregiver involvement.

An Australian case-control study conducted by Dudley, Hughes, Gullone and Tonge (2009) aimed to examine emotional regulation of school refusing children and adolescents. Their work identified that school refusal affects between one to five percent (1-5\%) of the school-age population and contributes to many longterm psychological problems if left untreated. The school refusal sample consisted of twenty one participants who presented with less than fifty percent (50\%) school attendance, remained at home with their parent's knowledge, and had a primary diagnosis of either a social phobia, generalised anxiety disorder, separation anxiety disorder or panic disorder. The non clinical sample were recruited from fifteen primary schools and nine secondary schools. If students met the criteria for each sample group, questionaires and interviews comprising questions aimed to assess the emotional regulation strategies employed by the students were conducted with both groups of students.

Dudley et al (2009) acknowledge research in this area is in its infancy and additional research is needed to confirm the findings. However the findings did indicate children and adolescents presenting with school refusal used less adaptive emotional regulation strategy compared to age and sex matched non clinical children and adolescents. The research suggests that school-refusing children are more likely to regulate their emotions through expressive suppression which may reflect the tendency for anxious individuals to perceive particular emotions unacceptable and consequently avoid emotional experiences. Therefore incorporating the development of healthy emotion regulation strategies for children and adolescents presenting with anxiety based school refusal would appear to benefit their treatment plans. School refusal is often an indicator of anxiety in young people, with persistent school refusers typically meeting criteria for one or more anxiety disorders. 
Findings significant to this research indicate students avoid situations they find challenging for many reasons and confirm school can be challenging for students who experience anxiety. However, students are able to learn to manage these situations by learning specific skills in particular those supported by a CBT approach. This involves learning to manage anxiety provoking situations, including having opportunities to practise the skills by experiencing exposure to challenging situations, alongside equipping parents to develop skills to support their child. The literature identifies unreasonable fears about leaving the home and parents can be successfully treated. It highlights the value both of intervening early before unhealthy patterns of avoidance are entrenched and further supporting parents to support their child. It appears from the literature a collaborative effort is needed from the child, family, school staff and clinicians to support a student returning to school.

\subsection{Transition planning}

Improving the process for determining the readiness of a student to return to school, followed by a carefully planned transition, is vital for a student to be able to re-integrate back to school successfully (Fuller, 1998). Due to the complexity of mental health, students need the process of transition to practise the skills they are developing to learn to manage situations they find difficult (Fuller, 1998).

The fact the student may still struggle should not be a deterrent but an opportunity for schools, family and community teams to support the student (Hawk \& Hill, 2001). As students who attend CRHS-City may be of an age at which they can leave school, transition into the tertiary sector and/or employment is considered relevant to this study.

Transitions through educational settings occur at several stages in a student's school life. These transitions are managed differently depending on the age of the student and the school setting (Fuller, 1998). For the purpose of this research, studies that focus on transition for adolescents are most relevant. 
Transition to secondary school takes place at a particularly vulnerable stage of a student's life (Hawk \& Hill, 2001). Students who have a mental health condition are not only at a vulnerable age but often do not have the skills or the mental health to be able to return to school. Planning carefully for a student's transition to secondary school including knowing the student needs, involving the family and having adult support have been identified as crucial for success (Fuller, 1998). In fact, Felner and Adan (1998) have shown that successful transition planning may prevent 'later substance abuse and delinquency' (as cited by Fuller, 1998, p.135).

In New Zealand a recent study of twenty-nine (29) students who had attended a residential school for students with emotional and behavioural difficulties (EBD) provides a basis for investigating the challenges specialist schools have reintegrating students into the community. Hornby and Witte (2008) found twenty-seven (27) of the twenty nine (29) students left their mainstream school early with no qualifications. The study identified students not only had difficulty gaining further qualifications and future employment but also found it challenging to re-engage in the community. Nineteen of the students reported having a criminal record with four being in prison at the time of the study. Although the nature of the study conducted by Hornby and Witte (2008) is different to this research in that the students had been residents at the school and had been diagnosed for EBD, the findings concerning transition have some relevance, as amongst other factors the prevalence of a mental health disorder and a serious disorder is higher for younger people and people with less education (Oakley Browne et al, 2006).

An article by Roberts and Vaughan (2007) draws on a longitudinal New Zealand study of one hundred and fourteen (114) young people's pathways and careerrelated experiences and perspectives. Their study suggests other research has tended to focus on young people who are socially excluded and subject to 
interventions. Therefore their study focuses instead on a cross-section of young people who had made a recognised pathway choice. Young people and educators are now presented with a wide range of possibilities for school subjects, qualifications, secondary-tertiary course alignment, and post-school student and career options. For students that find a return to school difficult, positive career options are still viable via other pathways which include: apprenticeships, polytechnic vocational courses, university bridging courses and government funded youth training courses. The researchers interviewed one hundred and fourteen (114) young people who left secondary school in 2003 and analysed the factors that determined post school pathway options. It identified four combinations of factors and characterised the groups into four categories. Category one were identified as young people with few or no qualifications taking less prestigious pathway options and with little rationale behind their vision for their future. Category two pursued army career apprenticeships, university and polytechnic bridging pathways merging discovery with careful planning. Category three were mainly youth trainees and university bridging students who felt ill equipped for navigating the complex array of career pathways. Category four included youth trainees, university students and bridging students who demonstrated a high level of short-term commitment and satisfaction with their current pathway. Although the four categories are fairly broad, the study served to create a better understanding about the place of process when understanding youth transition pathways. Roberts and Vaughan (2007) identify the remodelling of the New Zealand's tertiary sector to attempt to meet some of today's labour market and globilisation challenges resulting an explosion of tertiary education courses, modern apprenticeships and new institutions which may be viable transition options for students attending CRHS-City.

Findings significant to this research include the importance of establishing effective transition plans, providing specialist liaison and support, and involving families in transition processes. Hornby and Witte (2008) identify establishing procedures with the student's regular school, accompanied with education for 
staff specific to the student's strengths and needs was particularly important prior to transition along with on-going support for the student following transition. Their study also suggests more attention needed to be paid to procedures that supported the maintenance of the gains students had made in the residential school throughout the return to mainstream schools.

\subsection{School connectedness}

For most students, having a positive connection with school, including staff and peers contributes to their ability to feel good about being there. For students who are struggling with managing their mental health, being at school is difficult in itself and can be easier to avoid if there is not a positive connection with the school.

A review conducted by Cross, Runions and Waters (2009) of scholarly articles pertaining to adolescent connectedness to school endorses the relationship between a student's self-reported feelings of connectedness to school and improved health and academic outcomes. From the literature Cross et al (2009) developed a model to define school ecology and its positive influence on a student's need to feel connected to school. The model has 4 phases. The first

phase defines a school ecology involving a focus on relationships between people within the school, functions and structures of the school itself, a student's family environment and the influence of the wider community. The second phase focuses on the mechanisms for students to develop a connection to school such as the structure, clarity and quality of information regarding expectations of behaviour and consequences, the provision of choice and the amount of support, involvement and emotional support provided. The third phase describes the need to be responsive to the individual student including developmental stages, recognising the need for autonomy yet balancing this with external support such as caring and supportive relationships, structured use of time and clear and consistent boundaries. The final phase identifies the link between enhanced student connectedness to improved health, social and academic outcomes. 
Although the study does not identify the processes students experience within the school context to become connected or identify how this benefits health and academic outcomes, it does highlight the complexity of what makes up connectedness to school and factors to consider. The relevance of school connectedness is significant to this research given the link to improved health outcomes for students. Particularly for students who do not have a positive connection to their school this highlights the need to identify meaningful ways for connectedness to be established.

An Australian study focusing on the promotion of social inclusion and the effect of this on student health, risk behaviour and well-being identified the school's social milieu is significant to the prevention of health risk behaviours. Bond, Bowes, Butler, Carlin, Catalano, Glover and Patton's (2006) comparative study conducted in twenty-five (25) secondary schools in Victoria, Australia discussed teacher intervention of a structured process to promote a sense of social inclusion and connection over a two year time-frame including a four year followup. Research into this intervention indicated there were reductions of risky behaviours. Reductions were seen in substance abuse, antisocial behaviour and early initiation of sexual intercourse. However student emotional problems did not differ between groups. The study suggested the possibilities that the interventions were not specific or sustained enough to produce a detectable effect and the determinants for identifying depressive symptoms may not differ from health risk behaviours operating outside the school context. The relevance to this research is it highlights the need to have interventions tailored to the needs of students in the area of mental health and schools require a greater understanding of and support from mental health services to be effective.

Anderson, Henriques, Jacobson, Riesch and Sawdey (2008) designed a study in America to gauge influencing factors and characteristics of young adolescents who expressed thoughts of suicide using the Social Disintegration Model (SDM). The researchers acknowledge although suicide is rare, it is considered by a 
significant proportion of youth. The SDM summarises intra-personal, interpersonal, peer network, physical and health risk behaviour characteristics that may influence suicide ideation. The participants were part of a larger family strengthening programme. Data was collected from an in-home interview. For the purpose of this study one hundred and seventy nine (179) youth were presented the screening question: 'Have you ever thought of killing yourself'? Of the one hundred and seventy nine (179) young people sixteen youth answered 'yes' and ten did not respond. Data was analysed from the family interviews to determine the factors that contributed to thought of suicide. Factors and characteristics that contributed to thoughts of suicide included parent and child conflict and family dysfunction, low school connectedness, internalising ways of coping, early pubertal development and use of weapons or alcohol.

Of particular significance, youth who said that they had experienced 'thoughts of suicide' were found to feel less connected to their school and used more internalising behaviours. The measures of internalising behaviours included acting sad or depressed, having low self esteem, being easily embarrassed and experiencing isolation and social anxiety. Of those participating in the research 9 percent (9\%) reported being bullied and thirteen percent (13\%) reported bullying others. Anderson et al (2008) indicate frequent exposure to bullying is related to increased risk of depression and suicide. Implications for this research is the link between a student's mental health and the need to feel safe, highlighting the need for schools to establish effective ways of creating a safe environment.

An American study investigating the associations between feelings of social isolation in adolescence and specific psychological health risks including depressive symptoms, low self esteem, suicidal ideation and suicide attempts, identifies that families, schools and peers are among the protective factors influencing adolescent health (Hawkins \& Weiss as cited by Christenson, Eisenberg, Hall-Lande \& Neumark-Sztainer, 2007). Data was gathered by means of a survey of 4,747 adolescents in grades $7-12$. The study identified 
social isolation is associated with an increased risk for depressive symptoms, suicide attempts and low self esteem. Protective factors included family connectedness, academic achievement, and school connectedness which in turn influenced some of the relationships and psychological health risks. This would indicate the longer a student is disengaged from school the greater the potential for a deterioration in their mental health condition, hence the need for early intervention for students disengaged from school. However it was unclear from the study if social isolation causes psychological problems or if adolescents with psychological problems isolate themselves. This limitation was acknowledged within the study.

The studies indicate students are more likely to engage in healthy behaviours and succeed academically when they feel connected to school. The research indicates adult support, belonging to a positive peer group and the actual school environment all play a significant role for a student's well-being.

\subsection{Family involvement}

As identified earlier, findings significant to this research is the recognition 'intervention' is not completed with the student in isolation. Families are seen to be a fundamental part of the process and in some cases the family may require support to manage their child's mental health condition. Further, families are seen as an integral part of supporting their children to remain engaged in school. Given the importance of parents as co-therapists responsible for the implementation of procedures, means explicit training should be provided for parents to develop behavioural and cognitive procedures effective in the treatment of childhood anxiety disorders, phobic disorders and school refusal.

A study in six European countries conducted by Alonso, Angermeyer, Bernert, Bruffaerts, Brugha, Dietrich, Heider, Matschinger (2008) aimed at investigating the association between parental rearing styles and anxiety disorders identifies there is a connection. The study focused on four anxiety disorders: generalised 
anxiety disorder (GAD); social phobia (SOP); simple phobia according to DSMIV; and panic disorder with and without agoraphobia (PDAG). The study aimed to explore this association with particular anxiety disorders and to determine any cross-cultural variations. Their findings significant to this research are maternal overprotection was always significantly associated with anxiety and of the four anxiety disorders, inconsistent parenting styles was associated with GAD. The study indicated parenting patterns comprising of lack of parental care and maternal overprotection were consistent across anxiety disorders and across the countries under study. Alonso et al (2008) note understanding risk factors for anxiety disorders would enable targeted interventions to be developed. They recommend strengthening parental care associated with anxiety and other psychiatric disorders by means of public mental health programmes. Further they suggest intervention programmes on an individual level aimed at assisting parents to understand the basic needs of their children.

As part of a broader study of adolescents' and parents' experiences with mental health services, Moses (2009) conducted a study that involved interviewing seventy (70) parents to determine if the meaning they prescribe to their adolescents' diagnoses impacts upon their own behaviours and reactions to their children. Findings indicated parents who avoided psychiatric terminology tended to view their child's problems as reactions to life circumstances. Uncertainty about their child's condition was often linked to parents not distinguishing between normal and abnormal adolescent behaviour. What was apparent from the study was the loss and grief that came with parents acknowledging a mental health condition. It was noted parents may avoid acknowledging a more serious concern by likening the behaviour to 'normal' adolescent behaviour. A concern raised was if parents did not agree with the diagnosis, it may put them at odds with the mental health service providers resulting in a possible relationship unhelpful to treatment. The study did indicate it was difficult to determine if it was helpful or unhelpful for parents to have a thorough understanding of the psychiatric condition as this could potentially cause a higher level of distress for 
parents. A suggestion was for mental health professionals to explore with families how they make sense of their child's problems so interventions can help families cope with the realities and challenges of their child's mental health.

\subsection{Summary}

This chapter has reviewed the literature surrounding adolescents and mental health and the interventions, support systems and environments that best enable them to remain engaged with their education. The literature pertinent to this research identified:

- The prevalence of a mental health disorder is higher for younger people and people with less education.

- There can often be a mismatch between what a school can offer in terms of a supportive social and intellectual environment for adolescents and what students with a mental health condition actually need. This is an area identified as requiring further research.

- Intervention should not be carried out with the student in isolation. Rather it should involve the student within the social context of school, support from mental health services and include family as a vital support.

- Students, their families and schools require skill development and support to help manage the identified mental health needs.

- It is essential students maintain positive links with school as they are more likely to engage in healthy behaviours and succeed academically when they feel connected to school.

There were several gaps identified in the literature including a lack of empirical evidence that supported effective intervention, a lack of theoretical models that 
were rich in context and intervention descriptions. Research specific to school transition while concurrently enrolled in a specialist school for students with mental health conditions was also limited, indicating that more needs to be known about the outcome of this type of intervention for adolescents.

This research was carried out with the intention of contributing to national and international evidence in this area. It is hoped the publication of the results from this research will initiate a more vigorous discussion in New Zealand regarding provision for and the development of services for adolescents with mental health issues. 


\section{CHAPTER 3 Methodology}

The beginning of knowledge is the discovery of something we do not understand.

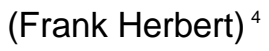

\subsection{Introduction}

This chapter describes the methodology used to answer the research question. A case study design was used as it was best suited to discover the experiences of students and their families who had used CHRS-City.

The chapter is written in two parts. Part A describes the research. Part B describes my role within the research.

Part $A$ has six sections. It begins with describing the aim of the research, followed by the research methodology and the tasks and procedures that were used to complete the study. It also covers the theoretical perspective, validity and concludes with the ethical procedures to ensure participant confidentiality and safety.

Part B has two sections. It begins with describing the role of the researcher and concludes with a description of the controls used to mitigate the risk of researcher bias.

\subsection{Part A - Research}

\subsubsection{Aims}

The research question guiding this study was:

"What are the experiences of students returning to mainstream education who are concurrently enrolled in a specialist school for students with mental health conditions and a NZ secondary school?"

\footnotetext{
${ }^{4}$. http://www.quotationspage.com/quote/26173.html
} 
In order to answer the research question the research was designed to explore five specific areas that pertained to the unique nature of the school and the students attending the school. These were:

\section{Access to Education:}

To investigate the student's educational experiences prior to attending CRHSCity, their access to education after attending CRHS-City and the role CRHS-City played in this access. This includes all areas of the curriculum, the student's own goals, key competencies, the focus on transition and future access to education/ongoing learning.

\section{Mental Health \& Well-being:}

To investigate the student's experience of CRHS-City as a therapeutic intervention working alongside achieving educational goals. In what ways did the therapeutic programme at CRHS-City support or hinder the mental health and wellbeing of the students?

\section{Social \& Peer Relationships:}

To investigate the student's experience of establishing friendships at CRHS-City. In what ways did attending CRHS-City help or hinder the student's ability to develop friendships, including maintaining friendships outside of CRHS-City?

\section{Transition Goals:}

To investigate the student's experience of the transition process while attending CRHS-City. In what ways did the plans put in place support or hinder the student's ability to return to school or further education? 


\section{Future Plans \& Ideas:}

To investigate the student's educational and future goals prior to attending CRHS-City and their current goals. In what ways did the student's time at CRHS-City impact on their plans and goals?

These five areas were selected as they are in line with the original intention of the establishment of CRHS-City. Further they follow the goal structure set with students who attend CRHS-City. The research aimed to identify both the supports and challenges the students and their families experienced in each of these areas.

\subsubsection{Case study research}

Describing a lived experience is complex because the researcher needs to understand what it is like to live in someone else's shoes. A case study approach is best suited to this research as the researcher aims to understand the personal experience including the successes and the challenges for both students and their families. A case study seeks to understand the dynamics present within this single setting (Berg, 2007). The purpose is not to predict the outcome but to tell a story through which there is a search for understanding, knowing there is no ultimate answer (Senge, 1990).

Several problems have been identified with using a case study approach:

1. Describing too much information can hide the important things. Geertz, (cited by Cohen, Manion \& Morrison, 2007 p.254) calls this a 'thick description'. To counter this potential problem, the decision was made to include the student's diagnosis on admission to CRHS-City within the case description. While features of the diagnosis may not be considered useful in the case description they may be useful for future analysis and provide rich contextual information regarding the decisions made post admission. 
2. Researcher bias can occur when the researcher has an interest in a particular outcome (Denscombe, 2006). As the team leader at CRHS-City it would be easy to select information which only supported my analysis of the situation or needs. To counter this potential problem, the outcomes were discussed openly and honestly with colleagues throughout the study and with a professional supervisor.

3. Drawing inferences from a single source risks overgeneralisation by the researcher (Denscombe, 2006). To counter this potential problem to an extent a multiple case study design was employed. This was not an attempt to compare cases but rather to provide an opportunity to identify patterns across the cases in order to improve the generalisation of the findings.

Case studies are a useful research strategy to employ when undertaking research within a real-life context (Denscombe, 2006). As the research question investigated a lived experience it was best answered using a case study. In this instance a 'multiple case' study design was employed as the 'analytic benefits would be more substantial' (Yin, 2003, p. 53).

The case study enabled a planned decision to focus on a particular instance (or instances) in order to create a deep understanding of the students and their parent's experiences of the students attending CRHS-City. The aim was to present a case that was rich in description (Densombe, 2006). A comprehensive understanding was provided to the researcher as a result of the in-depth account of events, relationships, experiences or processes occurring with that particular phenomenon. 'Case studies strive to portray what it is like to be in a particular situation, to catch the close up reality and thick description' (Geertz, cited by Cohen, Manion \& Morrison, 2007, p.254). The case study is a research strategy 'used in many situations to contribute to our knowledge of individual, group, organisational, social, political, and related phenomena' (Yin, 2003, p.1). 


\subsubsection{Theoretical perspective}

It was evident early in the research planning this would be a qualitative investigation. Qualitative research lends itself to an in-depth study of the area of focus, and 'scores well in terms of the way it deals with complex social situations' (Denscombe, 2006, p. 280). A qualitative approach was appropriate for this study as I wanted to capture the impact that attending CRHS-City had on a specific group of students and their transition back to a regular school or further education.

As the researcher, I hoped to gain an understanding of the lived experiences of the students and their family, therefore a constructivist paradigm was appropriate. Patton (2002) stated a constructivist perspective is fitting when the research aims to find out reported perceptions, truths, reality, explanations and beliefs. Because I wanted to interact with the participants and attempt to understand the complex world of the students and their families lived experience, it was appropriate to draw from an interpretive/constructivist model (Schwandt, cited in Mertens, 2005). This research did not expect to find one reality, instead, it was expected multiple realities of the students and their families experiences would be found. Denzin and Lincoln (2008) suggest a constructivist paradigm embraces relativist ontology where numerous realities exist.

\subsubsection{Tasks and procedures}

Figure 3.1 shows an overview of the tasks and procedures involved in this research. 


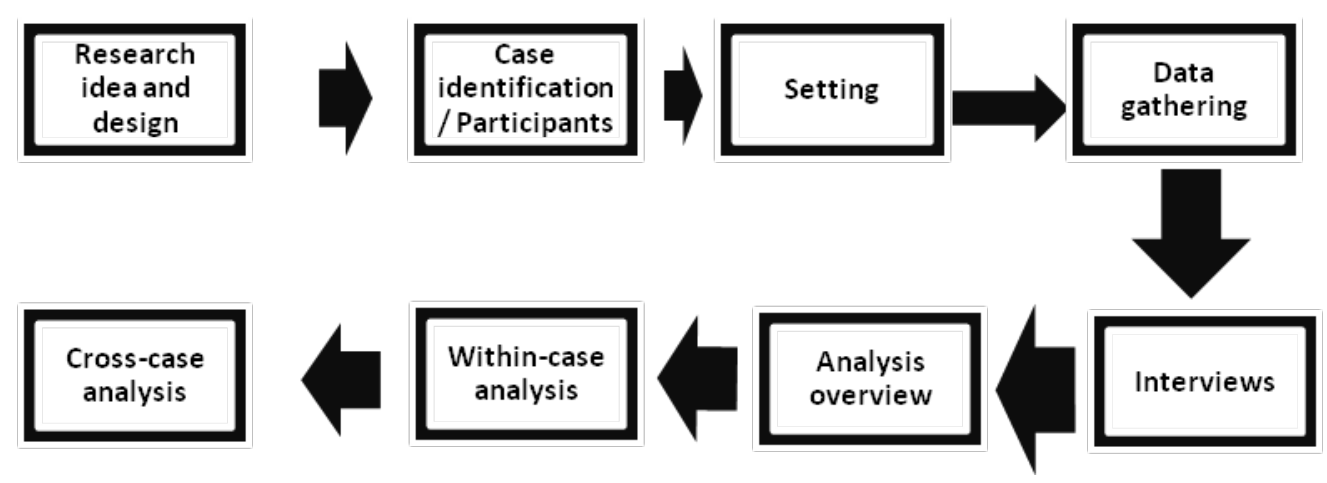

Figure 3.1 Overview of tasks and procedures

\section{Research ldea \& Design}

The focus of the study is to understand the experiences of students and their parents' experiences of the students attending CRHS-City. However not everything about a case can be understood. Therefore the case study requires a boundary to define the study. Without a 'boundary' it becomes impossible to determine what the case is (Denscombe, 2006). The case study in this research was bounded by the common experience of three students who had attended CRHS-City to support a transition back to school or further education. The unit of analysis was the student's and their family's experience of the student attending CRHS-City and the transition back to their regular school or further education. In this instance three independent case studies were conducted in order to analyse commonalities and differences thus providing more evidence to support the conclusions. Due to the complexity of mental health, the student's mental health diagnosis is described in their case story in chapter 4. But it was not the focus for this case study as I did not want to run the risk of compromising the 'thick description' that Denscombe (2006) claims is a feature of the case study.

\section{Case identification:}

The intention of this research was to explore at an in-depth level the student's experience of attending CRHS-City. Therefore participants were identified from the pool of students who had attended CRHS-City and had transitioned either to school or to further education. Due to the complexity of mental health conditions, 
and how these can present, students were identified by common features of their diagnosis. The feature in common between each student was the symptoms of anxiety impacting their functioning. Yin (2003, p.47) suggests when choosing two to three cases they should be selected following a 'replication' logic. Therefore students who had similar symptoms impacting their functioning and had experienced the transition process at CRHS-City were selected for this study.

It is acknowledged focussing on students who had common features of their diagnosis may narrow the 'experience' of the students. However as already mentioned, due to the complexity of mental health conditions, by focussing on these students it limited the variables that could impact upon the case so the focus remained on the 'experience' rather that the student's diagnosis and the impact this had on each experience.

\section{Participants}

The students that were contacted had been admitted to CRHS-City in 2009, and withdrawn following a successful transition within the first two school terms in 2010. At the time of admission to CRHS-City the student's ages ranged between fifteen to sixteen years and each student had not been attending their regular school as a result of their mental health condition. First the parents were approached to make my intentions known and to seek their approval. Subsequently when the students were contacted, parents and students were given the opportunity to formally express their interest in participation in this study (Appendices A and B respectively). Once students and their families had identified they would be willing to be a part of the study there was a follow up by phone, and letter to parents (Appendix C) and to students (Appendix D) formally informing parents and students of the research. Then an invitation to participate was sent to parents (Appendix E), and to students (Appendix F). After each student and their family agreed to participate, a consent form was completed by 
parents (Appendix G) and students (Appendix H) acknowledging their understanding of the study and agreeing to be a part of it.

Table 2.2 describes the participants.

Table 3: 2 Description of participants

\begin{tabular}{|l|l|l|l|l|l|}
\hline Participant & $\begin{array}{l}\text { Age (on } \\
\text { admission) }\end{array}$ & Ethnicity & $\begin{array}{l}\text { Year } \\
\text { level }\end{array}$ & $\begin{array}{c}\text { Admission/Withdrawal } \\
\text { Date }\end{array}$ & $\begin{array}{l}\text { Parent } \\
\text { Participant }\end{array}$ \\
\hline Student A & 15 & European & 11 & Sept 09 - May 10 & Mother \\
\hline Student B & 16 & European & 11 & May 09 - Mar 10 & $\begin{array}{l}\text { Mother/ } \\
\text { Stepfather }\end{array}$ \\
\hline Student C & 15 & European & 11 & Apr 09 - May 10 & $\begin{array}{l}\text { Mother/ } \\
\text { Father }\end{array}$ \\
\hline
\end{tabular}

\section{Setting}

CRHS-City first began admitting students in September, 2008. The school is located in central Wellington with easy access to public transport and community facilities. The school consists of a large open plan space, two meeting rooms, office space and a "chill out" room. CRHS-City takes up to fifteen students at one time. The roll varies depending on the number of students being admitted and returning to their schools. The staff at CRHS-City includes a team leader, two full-time and one part-time teacher, a support worker, and a DHB employed occupational therapist who provides clinical support and therapeutic interventions.

All students admitted have an individual plan (IP), detailing both their educational and therapeutic goals which actively support their transition goals. CRHS-City provides an integrated programme that enables students to access both education and mental health services as part of a multi-disciplinary process. 
The programme includes:

Curriculum studies/workshops

Co-operative group work focusing on social skills and life skills

Career and vocational programmes

Physical education programme

Adventure based programme

Creative activities including drama

Therapeutic groups

Active transition plans

\section{Data gathering}

This was qualitative research. Interviews and student individual plans were the methods used for data collection. The individual plans include education plans, therapeutic plans, transition plans and review notes. Qualitative methods of data collection can be criticised for being subjective and or biased (Denscombe, 2006). In order to combat these problems triangulation of the data is recommended to add strength to the findings (Cohen et al, 2007). By using multiple methods of data collection this perceived problem may be overcome as the credibility of findings can be strengthened through a variety of data sources. This research used triangulation by collecting data from multiple sources, for example interviews, educational and therapeutic plans, transition plans, review notes and anecdotal notes in order to provide a richer picture and stronger picture of the experience.

\section{Interviews}

Prior to the interview, participants were sent an interview schedule so they could have time to consider the essential questions central to the focus of study (Appendix I). Students and families were interviewed independently at the place most suitable to the participants. Both students and families were interviewed at their home. Semi-structured interviews were used with the aim of generating narratives and exploring the experience in depth (Denscombe, 2006). Semi 
structured interviews involve a range of questions. First the essential questions central to the focus of study were asked. These were the questions that had been sent to all participants prior to the interview. Second extra questions to check the reliability of responses and finally throw-away questions were used to develop rapport or to draw out more complete stories (Berg, 2007). As each student had differing transition experiences, questions were adapted accordingly. Individual plans were referred back to in order to ensure a true picture of the lived experience of that person within the context of CRHS-City. Interviews were tape recorded and transcribed for closer analysis. Transcripts were sent to each participant so they could be checked prior to analysis.

Yin (2003) suggests using questions specific to the line of inquiry accompanied with friendly and non-threatening questions asked in an un-biased manner. This suggests that an open-ended line of inquiry takes on a conversational manner. Each interview took between 50 - 65 minutes and began with re-establishing our connections and informal discussion to enable the participant to feel at ease. Throughout the interview I attempted not to impose my own understanding on participant responses. Rather I sought further clarification to ensure I had understood their experiences. Two interviews for each case took place, one interview with the student and a further interview with their parent/s resulting in six interviews overall.

\section{Analysis overview}

A defining characteristic of case study research is the focus on description, therefore data analysis aims to examine themes and patterns that can describe and explain the phenomenon being studied (Berg, 2007). Yin (2003, p.120) states to explain is to stipulate a set of causal links which may reflect critical insights.' In the first instance information was collected from the interview and the student's individual plan. Each interview was transcribed verbatim. Then each transcript was analysed and cross-checked with the student's individual 
plans to look for patterns in the data specific to each case. Finally each case was explored to look for individual themes.

In a 'multiple case' case study there are two stages of analysis, the 'within-case' analysis and the 'cross-case' analysis. Cross-case analysis enables the emerging theory to be checked (Creswell, 2008; Yin, 2003). For this purpose common themes were identified and explored across cases, including themes common to groups (for example the parent/child group; the parents as a group; and the students as a group) and again across all groups.

\section{Within-case analysis}

Content analysis was employed to examine data collected from interviews with each student and family. Leedy, Ormrod and Neuendorf state 'content analysis can identify patterns, themes, biases and meanings' (cited by Berg 2007, p.304) which are appropriate for this study. Content analysis is primarily a coding operation and data interpretation process (Berg, 2007). For the purpose of this research in which the participants' voice was paramount, the type of analysis used was inductive coding so the theory emerged from the data rather than applying a set of categories imposed by the researcher (Berg, 2007).

This study followed the framework for data analysis as suggested by Miles and Huberman. Miles and Huberman (cited in Punch, 2005) suggest an approach that has three main components: data reduction; data display; drawing and verifying conclusions.

All relevant content from the interview transcript was paraphrased and coded in terms of the research aims. The process of content analysis refers to an 'objective coding scheme' applied to the data to condense and quantify (Berg, 2004, p.265). In this case the transcripts were coded into content units. All interview responses were coded in all transcripts. The researcher did not decide what was important and what was not, but rather allowed this to develop from the 
data. To complete this task, irrelevant text was coded and categorised as irrelevant. Text coded as irrelevant was generally social talk and the establishment of a relationship between researcher and participant. The key factors evident in each case were recorded in a uniform framework to map factors and identify patterns.

Table 3.3 demonstrates an example of a coded transcript.

Table 3.3 Example of coded transcript

\begin{tabular}{|l|l|l|}
\hline Code & Example transcript & Paraphrase \\
\hline PC 01 & $\begin{array}{l}\text { Well it was - well - I think it was extraordinary for us } \\
\text { because we had hit a brick wall where she simply was } \\
\text { not capable of going to school and ultimately if you look } \\
\text { at the }\end{array}$ & $\begin{array}{l}\text { Hit a brick wall couldn't } \\
\text { go to school }\end{array}$ \\
\hline PC 02 & $\begin{array}{l}\text { - you know if you measure it by outcomes the outcome } \\
\text { was that she was transitioned back to being able to } \\
\text { attend school and then being able to attend school and } \\
\text { now enter into year 13 very strong. }\end{array}$ & $\begin{array}{l}\text { Outcome was transition } \\
\text { to school }\end{array}$ \\
\hline
\end{tabular}

After transcripts were coded the paraphrases were categorised according to similarity. From this process key categories emerged for each case.

The data collected from individual plans involved a description of the students' identified needs and how these were addressed. Links between the students' individual plans and the transcripts from the interviews were made by reading and re-reading all data sources. The writing up of each case story was also used as an analytical tool to clarify thinking.

\section{Cross-case analysis}

Yin (2003, p.133) recommends the use of 'cross-case synthesis'. Three cases were investigated to see if they shared similarities which in turn lead to further analysis, thus raising the possibility of typology of individual cases which Yin (2003) suggests can be highly insightful. 
As stated the paraphrases from each interview were sorted according to similarity to create categories. The categories identified from each case were then sorted and coded across cases to identify emerging themes. The emerging themes were recorded in a chart to identify the content units that made up each theme (Appendix J). The themes across students and across parent groups could be consolidated for analysis.

By reporting the frequency with which a given concept appears in text, researchers suggest the magnitude of this observation. It is more convincing for their arguments when researchers demonstrate the appearance of a claimed observation in some large proportion of the material under study (Berg, 2004). Eight common themes became evident across the cases. In order to identify the prevalence of these themes, each case and the recorded frequency that each theme appeared in the data was counted. Hence the significance of each theme was identified.

\subsubsection{Validity}

Case study data is gathered using a range of methods in order to see things from a different perspective, providing the opportunity to corroborate findings and enhance validity of the data (Denscombe, 2006). As mentioned earlier, triangulation is a process used to collect data from multiple methods to ensure the work is credible (Cohen, 2007). Within this study, data was collected from multiple source: the students' educational plans, therapeutic plans, transition plans, review notes, and anecdotal notes as well as interviews with students and families.

In order to increase the validity of the findings multiple case studies were employed. Yin (2003) prefers multiple case studies for their value in pattern matching and the potential of direct replication, thus increasing confidence in the robustness of the theory. However, Stake (2005) criticises the use of comparison in case studies because it 'obscures any case knowledge that fails to 
facilitate comparison' (Stake 2005, p.457). Although more time consuming, three case studies were conducted giving the opportunity to analyse and compare findings thus providing more substantial conclusions. It is acknowledged that not everything about the cases can be understood, but the research endeavoured to contain the focus strictly to the 'lived' experience of the students and their families from their own viewpoint.

Yin (2003) explains researchers can seek to use case studies to substantiate a preconceived position. However this can be overcome if researchers clearly identify their own point of view and position in relation to the case study (Creswell, 2008).

\subsubsection{Ethical consideration}

Due to the nature of this research, expert supervision was sought to oversee the project. The supervisor, Dr. Catherine Savage, a registered practising psychologist was able to provide both research and professional supervision. Ethics approval was sought from the Victoria University Human Ethics Committee (Appendix K) rather than the faculty ethics committee as the participants had a diagnosed mental health condition meaning they were a vulnerable research population. Prior to beginning this study consent was sought from the Principal of Central Regional Health School (Appendix L).

In selecting participants it was decided the initial contact should be made in person inviting them to participate. All the students and families approached indicated they would like to participate. They were then sent a letter describing the research and formally inviting them to participate. An information letter, sent to parents (Appendix C) and students (Appendix D) accompanied this invitation along with an explanation of informed consent which was further explained by the researcher in person before the data collection. 
There were three principles offered to participants of the study, based on Denscombe's advice (2006).

1. Participants are able to give their informed consent to participate and can terminate their involvement for any reason, at any time.

2. Participant identities will be protected by changing names in dissemination and published reports.

3. Participation will not harm the participants. There is no intent to draw attention to the students or school personnel so as to protect their privacy.

The students were not named and were asked to provide a pseudonym, including ones for any schools referred to. Tapes used during the interview process were destroyed at the completion of the research. The transcriber used was aware of and agreed to all confidentiality requirements (Appendix M). However, the singular nature of CRHS-City within the region means there is a chance participants may be recognisable to potential readers. For this reason every effort has been made to alter small details which may identify participants but not impede or alter the findings.

A summary report will be given to the participants accompanied with an opportunity to discuss the findings.

\subsection{Part B - Researcher role}

\subsubsection{The role of the researcher}

Within qualitative research there is often a close relationship between the researcher and the participants which needs to be acknowledged. 'The researcher's self plays a significant role in the production and interpretation of qualitative data' (Denscombe, 2006, p. 268). In this case study there was a close relationship between myself, as the researcher, and the students and their parents. I had been a part of the participants' journeys from the beginning of their admission to CRHS-City, to their withdrawal once they had transitioned. 
While this provided me with a strong understanding and connection with the students and the families interviewed, it also meant there was a potential issue of participants altering their responses in accordance with what they thought might be acceptable. In order to address this issue I emphasised to the students and parents the importance of the research in informing future development at CRHS-City.

\subsubsection{Researcher bias}

As I am the team-leader of CRHS-City there is a vested interest in this study which could possibly impose bias upon the data collection and analysis. As stated the families may not have felt at ease to share certain aspects of their experience as they viewed me as the 'team leader' rather than as a researcher. Therefore it was important that it was acknowledged to all families the purpose of this research was to give an in-depth understanding of their actual lived experiences. As I was known to the students and their families, consideration was given to what participants would be willing to share. It was important for me within my role as team leader to determine what the successes and challenges are for students to support the on-going development of CRHS-City. Therefore this was explained at the onset of the study, to encourage participants to feel at ease to share their experiences honestly and openly.

As I have established views in this area, interview questions needed to be checked to ensure they were unbiased. These were discussed first with critical colleagues and then a professional supervisor. Yin (2003, p.62) suggests seeking feedback from 'critical colleagues' within the data collection phase thus enabling alternative explanations and suggestions for data collection. As I had been a part of the student's transition journeys any pre-conceived ideas needed to be set aside at the onset of the study. I discussed possible biases openly and honestly with colleagues throughout the study and while working with a professional supervisor. I needed to be open to contrary findings. Stake (2005, p.454) acknowledges 'description and interpretation, opinion and feeling are all 
mixed together in interview data'. A challenge Yin (2003, p.137) recognises with cross-case analysis is for the researcher 'to know how to develop strong, plausible, and fair arguments that are supported by data.' As the cases depended on interpretation, consideration was given to participant subjectivity and researcher biases in part by cross-referencing with the student individual plans.

\subsection{Summary of methodology}

This chapter has detailed the process for the design, data collection and analysis. The purpose of this research was to capture the impact that attending CRHS-City had on a specific group of students and their transition back to a regular school or further education. A multiple case study design was employed to improve the validity of the findings and enable generalisations across the experience for both students and parents. Data collection methods for each case study consisted of a separate interview with each student and their family and data collected from the student's individual plans. Interviews were analysed using inductive coding and categorised according to similarity of themes across the cases. The following chapter will describe the cases and the results of the interview and document analyses. 


\section{CHAPTER FOUR}

Findings

"You can't help respecting anybody who can spell TUESDAY, even if he doesn't spell it right; but spelling isn't everything. There are days when spelling Tuesday simply doesn't count."

$$
\text { (A.A.Milne - Winnie the Pooh) }{ }^{5}
$$

\subsection{Introduction}

This chapter presents the findings of the interview data and document collection. It is written in two parts. Part A provides a summary of each case demonstrating the contextual and situational issues for each student participant. Part B describes the themes that arose during the analysis.

\subsection{Part A - Case stories}

In this section each of the student case studies is presented in turn. The purpose of presenting the results in this way is to give the reader a sense of the complexities surrounding each case and to provide the context for Part B and the cross-case discussion in chapter 5 . Each case study gives background information about the circumstances that led to the student's admission to CRHS-City and describes a summary of the student's individual plan while at CRHS-City. The case study provides a summary of the four areas in the student's individual plan; transition, key competencies, curriculum, and therapeutic. The purpose of the student's individual plans is to outline the student's present skills and needs, the skills that need to be taught, and how these will be achieved. Some details, which do not affect the case but add to the description, have been altered in order to maintain confidentiality.

The data for these case stories were the student's files which included information from individual plans, evaluation documents, weekly plans, review notes and anecdotal notes. A brief description of these data sources is recorded

\footnotetext{
5. http://thinkexist.com/quotation/you-can-t-help-respecting-anybody-who-can-spell/354686.html
} 
below. Information from the interviews was also used to substantiate information from the student's individual plans.

\subsubsection{Data sources from the student files.}

Individual plans: These included; transition goals, key competency goals, curriculum goals which make up their individual education plan (IEP), and therapeutic goals in their individual therapeutic plan (ITP). All are reviewed and evaluated every 8 weeks.

Student weekly plans: These are developed from the students' individual plan. They include a weekly break down of the four areas covered in the students IEP and are evaluated with the student weekly.

Review notes: The review process enables all involved in the students' team to meet every three weeks for half an hour to identify issues as they arise and to discuss and own together how best to support a student. The review notes from each meeting are reviewed at the next to ensure accountability.

Anecdotal notes: Recorded daily while the student attends CRHS-City.

Interviews: Information from the interviews was used to substantiate the data collected from the students' individual plans.

\subsubsection{Natasha}

\section{Background}

Natasha is European. She was fifteen years old and in Year 11 when she was admitted to CRHS-City in September, 2009. Natasha's diagnosis on admission to CRHS-City was Major Depression in partial remission (medical certificate completed by psychiatrist, 2009). She had been attending school regularly up until an admission at an adolescent psychiatric unit as a result of a suicide attempt, self-harming behaviours and low mood. She began attending CRHS- 
City following her discharge from the adolescent psychiatric unit. Prior to her admission to the adolescent unit Natasha had been finding her regular school increasingly stressful in part as she was experiencing difficulties with peer relationships and bullying. Natasha lived with her mother, older brother and younger sister. Prior to attending CRHS-City Natasha had goals of becoming an early childhood teacher and was keen to continue with her education towards achieving that goal. She was withdrawn from CRHS-City May, 2010 following a successful transition back to her regular school.

\section{$\underline{\text { Transition summary }}$}

When Natasha started attending CRHS-City she initially spent time exploring reasons why she found school difficult, accompanied with preparing a management plan that would assist her in transitioning successfully back to her regular school in 2010. Natasha was also linked in with a youth transition service to be an ongoing connection and support for her at her regular school post withdrawal from CRHS-City. The youth transition service works in partnership with the DHB to provide support and independence for DHB clients.

Natasha made a connection with her regular school at the end of 2009 to confirm her subject choices, met with her Deans and Guidance Counsellor, and discussed transition plans for the beginning of 2010. Although Natasha found it difficult being within the school grounds again, she did well to manage her anxiety and still participated in making constructive decisions that supported a return to her regular school.

Natasha made an extremely positive start at CRHS-City and her regular school at the start of the 2010 academic year. She managed a gradual transition back to her school attending for Economics, Early Childhood, Transition and Form time. Her time at school was gradually increased to include several morning tea and lunch times. 
Natasha was able to work with staff at CRHS-City and her regular school to evaluate her transition plan and discuss her associated worries. These mainly centred on her feeling isolated and misunderstood by her peers. The school guidance counsellor was a significant support for Natasha reconnecting socially with her peers and making new friends. Through this Natasha started to help in the Special Learning Unit during lunchtimes and joined a school social club. She reported to staff she was feeling much more positive and confident in her abilities to successfully transition. Natasha also made contact with a further youth agency and met with the support worker regularly at school.

Natasha managed a full time return to her regular school a week before the end of term one, 2010. CRHS-City continued to monitor her return to school. This involved Natasha returning to CRHS-City once a week for one hour for a checkin with staff. The decision was made to withdraw her from CRHS-City in May, 2010 following a successful return to school in term two after the school holidays.

\section{Key competency summary}

When Natasha first began attending CRHS-City, an initial focus was to attend CRHS-City regularly and participate in the programme with the goal being to develop a positive sense of self and develop her confidence in her own abilities. It was important Natasha had plenty of opportunities to meet with success, as well as opportunities to respond to, and develop her ability to work through situations she found more challenging. Further it was important that she had opportunities to continue to develop in similar respects outside of the CRHS-City setting.

A focus for Natasha was "Managing Self", specifically:

- Setting realistic and manageable learning goals

- Planning key steps, identifying success criteria and monitoring progress and "Participating and Contributing" specifically:

- Participating in group activities 
- Contributing to group activities

- Giving her opinion when required

When Natasha first began attending CRHS-City there were times when she would not engage in the programme or the transition plan put in place to support her return to school. Over time Natasha was able to reflect on her progress and identify success as well as acknowledge although the transition process was difficult, she needed to take responsibility for her part which involved her being on board and taking gradual steps each day. Natasha demonstrated strength and maturity in improving in these respects. Natasha was able to develop new goals specific to her current needs. She developed the ability to break goals down into more manageable steps and identify possible barriers and ways to eliminate or minimise these.

While at CRHS-City Natasha enthusiastically grasped every opportunity to develop herself as a person and participated in the programme to the best of her ability. She was supportive of other students. Natasha was able to demonstrate she was able transfer the skills learnt at CRHS-City to her regular school setting.

\section{Curriculum summary}

When Natasha first began attending CRHS-City she was already enrolled with The Correspondence School - Te Aho o Te Kura Pounamu (Te Kura) for English, Maths, French, Science and Economics as a result of her admission to the school at the adolescent psychiatric unit. While attending CRHS-City she continued the course content provided by Te Kura and sat the external exams for English, Maths, French, Science and Economics. She remained positive throughout her exams and felt confident she had achieved some achievement standards.

For the start of 2010 when a focus included a return to school, Natasha was studying a combination of work provided by Te Kura and her regular school at 
National Certificate of Educational Achievement (NCEA) Level 2. She was enrolled with Te Kura for English and Maths and in 2010 was attending her regular school for Economics, Early Childhood and Transition Classes. While at CRHS-City Natasha also participated in English workshops (with a focus on reading a range of text and creative writing) as well as working individually with the mathematics teacher.

Natasha was a motivated and capable student. She was very focused on her work during the curriculum study component of the programme. While at CRHSCity she was able to continue working towards completing NCEA level 1 and returned to her regular school for NCEA level 2 in 2010.

\section{Therapeutic summary}

Natasha was referred to CRHS-City following difficulties maintaining attendance at her usual school. This was in the context of symptoms of major depression. Natasha presented with difficulty coping with stress and managing helpful responses when feeling overwhelmed by emotions. Her usual school was perceived as a stressor she could not cope with at that time.

A therapeutic focus for Natasha was for her to have the opportunity to develop a more positive and helpful self image. Also she aimed to develop skills to manage stress and emotions, to communicate needs clearly and to develop confidence when socialising.

Attendance at CRHS-City allowed Natasha to experience challenges and periods of distress and practise ways to manage them with support and encouragement at hand. The programme allowed her to receive direct feedback from staff and other students to assist her to develop both a clear and accurate sense of self and confidence in her abilities and strengths. Over her time at CRHS-City, Natasha's evaluation of her skills, abilities and confidence greatly improved helped by staff reinforcing the changes she made. 


\section{$\underline{\text { Transition outcome }}$}

About three months following Natasha's withdrawal from CRHS-City there was an incident at her regular school involving an altercation with her peers. This resulted in Natasha making the decision to leave school. Although she had left school, she still wanted to continue with her education. As she had maintained her relationship with the youth transition service, staff were able to offer advice to support her goals. This resulted in her enrolling in a government funded programme that enables students who have not completed their education to continue with their learning while also providing career advice and support. Natasha attended this programme for the remainder of 2010 and returned in 2011. She has now completed NCEA level 2 and begun working towards NCEA level 3. At this stage she wants to continue with her career goal of becoming an early childhood teacher. She is hoping to begin a relevant course in July 2011.

\subsubsection{Jimmy}

\section{Background}

Jimmy is European. He was sixteen years old and in Year 11 when he was admitted to CRHS-City in May, 2009. Jimmy's diagnosis on admission to CRHSCity was panic disorder, agoraphobia and generalised anxiety disorder (medical certificate completed by psychiatrist, 2009). He had not attended school regularly since Term 4, 2008. His participation had gradually decreased with his last full day at school two and half months prior to his admission. While at his regular school Jimmy had experienced significant bullying.

When Jimmy was admitted to CRHS-City he was living with his mother, stepfather and two brothers in another suburb but was still enrolled in the school in the suburb where he had been living prior to his parents separating. Jimmy's father and step mother lived there. Due to family circumstances Jimmy could not return to live with his father. The local school in the suburb where he now lived with his mother was not a school he had attended before. To return to his 
regular school would involve Jimmy developing the skills and confidence to catch three lots of transport to and from school. As a result of Jimmy's experiences of bullying at his regular school and the difficulties with the transport to get there, the options were either beginning a new school or looking at tertiary options. As Jimmy was sixteen he was old enough to leave school. Therefore tertiary options were explored resulting in him making the decision to leave school and focus on transitioning into a polytechnic course. Jimmy was withdrawn from CRHS-City in March 2010 following a successful transition to a polytechnic course.

\section{Transition summary}

Jimmy initially required a supported transition to CRHS-City. This involved family driving him to CRHS-City a few times without him entering, then walking into CRHS-City, followed by eventually attending an admission meeting. Jimmy was able to attend for 10 minutes only, needing to sit in another room while the meeting took place.

A Child and Adolescent Mental Health (CAMHS) support worker was put in place for Jimmy's first two weeks to provide support at home for him to leave the house. The support worker remained at CRHS-City for the first hour while Jimmy settled in and a family member picked Jimmy up from school.

Soon after Jimmy's admission to CRHS-City he was able to attend daily, however he was unable to manage going outside. Therefore plans were put in place supporting a graded exposure to moving outside the school building. This meant if students were going to the park for Physical Education (PE) or into the City for Education Outside the Classroom (EOTC), it was planned Jimmy would be exposed gradually, for example, walking to the end of the street or driving regularly past a destination before attending. Within his individual plan he was required to go to the post box to post and receive the mail with the CRHS-City support worker. 
Jimmy continued to attend CRHS-City daily and throughout the year made real progress in getting out and about. The decision was made as part of the review process he would not return to his regular school or to school in general. The reasons were Jimmy's future goals did not necessarily require a return to school and his current living situation was not necessarily permanent resulting in uncertainty about which school he would attend. Jimmy was also motivated to explore areas of interest - music and the arts - so was supported to research if there was a course that was appropriate for him taking into account his current lack of academic qualifications.

In Term 4 a referral was made to a CAMHS transition service. The transition service provides transition support for young people leaving school who are clients of CAMHS. This service provided Jimmy with career advice, in addition to providing him with support that could continue post his admission with CRHSCity. Throughout Term 4 Jimmy continued to work on curriculum content set by Te Kura as well as focusing on relevant key competency and therapeutic goals specific to his mental health needs. He was also provided with the opportunities and supports to explore his interests and relevant courses.

Jimmy made the decision he wanted to pursue his passion for music, particularly drumming. His family were supportive and the decision was made to enrol him in a foundation music course at a local Polytechnic for the start of the 2010 academic year with the ongoing involvement of the CAMHS transition service and his CAMHS case manager. As Jimmy was to begin this course after the summer holidays, plans were put in place for the holiday period to ensure Jimmy kept moving forward with his key competency and therapeutic goals. There was commitment from Jimmy, his family, CAMHS and the CAMHS transition service throughout. CRHS-City remained involved for the first few weeks of the year to ensure Jimmy was able to manage this transition successfully. As he had positive relationships with CRHS-City staff, they provided him with background 
support in the early stages of his transition. Jimmy transitioned successfully into his course which involved him performing in a variety of gigs throughout the Hutt Valley and Wellington area.

\section{Key competency summary}

Jimmy was encouraged to walk to the shop daily with the support worker from CRHS-City, gradually increasing his tolerance levels by walking further and going in different directions. It was recognised EOTC events would be too much for Jimmy initially however he was expected to participate in some of these activities. He would be taken to the event's location a couple of days in advance to familiarise with the surroundings. On the day of the excursion he was expected to go but knew if he was not managing he could return to CRHS-City to complete an activity specific to the EOTC event. For PE, Jimmy initially went with the support worker as far as the fire-station, then to the end of the street, then across the road, until he was able to manage going to PE independently. Throughout his first term at CRHS-City there was a notable increase in his ability to manage his anxiety and to participate in components of the school programme involving him moving out of his comfort zone. He was also encouraged to take responsibility for himself by reflecting in a diary each day so he could acknowledge the steps he was making and refer back to his notes when he was feeling he was not moving forward.

A focus for Jimmy was "Managing Self", specifically:

- Developing ways to manage his anxiety to be able to participate within a school setting and enter social situations.

- Recognising when he participates in structured and non-structured activities and transferring this to new situations

- Self reflection to determine realistic and achievable challenges and "Relating to Others", specifically:

- Developing helpful, supportive relationships in and out of school 
Jimmy made significant progress throughout his time at CRHS-City, specifically in relation to his goals of moving outside his comfort zone and getting outside CRHS-City, getting home and into public areas. He had a real determination and challenged himself regularly. He developed the ability to go out daily on his own to the post office, the dairy and New World. He was also able to participate in most of the EOTC activities at CRHS-City, involving trips to a recreation centre, a rock climbing centre, the local park, a local theatre company, and an Asian cooking centre as well as visiting The Royal Music Academy.

Jimmy developed positive relationships within the Polytechnic and was able to make steps to increase his responsibility by managing different situations within the Polytechnic environment. He was able to make good connections socially and voiced that he had a lot in common with the students there. He was keen to continue to work on challenges as they arose, such as being assertive and was aware this was an area for him to develop further. Jimmy acknowledged his involvement with the course created an opportunity for such personal growth.

\section{Curriculum summary}

Jimmy worked on three curriculum areas while attending CRHS-City. He was enrolled at Te Kura for Maths, English, Science and later Skills for Job Seekers. As the Key Competencies were a major focus in the initial stages of him attending CRHS-City, it was decided he would focus solely on Maths and English until he was comfortable attending. Once he was settled into the routines of the school Science was then included. He achieved unit standards in the areas of Maths and English. As he began to explore other options rather than returning to school, Science was replaced with Skills for Job Seekers enabling him to work on purposeful topics relevant to beginning a course or work and to gain relevant credits. This is what he did. 


\section{Therapeutic summary}

Jimmy's struggle with managing his symptoms of panic disorder and agoraphobia resulted in him receiving CAMHS services. His difficulties were affecting his ability to engage in his usual occupations and his lifestyle had been so affected he needed support and assistance to leave his house.

Through his time at CRHS-City a clinical focus was on providing a cognitive behaviour therapy programme to enable Jimmy to develop the skills to manage his anxiety and engage meaningfully in his life occupations. This included both individual and group education about managing anxiety. Equally important was the opportunity for him to engage in the behavioural therapy part of this programme which involved him gradually being exposed to anxiety provoking situations (for example entering the school, being in a group of people, walking outside, being on a bus). Jimmy required support to do these things in a way that enabled him to practise using skills learnt. It was a successful therapeutic experience.

A well supported and structured plan then enabled Jimmy to re-engage gradually in activities and to increase his sense of efficacy and confidence to engage in life. Jimmy was able to learn skills to experience success which he needed to continue to practise in his future occupations.

\section{Transition outcome}

Jimmy successfully completed a foundation music course at a Polytechnic in July, graduating with distinction. Throughout this time he performed (playing the drums) at a variety of gigs in the Hutt Valley and Wellington region and has frequently said he is following his passion. He has been enrolled with and accepted into a full-time diploma of music course that begins in February, 2011. While waiting for the course to begin in February he began working as a building labourer for a family member. He has decided to remain doing this and is exploring getting into landscape gardening which he believes uses his creative 
abilities. He has decided he does not want to pursue music as a career choice but is passionate about continuing with it as a hobby. He continues to experience times when he struggles with his anxiety but is aware of how to manage these intense feelings. In addition, his family members report they are now aware of how to support him.

\subsubsection{Anna}

\section{Background}

Anna is European. She was fifteen years old and in Year 11 when she was admitted to CRHS-City in April, 2009. Anna's diagnosis on admission was a major depressive disorder (medical certificate completed by psychiatrist, 2009). She had missed a considerable amount of school due to her depressive symptoms. The stress and anxiety of attending school was detrimental to her health at that time. She had not attended her regular school full-time for close to one term. Anna was a high achiever both academically and in terms of leadership. She had responsibilities within the school and hopes of having a position of academic leadership within the school during her final years of school. Anna lived with her mother, father and two sisters. She was the eldest daughter. She was withdrawn from CRHS-City following a successful transition back to her regular school in May 2010.

\section{Transition summary}

Anna initially attended CRHS-City full-time until September 2009 when steps were made to begin a gradual return to school. Anna started making connections with her regular school towards the end of Term 3 and gradually built on this throughout the remainder of that term and during Term 4. Due to exams being the focus of Term 4 for NCEA students, Anna remained at CRHSCity throughout term 4 , sitting exams at CRHS-City. She continued her transition back to school at the start of the 2010 academic year. 
An initial focus of Anna's transition back to her regular school was to attend for one subject area, participate as she felt able to, and reconnect with friends and teachers. Anna gradually extended her plan from one subject to four subjects, including morning tea and lunch times. Although she struggled initially, she managed to work through most difficulties and complete most of her plan. Anna was supported with her transition by her case manager from CAMHS. Her case manager assisted by picking her up from home on a Monday morning to enable her to develop a consistent morning routine. Mondays tended to be more difficult for Anna following the weekend break from school. Anna's parents put in place a reward system to encourage positive behaviour and independence. Throughout her transition, Anna was encouraged to tolerate her distress and continue moving forward in her plan by breaking each stage down into manageable steps. The school nurse was supportive of all transition plans and was a key figure for Anna within the regular school environment. The school nurse made herself available to Anna at school if she found it difficult managing her anxiety in class. Anna was able to keep moving forward with support when she was feeling calm.

At the beginning of 2010, Anna was encouraged to attend her regular school 'start of year' events such as confirming subjects, meeting with her Dean and teachers and attending classes. It was recognised Anna would need to transition back to school at a steady rate from the outset of the academic year so as not to miss too much subject content. In addition, it was important she was involved in extra curricular activities to foster her sense of belonging within the school culture.

Although Anna made a successful transition back to school, there were days during the transition process her family could not get her out of the house to attend either CRHS-City or her regular school. Both CRHS-City staff and her CAMHS case manager were then actively involved in supporting both Anna and her family, reminding her of the plan they were all working towards, helping her to break the plan down each day so she was not overwhelmed, and assisting her to 
practise the coping strategies she was developing. There were times when both Anna and her family felt she would never return to school.

\section{Key competency summary}

Anna values education and academic success. She was committed to continuing her studies at her regular school and achieving NCEA Level 2 in 2010. Although she expected a high standard from herself, she was able to accept her focus for a time was on returning full-time to school, improving the skills necessary to manage her stress and anxiety and developing a healthy sense of self.

A focus for Anna was the Key Competency "Managing Self", specifically:

- Recognising her strengths and achievements

- Setting realistic and manageable learning goals

- Monitoring and evaluating learning goals

This involved Anna learning to articulate specific worries, reflect on them and come up with helpful solutions. At the same time she was supported to develop the ability to seek out and use supports effectively. What was evident throughout the time Anna attended CRHS-City was her developing ability to recognise her strengths and achievements. She was able to communicate these, giving thoughtful and reflective insights into her success and on-going needs. Anna was also supported to develop and strengthen friendships at school and to get more involved in school social activities. She began taking an active role towards developing a more balanced approach to life and school by socialising regularly with friends, participating in school wide events and engaging in activities outside of school. Although at times Anna struggled with her feelings of failure through not becoming an academic leader within her school, she was much more forgiving of herself, identifying that for a time her focus was on transition and that this failure was temporary. 


\section{Curriculum summary}

Anna worked on four curriculum areas while attending CRHS-City. She was enrolled at Te Kura for Maths, English, German and Food Technology as well as working on the planning set by her regular school in English to support her transition. She achieved credits in each of these areas while attending CRHSCity as well as participating in exam preparation and revision workshops, often taking a leadership role. She sat external exams in English, Maths and German. Although she was nervous before each one, she reported she felt confident about achieving some achievement standards in each subject. An additional focus towards the end of Term 3 and throughout Term 4 was on school transition, actively spending time within her regular school setting.

Anna attended a full academic programme at her regular school throughout Term 1, 2010. She found Maths and German particularly difficult subjects to transition back into primarily because she had missed subject content from the previous year. She was able to discuss these worries with her parents and teachers and to utilise the supports to help her feel more confident in these classes. Anna was given a box of revision activities in Maths she could access in class if she was feeling anxious. She was also able to work with her school to choose specific standards to focus on for 2010. Her family organised a maths tutor for her. Anna continued to visit CRHS-City weekly for one hour which provided her with an opportunity to address issues as they arose.

\section{Therapeutic summary}

Anna was seen by CAMHS as she had struggled with symptoms of depression and anxiety. She found it difficult to continue functioning within the school environment while experiencing these symptoms. She felt easily overwhelmed by distressing emotions and expectations of herself to cope with her symptoms.

Attendance at CRHS-City enabled Anna to develop skills to manage and alleviate her mental health symptoms. The 'safe' environment at CRHS-City 
enabled her to continue to engage in school activities and to develop a sense of coping and mastery which in turn built her confidence in developing other skills.

Anna was able to develop cognitive and behavioural strategies for managing anxiety and emotional distress. Learning these in the CRHS-City environment enabled her to gain feedback and access support to put such strategies into practice effectively. Guidance for her family members to enable them to support Anna effectively was an important part of her therapeutic plan. Having time and appropriate support at CRHS-City to set achievable and realistic goals enabled Anna to build a personal sense of achievement and mastery. These skills became essential to improving her mental health and supported her successful return to school.

\section{Outcome of admission}

CRHS-City remained involved, supporting Anna and monitoring her transition throughout Term 1 of 2010 and into the first week of Term 2 in order to facilitate her return following the holidays. Throughout this time Anna attended CRHSCity, initially on a weekly basis for one hour and subsequently fortnightly for one hour as she became more able to manage within her regular school. This time was used to monitor her transition as well as providing her with the opportunity to discuss issues if required in a setting in which she was comfortable and confident.

Anna was withdrawn in May 2010 as she was attending her regular school fulltime. She was successfully demonstrating the ability to utilise both personal coping strategies and external systems in place to assist her to remain in school if she was feeling stressed and anxious. Although Anna still struggles with anxiety she has developed strategies and skills to manage and a more positive sense of self. In addition, her family are more aware of how best to support her. Anna continued to attend her regular school throughout 2010 and returned in 
2011 to work towards NCEA level 3. She has also returned to CRHS-City to speak to and encourage students there.

\subsection{Part B - Themes}

Data collection methods for each case study consisted of an interview with each student and their family in January, 2011 and data collected from the student's individual plans. Interviews were analysed using inductive coding and categorised according to similarity of themes across the cases. Part B describes the eight themes that emerged from the analysis. Six themes were common across all cases with a further two being common to either the student group or the parent group. A summary of the eight themes that emerged from the analysis including the frequency of the findings across cases is shown in Appendix N. The content units that made up each theme are shown in Appendix J.

The themes are reported in order of the frequency with which they arose across the cases.

The chapter concludes with the identification of six issues arising from the research for further consideration.

\subsubsection{Theme A}

CRHS-City provided support for students to learn to manage their mental health, they learnt coping skills.

The interview data demonstrated equally for parents and students the most important feature of CRHS-City was the support CRHS-City provided for students to learn to manage their mental health. Although parents and students saw academic achievement as important, the ability to learn to manage their mental health was seen as more important at this stage of the student's life. The content 
units that make up this theme are; the supportive environment for students, graded exposure to challenging situations, skills taught to manage these challenging situations, and opportunities to practise using skills to help with managing challenging situations. In these ways confidence was developed in the student's ability to deal with future challenging situations.

As students had not been attending their regular school, the very fact they were actually able to get to CRHS-City and be at school was seen as a relief for parents and students. As this parent described; "I remember her first day there, she just really enjoyed it......she actually liked it. I think it was because the pressure...... felt it was just like releasing the pressure valve, the pressure was off, she was able to somehow take the pressure off herself and we never had any trouble about her getting up in the morning and going to CRHS-City. So for us just the mere fact of her getting up was a fantastic first step......."(Anna's parents).

It was felt the supportive environment enabled students to begin the process of getting back to school and to start to learn to manage their return. "It was just that supportive environment as much as also a place that was teaching her skills that she could use outside of it" (Anna's parents).

Students identified they were taught skills to manage situations they found challenging as well as steps put in place to support getting to the overall goal. "It's a huge achievement if she puts on her uniform and goes in a car.....the reinforcement of tiny steps...." (Anna's parents).

Student's reported this support enabled them to have frequent success in managing and tolerating situations they found challenging which in turn developed their confidence in their ability to manage. As Natasha describes; "Just having the self-confidence knowing that I can do it" (Natasha). 
In particular parents valued the strategies that students had learnt to manage stress and anxiety. "I think he's got quite a few tools as to what to do when he feels a bit anxious" (Jimmy's parents).

These strategies were also mentioned by students as they described how they used them in daily life to manage. "It's definitely shown me tools and even just sort of you know not just the tools of breathing..., but also just you know taking it slow, just sort of look around...enjoy it you know more... like enjoy it and just take your time but also push yourself" (Jimmy).

"Just the whole thing with the putting your worries away. I do that quite a bit. Just write them, rip them up and throw them away" (Natasha).

Students and parents talked about how CRHS-City provided an environment that had the structure of a school which enabled opportunities for students to experience situations they found challenging. Students reported there was a supportive and reflective setting for students to practise managing and tolerating situations which they might not have managed in another setting. "But also too you guys helped sort of bring things that weren't in the routine, sort of get me off balance too... sort of gradually get prepared for things.... things could happen like that" (Jimmy).

As an example, for students who found interacting with peers challenging, CRHS-City provided a social network and social time that allowed students to practise skills, to make small steps in peer interactions and to manage anxiety when it arose. "Just having more teamwork and social time at CRHS-City helped a lot" (Natasha).

These social learning opportunities were also valued by parents as they believed their child had gained confidence to manage while being at CRHS-City "I think it gave her the skills, you know she was starting to rebuild the skills and the 
confidence to go back and the understanding of her anxieties and the fact that it was going to be okay" (Anna's parents).

Students reported they felt more confident and better equipped to enter situations they had previously found challenging. They felt they had the skills to manage better. "Just being able to calm myself down if I get really worked up. Knowing that I can actually do it" (Natasha).

Students and families both discussed situations where they had used the skills learnt to manage their mental health. "Well her level of resilience is, I mean it's a bit difficult to sort of cut and paste it but the level of resilience has clearly improved...so specifically when she's in a position where she's massively outside of her comfort zone she's more likely to be self aware about it and able to sort of articulate it and sort of forgive herself in the context of understanding why that might be the case etc and she's much stronger in believing that you know this too will pass" (Anna's parents).

As an example, one student reported how once he felt he had learnt the tools he found managing new contexts, like a new course, much easier. "I learned how to sort of use the tools....it was a lot easier going to the course than starting at CRHS-City because I was aware you know, it was nothing to do with CRHS-City it was just me. It was just after CRHS-City because l'd worked through stuff...I was ready to go" (Jimmy).

Students were able to describe situations where they had used the skills they had learnt at CRHS-City to manage challenging situations. One student in particular acknowledged now they have left CRHS-City they are continuing to learn new skills that help them manage different situations. "I'm sort of learning more about myself too. Sort of knowing that...just sort of figure out the boundaries..." (Jimmy). 
"Yeah just breathing and just sort of knowing okay yep l' $m$ in Mitre 10 okay yep the door, just sort of make sure where my surroundings are and up ahead there's the exit just in case you know.... and then the more I did it the more I just come into a habit" (Jimmy).

It appeared from the interview data for parents especially, learning the skills their children needed to manage daily life was far more important than focusing on academic learning ability "Qualifications mean nothing he's actually needed to get over his anxiety and other issues to help him learn later on in life you know" (Jimmy's parents).

It's about giving him the tools to be able to cope and so it's not whether he can read a page, don't you think?...You know it's if we hadn't had that, if you guys hadn't have been there then he would never learn" (Jimmy's parents).

\subsubsection{Theme B}

Transitions were more successful when students returned to a supportive school that also included positive links with peers or to a smaller environment geared towards student interests and goals.

This theme was considered important across all cases, however it was significantly more important for students than parents. The content units that make up this theme are: a student transitioning to school is working hard at managing their mental health therefore, the ability for a school to recognise and support this impacts specifically on the student's ability to transition and having positive links with peers at school being considered an important part of the transition process.

Having a gradual process with specific plans in place, accompanied with a supportive environment assisted with a return to school. "I found just putting on my uniform really hard but it became easier by just taking it one step at a time, so 
one day I just put on my uniform and that would be all we would do and then Tania would just drive me to my school but I wouldn't get out of the car..... and then I just started taking English at school........"(Anna).

It was important students felt there was an understanding from their teachers. This involved teachers understanding the student had a mental health condition and just being at school was difficult. More than one student reported support from the teachers enabled students to be at their regular school. "They were very supportive, yep. At times I felt like my teachers weren't supportive but I realised that, I mean they did really care and often they sort of forgot that there was a troubled student amongst the classroom. But like a couple of times I sent emails saying that I was sorry that I hadn't been able to keep up with the homework or whatever, and they were just, they sent really nice replies saying like you know oh we're just so glad to see you smiling in the classroom and that kind of thing" (Anna).

One parent reported the regular schools' teachers were not supportive for her child and described going to school as a negative experience. "I thought they were pretty useless with supporting. So it was negative going back to that school...." (Natasha's parent).

Across all cases the students found managing a large school environment difficult. For two students, attending a course with fewer students who were all there for the same reason was easier. "I think because he was in such a small setting with so few other students he's probably been able to develop proper peer relationships and get to know people without feeling anxious" (Jimmy's parents).

Some students had experienced being bullied at their regular school. It was felt attending a course was easier as students attending a course were often more mature because they wanted to be there. "It was a more adult environment so 
you're not getting the bullying. People pay their way to get in there don't they... well it's a different environment from a school." (Jimmy's parents). Adding to this point it was felt that at a course there were not as many students for the staff to manage and tutors at a course were more available to support a student. "Yeah we've got pastoral care which we can just talk to plus the old tutors are really good to talk to" (Natasha).

A further issue identified as a supportive factor for students to remain engaged with their regular school was the link the student had socially with their peers at school. However remaining engaged with their peers was a struggle for students and impacted the student's ability to return to school. Linked to this, one student identified the challenge of meeting new people at a difficult time. "It was definitely difficult to develop new friendships...I was sort of not in a great enough space to go and introduce myself" (Anna). (Peer connections at a student's regular school will be discussed further in theme $F$ ).

Students who had been absent from their regular school and then were attending part days as part of the transition process, reported questions from their peers could be challenging. "Just the amount of questions 'oh where you've been, we've heard this has happened'... it was kind of nerve-wracking. Just want to get there and do your stuff and leave again" (Natasha).

One parent identified it was helpful CRHS-City engineered the process of reconnecting with peers. "CRHS-City worked with us very well and with the regular school at realising that we needed to get her reconnecting with her friends at school and allowing, no actually sponsoring that taking her up and letting her have some lunch hours and whatever at the school and that sort of thing can't be underestimated" (Anna's parents).

A further point raised was the potential for CRHS-City to become difficult to leave. "I think possibly a slight difficulty I think was that she'd almost got too 
comfortable at CRHS-City you know she was a bit reluctant to leave the cocoon there" (Anna's parents).

It appeared for some the safe environment at CRHS-City could become a barrier which prevented the student moving forward. As Anna's parents describe she had become so comfortable it became a challenge for her to move forward. "Because the danger is that at CRHS-City you know I mean you can imagine that you can get this you could have this sort of fluffy you know a whole fluffy common thing going. You know painting. Which actually ends up, no matter how comfortable the nest, it ends up not doing what it's designed to do which is to be caring, strengthening and transitioning. You know it's not a cure it's a you know let's get you well enough to go back into... reintegrate into the community that you know that is going to take you forward" (Anna's parents).

Anna's parents discussed how this was a balancing act for the staff at CHRS-City as they provided a supportive environment for students, while at the same time providing enough of a challenge to move students on. "Possibly a negative you could say is that you know that she had got so comfortable there....she had to really push herself hard to sort of get....step back out of the comfort zone to start going back but you know I think you guys got the balance right" (Anna's parents).

Parents valued having the goal of transition as the focus for everyone and felt this supported the overall aim of moving on from CRHS-City. "The formal structure around transitioning meant it was inescapable" (Anna's parents).

\subsubsection{Theme C}

\section{Students were able to continue with academic achievement and work towards future goals.}

Equally important as the previous theme, academic achievement and working towards future goals were significant across all cases. However this was 
referred to more often by parents than students. The interview data demonstrated it was important for both groups that students were able to continue with their education and continue to work towards future academic and career goals. Parents who initially expressed concern about students falling behind at their regular school felt it was particularly important when their child returned to their regular school they would not be further behind.

In contrast students expressed confidence they had maintained their achievement and they were able to continue working towards the National Certificate of Educational Achievement (NCEA). Several of the students discussed how they returned to school with a renewed confidence in their ability to achieve. "Just keeping up with work was good because then I didn't feel so completely behind" (Anna).

"What I am doing now is really great. I've made all these steps that I definitely wouldn't have been able to do a couple of years ago. I went for a job interview. I'm going on a school trip to Fiji. I've got NCEA level 1 and 2 with merit" (Anna).

The students who did not return to school continued to have goals for academic achievement. All students interviewed were able to articulate their goals. Although some were unsure of what they wanted to do, they all agreed they wanted to have access to an education to gain skills and qualifications for their future. Some students spoke about how the time at CRHS-City assisted them to cement their future goals, perhaps consider options they had not thought about, or raise their expectations of post-school achievement. "Just knowing that there are choices out there which I didn't know before" (Natasha).

"Yeah I think the whole thing is like Nigel he would, discuss.... the whole kind of thing....because I wanted it at that time...my decisions were either to go to art school or music and, and he would show me what credits I need.... and so l'd sort of sort out okay if I wanted to go there I could, I'll have do to these certain 
amount of papers because you know Maths for just example. So l'd sort out the education side with Nigel, he would help me and he got me ready so I could choose. What I did was music" (Jimmy).

Parents felt if their child had not attended CRHS-City they would not have been able to continue with their education. "If he hadn't have gone to CRHS-City he couldn't have gone to the polytechnic" (Jimmy's parents).

Students also recognised they had got to a place where they required support to be able to continue with their educational goals. "I think I definitely needed CRHS-City as a bit of a launching pad to move onto the next step. Like I'm really glad that I have stayed at school and getting my education because now I can go to university or whatever, because I'm not sure where I would have been if I...I don't know if I would have gotten back to the school without help or not. But we'll never know" (Anna).

For one student the limited curriculum options meant their learning experience at CHRS-City had to be narrowed. This student commented having specialist teachers for additional subjects would have allowed her to continue with her subjects. "I think I am okay with it, that I didn't do it, but yeah, I mean my...by choosing those subjects, that was sort of what I was going to do for the next couple of years, like I didn't do art, which would have just been too hard with CRHS-City so then I didn't do that in Year 12, but I'm now doing it in Year 13" (Anna).

\subsubsection{Theme D}

CRHS-City is a smaller environment set up to meet the needs of students who have similar issues.

Although this was an important theme it was not addressed as frequently as

previous themes. However it was considered equally important across parents 
and students. This category contained the content units that described CRHSCity as a small environment purpose built for students who had similar needs. The size of the school and the fact the students who attended had similar needs was a recurring feature in the data and demonstrates the participants felt the therapeutic milieu of CRHS-City, including class size, was particularly important in terms of meeting their needs. Following an absence from school, CRHS-City also provided routine for students, a place to go each day.

Students and parents agreed regular school was too difficult to manage when the student was struggling with a mental health condition. Students and parents reported the large school environment perpetuated feelings of anxiety and alienation. "I was just not used to being in a crowd of people...I just didn't feel comfortable.... it was very hard I just didn't know what to do, I felt like an outcast" (Natasha). They felt the environment at CRHS-City and being with students who had similar struggles normalised their behaviours/anxieties making it easier to be at school and to begin to function within a school setting again. "She suddenly went into sort of a safe nest, yes, safe place for her...l think any sort of school would have been almost symbolic of all the things she wasn't able to achieve and do whereas, she went into a sort of safe nest where everyone was saying, well actually there's a lot of us that are... that suffer as teenagers and do it hard and....so she was sort of coming home and saying l've got a mental illness and this is what it looks like and other people have it and people get better....sort of gave her a place to be really, while she went through that period of illness in her life" (Anna's parents).

CRHS-City was seen by all parents and students as a safe environment. The smaller class size enabled students to interact on a personal level, encouraging relationship building for some students who had found this challenging at their regular school. Parents and students felt maintaining small class sizes was essential for creating a safe environment. As this parent commented "you know CRHS-City wouldn't work if there were 25 kids in the class, even if you had more 
teachers.... think it's that ability to have such a small group of youngsters with the amount of staff there, I don't think it would function if it was a school sized class" (Jimmy's parents).

Similarly a student discussed how they found it easy to make friends when they had previously found this challenging. "It was difficult at first because I was shy but then once I started opening up it seemed like I was everyone's friend. It was really weird for me because I haven't had many friends before" (Natasha).

Students and parents identified it was positive being with other students who shared similar experiences. "I thought it was good that there were other students there with similar experiences and going through similar things" (Natasha's parent). In addition, students felt as students were at CRHS-City for a similar reason they were accepted for who they were which included their mental health condition. "We go and do the same thing they understand you and they treat you like a normal person and they all know. You know all it is really is just fifteen maybe close to twenty students who have just gone off a little bit off track and they all know why they're there and all support....it's really cool because you know that going in there that l've got ten other people maybe when I started that know why I'm there, and they know why they're there, so they're going through the same thing" (Jimmy).

For students who had experienced significant non attendance at their regular school, attending CRHS-City each day established a routine. The students reported the routine of attending school and the daily programme as purposeful and considered this helped them learn to manage aspects of their mental health condition. "Yeah routine. That was really helpful because I think before I was sort of you know all over the show....yep because it had all the you know just the simple things okay Maths at ten or something like that. But also knowing okay that your Managing Me group would be every couple of days. But you know it 
was sort of, okay l'll be going to the post office with Tania on Tuesdays. So l'd know, you know" (Jimmy).

\subsubsection{Theme E}

The time spent at CRHS-City is seen as a way to get students back on track, assisting them to maintain their education, at a time when parents felt both they and the students could not do it anymore.

It was evident across all cases, attending CRHS-City was a way of getting "back on track". However, this was significantly more important for parents. The interviews identified parents often felt at a loss by the time the students were referred to CRHS-City. Parents reported they could no longer manage the impact their child's mental health condition had on their school attendance.

Parents felt they had tried everything they could to enable their son or daughter to attend school and reported feeling stuck. Attending CRHS-City was seen as a way to break an unhealthy cycle. "We'd hit the brick wall I mean we couldn't get her back to school and the more she stayed away of course the more schoolwork she missed and so the more anxious she got, you know because then when she did go back then was so far behind. So going to CRHS-City sort of broke that circuit" (Anna's parents).

Linked to this concern parents identified they felt they were too familiar to help with the process of getting their child to school. "I think it was that constant day in day out of attending CRHS-City that you were doing what we couldn't manage to do because it was just too hard. I think sometimes we're too familiar" (Jimmy's parents). It was a relief for parents to have their child at school. "It was a relief.....made a hell of a difference....to go to school and stay at school" (Jimmy's parents). 
Students agreed that attending CRHS-City helped them to get back on track. "....As I had derailed a little bit it sort of got me back on track" (Jimmy).

All students acknowledged attending CRHS-City happened at a time that was very low for them, they could not see a future at that point. "I really didn't see any options open to me before I came to this school. I think one of my goals was to start a family or something but I really wasn't sure. I think I couldn't really think ahead too much because I wasn't in a good space, about what job I could get or you know even if I'd stay at my regular school or whatever..." (Anna).

Adding to this point, students identified they may not have continued with their education if they had not been able to attend CRHS-City. "I just wanted to drop out and just do nothing. I just found it too hard" (Natasha).

Parents felt supported practically by CRHS-City with the issues that arose as part of the student's transition. "I'll never forget it...we drove in, something had tipped Jimmy off and nothing had happened here and he wouldn't get out of the car....and I can still hear the tone of Nigel's voice 'hold your head up Jimmy, you are staring it right in the eye and you are beating it'. You know it was like this, this old Maori fellow with his wise, wise saying you know and it was just things like that... whereas I would go yabber, yabber, yabber, yabber, yabber, he was just saying come on. You know virtually you get to the point where you want to actually physically push them out of the car. So he got out. I don't know of anybody there that's not excellent at their job" (Jimmy's parents).

As discussed in theme $B$ the transition back to school can be difficult for students. Parents identified this was difficult for them too, they felt at a loss, and the support provided to parents from CRHS-City was valued. "If you'd said to me to what extent do we need support....I would have said, nothing at all...just put $100 \%$ of your energy into Anna, I mean if she's well we don't come here with any issues. As someone who has participated in the process I would have a 
different view now which is that even though we would rank very high on an optimism scale, you know day by day, wake up every morning very optimistic, both of us hit points of being very, very...so discouraged that there would've there would be you know that you've drawn and drawn on your levels of sort of support and goodwill and belief and optimism and there was a couple of really quite central conversations that we had with you where you said 'you know it will this will pass and it will get better, it will come right you know. Anna's one teenager we've seen huge numbers of teenagers, it does come right'. Sitting where I am now I can't believe that I was in a position to, to doubt that but I doubted that so fundamentally to my core...we did....those... a couple of those conversations... and that was probably enough for us to then go back into the fray and just continue to be you know completely supportive and believing and optimistic. You know just those few words... see you don't know how core those... that those little bits of encouragement...because of the occasional depths that we ourselves feel you know, and that is I mean, how do you measure that, how do you know" (Anna's parents).

Parents were extremely grateful their son or daughter was now in a position to continue with their education. "So she's gone from a... you know she'd gone into an abyss where she wasn't functioning at all and we couldn't see a way forward and when she left CRHS-City, you know she has re-entered school life for a year and she completed NCEA one and two with merit and you know is going in with some optimism into Year 13" (Anna's parents).

The interview identified parents felt an inability to get their children to school and/or manage the impact their mental health condition had on this issue. "We wouldn't have been able to do it. We just wouldn't, if we'd had him at home for any length of time it would have driven us mad, we didn't have the skills to do it" (Jimmy's parents). 


\subsubsection{Theme $\mathrm{F}$}

\section{Not only while at CRHS-City was it difficult to maintain friendships with peers at the student's regular school but also it was difficult for students to connect with them when returning to school.}

This theme was addressed equally across all cases, although was not raised as frequently as other themes. As theme B has indicated, students having positive links with their peers at school is one of the key factors supporting successful transitions. Two of the students interviewed either did not return to, or maintain their return to their regular school. The interviews identified difficult relationships with their peers made it more challenging.

All the students had not attended their regular school for varying degrees of time which also culminated in becoming socially isolated from their peers at school. "But I think I would say that it was probably the area that was in a way the most not troublesome, but you know she was away from her friends and peers and she did start to feel you know isolated from them you know and I mean she's also not particularly good at staying in touch and....so you know that that is something that is quite hard to basically when you are not at school to sort of stay kind of in the loop" (Anna's parents). Associated with this feeling of isolation, students identified their absence had made it difficult to fit back in. "Oh I found it really difficult because like there were heaps of rumours why I wasn't at school and I just didn't seem to fit in with anyone there" (Natasha).

Students felt that they lost touch with their friends. "It was very hard because I just didn't know what to do, I felt like an outcast. I didn't know like anyone there" (Natasha).

Although it was important for students to have insight into their own mental health, they found it difficult as peers at their regular school did not share this understanding. "My friends were quite keen to stay in contact with me but at 
certain points I really felt like I didn't really have friends because my friends found it a bit hard because when I'd go in and l'd be really happy because I'd be happy to see them and they'd be like 'oh why is she not here if she is doing so well' kind of thing because they didn't see my bad side" (Anna). Associated with having an understanding of managing their mental health condition, it was identified this could set students apart from their peers as they were more mature. "You learn a bit more than what a normal seventeen year old would know" (Natasha's parent).

One student reported that it was difficult to establish and maintain connections with peers. ".... it was quite hard because I was trying to make new friends at CRHS-City as well as trying to maintain those friendships" (Anna).

For some students not having positive relationships with peers to begin with was a factor. "I know this sounds a bit stupid but I mean you know a lot of people at my old school would always sort of push around, I just thought that how, how you're odd until I met people at CRHS-City...." (Jimmy). Coupled with having experienced being bullied. "People there I just didn't want to see them again" (Natasha).

\subsubsection{Theme $\mathbf{G}$}

CRHS-City was difficult at times but it kept students focused on where they were going and challenged them to get there. This was good as it could become too comfortable and hard to leave.

As indicated in theme $\mathrm{B}$, there is the potential for CRHS-City to become too comfortable for students. The interviews identified although students found it difficult to work towards their transition goals, they recognised if they had not been pushed they wouldn't have moved forward. 
The supportive environment at CRHS-City enables students to settle in and establish helpful routines and it is difficult for students to begin a return to their regular school. "I think I settled in a bit too well and then when we began transitioning that was a bit of a shock" (Anna).

Each student identified it was important CRHS-City challenged them to move on even though it was difficult at times. "...you guys were pushing me because otherwise I wouldn't go l'd just be staying there the whole time" (Natasha). Coupled with the potential to really enjoy CRHS-City being a barrier to their transition. "Maybe enjoying it too much at CRHS-City and not actually really wanting to go back to my school at points. That was a bit of a barrier" (Anna).

The interview identified although it was difficult for students to work through the transition plans established with them, it kept them focused on where they were going. "Ah, yes. We went through a couple of rough patches but they, I guess they really got in tune with my needs and what... when I was able to do it and when I really wasn't, like I said before doing the sort of one step at a time thing and just being really supportive with each step and I mean eventually I got there so..." (Anna).

Student's acknowledged how difficult it was at times to work on the steps supporting their transitions. "I found that difficult because if I just wouldn't want to do something...you'd keep pushing me and pushing me, I was at my breaking point quite a few time." (Natasha). However they reported it became easier. "I found just putting on my uniform really hard but it became easier by just taking it one step at time....." (Anna).

One student identified there came a point when it was easier to be at her regular school. "When I started sort of fulltime I just sort of got into it and I think that was quite good because I didn't have the sort of waking up and thinking 'Oh can I just go to CRHS-City today, that's all I'll do'.... and it was good to start full time so I 
didn't get behind and it sort of...everyone sort of, it felt like I hadn't been gone at all almost" (Anna).

Each student reported feeling positive having gone through the transition process. "You went there to get back on track and then you got back on track because in the end that's how you graduated and it was a lot of, lot of you know sweat and tears and sort of, it was really good. Really" (Jimmy).

\subsubsection{Theme $\mathrm{H}$}

CRHS-City is a great support for parents and schools, linking them all together, including with mental health services. The focus on transition meant everyone knew the goal.

As indicated in theme $\mathrm{E}$, parents often felt they could no longer manage the impact of the student's mental health condition on their school attendance, accompanied with the ongoing effort of trying to get their child to school.

Parents reported their feelings of isolation and the fact people did not understand their situation. "So unless you are a parent who's gone through similar experiences I don't think anyone else can understand" (Natasha's parent). Associated with this was the thought people would not understand the actual mental health component. "You know these people would you know if you told people your friends the sort of things that he wasn't able to do they would just think this is nuttyville you know" (Jimmy's parents).

Parents expressed having CRHS-City linking the student, family, mental health team and the student's school was a significant support. "....and keeping everyone in the loop and just having the regular phone calls, the conferences with doctors and everything else I thought it was really good" (Natasha's parent). 
Parents felt the review process contributed to keeping people accountable and up to date with plans and goals. "Once every three weeks we would all sit round and you'd have someone taking notes and an agenda and yeah okay, what were the things that had to be you know... so someone with a business background I loved the fact that there was that type of you know formal meeting with accountabilities and things and that had an extra upside... if we ever talk about how it helped us as parents quite separate from how it helped Anna...but you know I think that transitioning, the formal structure around the transitioning meant that it was an inescapable you know the consequence" (Anna's parents).

Each parent reported finding it difficult to explain to the student's regular school the impact of their child's mental health condition on their school attendance. They identified having the regular school linked in to the student's admission to CRHS-City supported the schools' understanding. "And then the other thing which we haven't mentioned I think is that CRHS-City worked very actively at engaging with the school and that allowed a transitioning which if that hadn't been a central tenet as well administered as it was, would not have achieved for Anna what it did - which was allow the school to understand better what she was going through and what her needs were..." (Anna's parents).

Parents felt it was positive CRHS-City consistently reminded the team of the goal as they acknowledged it could become too comfortable for their son or daughter. "Yes, that they knew from day one the idea was that you spend a couple of terms here and then you definitely....you know you don't get too comfy because you're going back." (Anna's parents). Including reminding the regular school of this goal. "...... think it is important to keep that connection going because you can imagine there'd be a temptation on the part of the secondary school to just sort of say oh well thank God...there's that child you know gone - you know woo hoo you know let them take care of her now and then out of sight out of mind a bit..." (Anna's parents). 


\subsection{Issues for further consideration}

From the interviews the eight themes above emerged as significant across all cases. Issues arose from the interviews that require further consideration and will be discussed in chapter 5 . These are:

- Connections with peers at the student's regular school were difficult. It either may have already been difficult and/or was difficult for students when focusing on transition. Bullying may have been a contributing factor of a student's refusal to attend school. Having a social connectedness to school assists students respond better to it. "I think that's Jimmy just getting over the fact of being rejected and maybe a little bit of can't be bothered....it was sad actually....there's nobody, no peers in his life...." (Jimmy's parents).

- The environment of CRHS-City suits some students better than a large mainstream school. However the purpose of CRHS-City is to support students to return to their regular schools. Some students may not be able to achieve as well academically in a large mainstream environment and require a smaller school environment such as CRHS-City to be able to achieve academically. "Yeah it's better to be out of the school environment I think. Out of a regular school environment it's a lot better. Well it seems to suit Natasha more than being in a state school" (Natasha's parent).

- For new students to attend CRHS-City, current students need to transition out which creates a certain amount of pressure to keep students moving on while still ensuring their needs are met. "I found it difficult because sometimes I just wouldn't want to do something then you'd just keep pushing me and pushing me.... was at my breaking point quite a few times" (Natasha). 
- Parents felt they did not have the skills to manage their child's mental health condition and specifically the impact on their school attendance. When supported by CRHS-City, parents developed the skills and felt empowered through the process to manage. "...yes you were here to support her but on the other hand you do need to do this and you knew when to sort of you know just say look and put your foot down and say you know enough fuss you know let's just do it...." (Anna's parents).

- For students who want to go on to university the fact they cannot cover all subject areas while at CRHS-City could create a barrier for future plans and goals. "By choosing those subjects, that was sort of what I was going to do for the next couple of years" (Anna).

- Of the three cases one of the students' had attempted suicide. For the two other cases the parents acknowledged this could have been a risk factor for their child if they had not attended CRHS-City and learnt to manage their mental health condition and return to either school or further education. ".....Anna has gone through something which is incredibly dire without ever presenting as a serious sort of suicide risk and .... whatever extent that the involvement of CRHS-City has helped in that, we are extraordinarily grateful...." (Anna's parents).

\section{5 Conclusion}

Students and parents described positive outcomes from their experience of attending CRHS-City. Being at CRHS-City helped students explore different ways of managing their mental health condition and gain confidence in their abilities to do so which in turn supported the overall goal of a return to school or further education. Parents and students identified the supportive environment of CRHS-City enabled students to attend school again and continue to work towards academic achievement and future goals. 
Parents and students reported the overall goal of transition was very difficult. Transitions were more successful when students returned to a supportive school or a smaller environment geared towards student interests and goals. While at CRHS-City it was difficult for students to remain socially connected with their peers at their regular school.

Parents identified the structure of CRHS-City provided support to link all services together while remaining focused on the transition outcomes for students. Students identified there was the potential for CRHS-City to become too comfortable and although it was difficult to transition on it was important to be challenged to do so. 


\section{CHAPTER 5}

\section{Discussion}

"Inclusion is a process of identifying, understanding and breaking down barriers to participation and belonging."

(Early Childhood Forum (2003)) $^{6}$

\subsection{Introduction}

This research was designed to improve understanding about the experiences of students' and their parents' experiences of the students having attended CRHSCity in order to support transition back to school or further education and to meet the needs of students more effectively. More specifically, I wanted to identify what challenges and supports if any the students and their families encountered so that these might be anticipated in the future. The challenges and supports students and their families encountered will be discussed throughout this chapter.

The question guiding this study was: "What are the experiences of students returning to mainstream education who are concurrently enrolled in a specialist school for students with mental health conditions and a NZ secondary school?" The three cases described how each student and their family experienced the student attending CRHS-City and the ways in which the students were supported to either return to school or further education. From these descriptions eight themes emerged from the within-case and cross-case analysis. The major findings from the eight themes can be grouped into five areas:

1. Significance of context

2. Issue of inclusion

3. Value of learning skills to manage mental health

4. Implication of establishing school connectedness

5. Importance of family

\footnotetext{
${ }^{6}$.http://www.everyoneisincluded.us/inclusionquotes09.html
} 
This chapter discusses each of these areas in relation to the existing literature.

\subsection{Significance of context}

The findings demonstrate context, in particular the social and emotional environment of school appeared to contribute greatly to the student's wellness. This supports Fuller's (1998, p.6) assertion that 'the culture of a school is an important determinant of the mental health of its inhabitants'. The interview data demonstrated several features of the school and the environment contributed to an overall culture that supported wellness. De-Hayes et al (2008) note every school is unique and has its own culture. This can include the physical layout, school routines, and student and staff relationships.

Students who participated in this research had not attended their local school as a result of a mental health condition, in these cases anxiety was a common factor. Participants identified the environment and culture of CRHS-City as contributing significantly to the student's ability to attend school. Students and their families described having access to supports enabled them to manage within a school setting. The school culture at CRHS-City is reported by these students as accepting and in some cases normalising for them. Further, aspects of the programme such as the routines, and the focus on learning new skills to manage their mental health condition assisted the students to gain the confidence to utilise the new skills they acquired.

Students reported a desire and willingness to attend their local school but found without support and programme adaptation this was not achievable. It appeared not being able to attend their regular school highlighted for each student they were not normal, resulting in them feeling different from their peers and becoming more socially isolated. Yet with support within the culture of CHRS-City each student was able to manage either a transition back to school or into further education and to continue to work towards their goals. Transition back into regular environments is of course vital for these students and their wellbeing. The 
Like Minds, Like Mine national programme acknowledges social inclusion for many reasons is an essential component of recovery for people with experience of mental illness (Ministry of Health, 2007).

Koller and Svoboda (2002) recognise a paradigm shift when working with adolescents with a mental illness with a focus being on what is 'right' with the child rather than what is 'wrong'. Their work explores how to construct a positive environment that allows not only learning but also mental health to flourish, thus recognising schools can help bring preventative mental health services to students who have mental health needs. CHRS-City appeared to offer an environment where students were able to attend and work from a strengths based perspective. The students and their families in this research reported attending a regular school made them feel that they were 'different'. Whereas when they came to a context where mental health was normalised and staff were able to respond to the needs of individuals they were able to work on their strengths and learn new skills.

Cooper, Hunter-Carsch, Sage and Tiknaz (2006. p.26) propose mainstream schools need to spend more time on the social and emotional needs of students, but curriculum pressure and expectation of academic achievement take precedence. They suggest 'there would need to be a fundamental shift in the attitude of government in terms of expectations and focus. It would need a focus on inclusion targets, an acknowledgment time spent on relationships is an investment and human resource management is in fact the key to effective education'. It appeared from this research the student's regular school was not able to put in place the level of support the student required to support their social and emotional needs until support and collaboration was available. For one school, the relationship with CHRS-City and the successful transition of the student led to the student's regular school being educated in how to manage the student's mental health condition, including the support to do so. The fact the school had the support of CRHS-City's knowledge of the student's mental health 
condition appeared to provide them with confidence to support the student. This also required the school being flexible, including all staff being willing to provide support and knowledgeable of the student's mental health condition

Every school is unique with its own culture and environment. The participants of this study found CRHS-City provided an emotionally supportive environment for the students. The factors pinpointed by the participants as providing an emotionally supportive environment at CRHS-City were:

\section{Staffing and skill level of staff}

Students could attend CRHS-City even if they were having a difficult day knowing support was available. As a result of having fifteen students and five full-time staff, staff were able to put in place more interventions and provide more support for the student than their regular school. Having an on-site mental health clinician meant students could have therapeutic input throughout the day if this was required. The clinician was able to give advice to the teachers and support staff on how to support the student's specific to their mental health needs. Students in this research reported feeling their needs were understood and they were supported. Similarly parents reported valuing the clinical knowledge of staff and the regular contact staff made with clinical case managers and the regular school. This meant the student was provided with a consistent approach and support from a wider team.

\section{Size and layout of the school.}

The physical environment, in particular the size and the layout of the school, made it easy for students to attend. The fact students did not have to move around the school, find their way to classes and encounter large numbers of students, noise, and people they did not know, made it easier for them to attend. Although students had to interact with other students throughout the day, the layout ensured they had the opportunity to take time out in a safe place when they became anxious. 


\section{Structure of the day.}

Students reported the routines of the day meant they knew what to expect. If there was a fear of a certain subject or activity, rather than avoiding the situation and not coming to school, students were supported by staff and peers and given opportunities to develop skills to manage. This became part of their programme.

\section{$\underline{\text { Peers }}$}

Students found their peers at CRHS-City supportive, there was a shared understanding of each other's needs. Students knew they were at CRHS-City for similar reasons and reported not feeling judged or different. Students were able to practise socialising in a smaller setting, developing their social skills, confidence and friendships.

\section{Academic learning}

Students were able to learn at their own pace. If required, curriculum demands could be reduced while focusing on learning to manage their mental health condition. CRHS-City is in a privileged position of having both education and health professionals working within the school context and adequate resourcing to provide for the needs of the students.

These factors contribute significantly to the ability of staff to be able to provide an emotionally and supportive environment for the students. Although this is important for the students attending CRHS-City, it is not the reality of a regular school context or in fact life. Students can become too comfortable within the CRHS-City context and too dependent on the level of support available for them. Further, students reported attending CRHS-City made it difficult for them to maintain connections with their peers at their regular school and for some students this provided a reason to avoid attending their regular school. Therefore it is important students continually experience the process of transition, are provided with frequent opportunities to keep linked in with their regular school, and learn coping strategies to self manage their mental health condition. 


\subsection{Issue of inclusion}

This research demonstrates the current focus on inclusion in education can be problematic for students who have a mental health condition. The New Zealand Special Education policy works from an inclusive paradigm and wherever possible looks for the least restrictive environment in which to educate students (Ministry of Education, 1996). These students were unable to continue attending their regular school resulting in self-imposed exclusion from the school system. While CHRS-City may be viewed as a 'special school', it is closer to inclusion than the isolation of a home environment.

Analysis of the data suggests all students valued the ability to work on their regular school work, including working towards achieving NCEA. They were future focused and had goals but required support to be able to work towards those goals. Participants reported coming to CRHS-City was preferred to staying at home. The data demonstrated having the opportunities at CRHS-City enabled students to develop the skills to manage their mental health condition which in turn meant they could pursue their academic and future goals.

Prior to attending CRHS-City, each of these students was not attending school resulting in the probability of them not achieving their academic goals. The mainstream context was not sufficient to ensure students were able to attend school even for some with additional support. For these students return to school was reported as being incredibly difficult and was only able to happen with a considerable amount of time and effort by all involved. Loxley and Thomas (2001) identify schools can often focus on packaging students difficulties as the students' problem, diverting attention from ways in which schools can become more friendly and inclusive places. 


\section{Students who have high health needs}

If due to high health needs students are unable to go to their usual school or they require support to be able to attend school safely, Special Education (MoE) has two initiatives to support them to continue their education. These are:

1. The School High Health Needs Fund (SHHNF) which provides teacher's aide time to support students with serious medical conditions so they can attend school safely.

2. Three regional health schools which provide teachers to teach or guide students' learning in hospital or at home if they are unable to go to school because they are sick (Ministry of Education, 2011).

The expectation is these students once receiving sufficient health services would return to their mainstream environment, if required with the assistance of a teacher aide. However given the growing number of students out of school applying for regional health school support for mental health conditions, it appears these initiatives and perhaps the suitability of some aspects of the initiatives are insufficient.

The aim of CRHS-City is to reduce the time students spend out of school by providing quality teaching and learning programmes combined with active therapeutic interventions to support them with their transition plans. However for some students the return to school can be too daunting an experience if there is lack of understanding, support and resource to assist them to manage within the regular school setting. This research indicated to support a student to remain in school, significant support was required from the school. Also a considerable amount of time and effort is required by all involved to support a student's return to school. In view of the responsibilities placed upon schools, it is not surprising 
many teachers question the wisdom of including a student whose behaviour is 'beyond the scope of normal school boundaries and control' (Jones \& Smith, 2004, p.115). When the support is not available within the regular school setting, transition is extremely difficult and can compromise the student's wellness. As an example one parent from this research reported the experience of going back to school was negative for her child as the teachers were not able to support her mental health needs.

To support students who have a mental health condition, the needs of the student's regular school should be considered too. Schools may require input from mental health services and time to put appropriate interventions in place to support students. This includes the availability and expertise of staff to accommodate the needs of students who have a mental health condition. Schools need to be willing to work across agencies, accompanied by agencies supporting schools in order to draw on the strengths of other areas of expertise. Henderson et al (2006) identify the lack of aftercare resources and/or a fragmented service system, impacts the gains made by students following an intensive plan to assist reintegration back into a classroom. The cabinet report, Review of Special Education - Recommendations for Change in 2010, sets out changes to ensure children with special needs get a fair deal including schools being ready to meet student's needs (Minister of Education, 2010). However schools providing for the needs of students with a mental health condition are not mentioned specifically.

This research highlights for students who have a mental health condition the importance of remaining engaged in school because it provides opportunities to have social connections, to continue to work towards future academic and career goals and opportunities for them to learn to manage their mental health condition. However the school needs to have the ability to be flexible and have staff able to put in place interventions and support for the students. Therefore schools 
require adequate resourcing and expertise to support students who have a mental health condition to remain included within the school context.

Currently as this level of support and intervention is not provided in mainstream schools, there needs to be provision for students to attend schools like CRHSCity. The focus of CRHS-City is to support the transition of students back into mainstream education. However in some cases as demonstrated in this research, transition can be put at risk if students are returned to a large school without the necessary supports. As a group, students with a mental health issue are marginalised in New Zealand as provision for them is not covered in special education policy. This issue identified by the research requires further investigation.

\subsection{Value of learning skills to manage mental health}

Within the CRHS-City context, student's individual plans include key competency goals and therapeutic goals requiring students to learn specific skills to manage their mental health condition. These goals are a feature of the student's plans. Participants in this research agreed attending CRHS-City enabled them to learn new skills to manage. These skills included aspects of Cognitive Behavioural Therapy (CBT). For those students who had experienced services through the therapy room at the Child and Adolescent Mental Health Service (CAMHS), transfer to CRHS-City provided an easy and supportive way for them to 'experiment' and find out what worked. Being at CRHS-City provided a context for students to get feedback on skill learning immediately either from staff or other students. As an example, one student described the difficulty they had returning to school. However by taking small steps such as putting on the school uniform, then driving to school, the student was eventually able to go into school. Throughout the process the student was able to build up tolerance to situations that were difficult while being reminded of specific coping strategies such as breathing techniques and positive self-talk. This developed confidence to try further challenges. Constant evaluation of skills used is important particularly 
around the time students are beginning a transition back to school. Further each student participant indicated they still struggle with their mental health symptoms. However knowing how to manage them gave them confidence to continue working towards their transition goals and manage other aspects of their lives.

Heyne et al (2005) identify flexibility and exposure is a critical component of intervention programmes. For each student participant having a place such as CRHS-City to practise managing coping skills was considered essential. It enabled students to become familiar with their early warning signs and determine what strategies worked for them. They also gained confidence to put these strategies in place. A feature that enabled CRHS-City to work effectively is having a mental health clinician on site working within the school to support students and provide advice for staff to understand the condition and provide useful interventions. Collaboration between education and health professionals from the perspective of participants was successful. This collaboration could be explored further in research.

\section{Key competencies and skill learning}

The key competencies listed in the New Zealand Curriculum are conceptualised as the capabilities people need in order to live, learn, work and contribute as active members of their communities. The five key competencies identified in the New Zealand Curriculum are: Managing self; Relating to others; Participating and contributing; Thinking; Using language, symbols, and texts (Ministry of Education, 2007). Key competencies are intended to replace the "essential skills" from the previous curriculum framework (Ministry of Education, 1993, pp.17-20). The Defining and Selecting Competencies (DeSeCo) project defined them as the things all people need to know and be able to do in order to live meaningfully in, and contribute to a well functioning society (Hipkins, 2006). This suggests when considering curriculum coverage, opportunities need to be made available for students to 
develop these key competencies and as stated within the document, in social contexts.

Atkins et al (2010) recognise schools represent the most influential context on children's cognitive and social development. They suggest an ecological model conducive to students learning not only academic skills but 'competencies' specific to functioning and managing their mental health within the school context. However their work highlights this is an area in great need of research because there is a weak research base supporting effective interventions. An area that could be investigated further is the development of the key competencies within schools taking into account the mental well-being of students and competencies specific to students managing mental health needs.

\subsection{Implication of establishing school connectedness}

Social connectedness is an important part of adolescence. It includes not only making and maintaining friendships and social connections but also a connectedness to school. Cross et al (2009) endorses the relationship between a student's self-reported feelings of connectedness to school and improved health and academic outcomes. Further, Christenson et al (2007) identify social isolation is associated with increased risk for depressive symptoms, suicide attempts and low self esteem. This would indicate the longer a student with a mental health condition is disengaged from school the greater the potential of a deterioration of their mental health condition.

The student participants in this research had become disconnected from their regular school due to not attending as a result of their mental health condition and/or through 'negative' experiences at school. This research indicated for each student participant the ability to attend CRHS-City was a positive connection with school re-established. However each participant highlighted how difficult it was to maintain a positive connection with their regular school. 
Two student participants had experienced bullying from peers at their regular school which may have impacted on their school attendance and their ability to return to their regular school. For students who had negative experiences at their regular school, attendance at CRHS-City enabled a new relationship to school because of focused care and close specific work with the student in a small environment. This close connection with CRHS-City enabled the needs, strengths and passions of the students to become clearer. Students were able to feel connected to CRHS-City which provided a place for the student 'to be' and begin to be more self aware. The challenge for these students was to be able to transfer this sense of belonging to their regular school setting. While the impact of students experiencing bullying and the possible relationship with anxiety and school refusal has not been a focus of this study, Anderson et al (2008) report frequent exposure to bullying is related to increased risk of depression and suicide. This is clearly an area that requires further investigation.

\section{Transitioning back to school}

Two student participants emphasised the importance of staff at the regular school acknowledging the hard work they were putting in to 'manage' being at school and not having their success measured solely on academic achievement. Having a key staff member from the student's regular school linked into the process of the student's admission to CRHS-City, enabled an understanding of the impact the student's mental health condition on their ability to attend school. The staff member was aware of the strategies the student was working on to enable a return to school.

This research indentified the challenge of ensuring relevant information was transferred to the student's teachers within their regular school and building their understanding and willingness to support the student. For one student the inability for the teachers to understand her needs within the classroom made it increasing difficult to be at school. In contrast, transition worked well for another student who was focusing on tolerating being at school rather than keeping up 
with academic requirements. When she e-mailed her teachers about her concerns, they acknowledged the academic work was not the focus at that time, it was her attendance at school. Having this type of understanding and support enabled this student to continue to persevere with her return to school.

There appears to be a tension between the academic expectation of schools and keeping health and wellbeing of students as a priority. Murray (2002) argued increasing demands to improve academic outcomes may reduce the amount of time teachers can devote to developing and maintaining supportive relationships with students. Further such relationships have a powerful and lasting effect on the lives of students and may be particularly important for students with high incidence disabilities. Wearmouth, Glynn and Berryman (2005, p.119) note 'for many teachers there seems to be an inherent conflict between meeting the needs of the student and meeting the demands of a prescribed curriculum'. With such a focus on curriculum coverage and attainment there is little time for teachers to attend to the pastoral needs of their pupils. 'In the current climate of competition between schools, performance management and teacher shortage, educators managing the issue of students who exhibit difficulties is challenging' (Cooper et al, 2006, p.26). However, one of the main challenges is to realise the rising expectations all students will achieve, rather than those who are relatively easy to teach (Ancess, Cochran-Smith, Lytle, Newmann \& Wehlage as cited by Timperley, 2005).

The data from this research demonstrates students can experience isolation or have anxieties over friendships especially at a time of transition. It is important to note attendance at school may not be indicative the problem is solved. As an example one student participant left her regular school following an incident with a peer after a term of what appeared to be a successful transition back to school. Difficulty with peer relationships can significantly affect the ability of students to manage within the school setting. Students may require on-going support including skills explicitly taught to manage social situations. De-Hayes et al 
(2008, p.118) identify as 'social skills show signs of improvement, isolation decreases'. Given social isolation is associated with an increased risk for depressive symptoms, suicide attempts and low self esteem it would appear student's learning skills to manage social situations is an area that needs to be addressed within schools. Schools will continue to have students with mental health issues, therefore it is important the necessary strategies and supports to assist these students are provided using both education and health agencies working collaboratively.

\subsection{Importance of family}

A key finding from this research was the importance of family participation in the process of supporting their children with their mental health condition. Parents valued the support of CRHS-City to assist them to cope and learn skills to help them manage their child's mental health. Further parents appreciated the support of CRHS-City when dealing with their child's regular school. For CRHSCity to assist students to learn to manage their mental health condition accompanied with a return to school, parents need to support the transition initiatives. This research showed there was a need for some parents to learn new skills to support their child in the transition process. It was clear from the data parents often needed to tolerate some very difficult situations with their child and at times wanted to give up because of 'fights' and resistance from their child. The research demonstrates CHRS-City had a role in supporting families not only with managing the mental wellness of their child but also with negotiating the transition goals.

\section{Supporting families}

The interview data demonstrated parents felt attending CRHS-City had enabled their child to learn the skills necessary to manage their mental health condition. Parents indicated prior to attending CRHS-City, as parents, they were not able to manage the impact their child's mental health condition had on their ability to attend school. Further parents felt CRHS-City was able to support the student's 
regular school to understand the impact the mental health condition had on their child's school attendance.

Students identified learning new ways to cope was challenging as they were expected to put in place skills to manage situations which previously may have been avoided. Parents indicated this could cause tension in the home as they tried to support and implement skills they were learning to support their child. These times were difficult for families and parents reported losing hope things would ever change. The research indicates parents found having the support of CRHS-City with this process helped them to continue to support their child. As Moses (2009) suggests, a parents' understanding of their child's mental health condition impacts on how they are able to respond to difficult situations, support their child, and provide interventions. Support from CRHS-City was either provided on the spot via a phone call to parents of the students attending CRHSCity or by response to e.mails including linking in the student's case manager to provide support. The review meeting process was seen by parents as a useful way to link the student, family, school and case manager together thus providing an opportunity for the parent to feel supported by a wider team.

\section{Skill development for families}

As demonstrated from this research, family are a vital part of the intervention plan for students. For some, this intervention plan may involve the family being supported to develop skills to assist their child, including post intervention. Aggleton et al (2008) suggest parents could not only substantially complement work undertaken by others with the young people but could themselves be a stand-alone intervention if altering parental perceptions and improving parent's skills to cope with their children's needs had occurred.

It appears from this research parents perceived themselves as lacking the skills to support their child appropriately when their child was struggling with a mental health condition. This study indicates CRHS-City has a significant role 
supporting parents to be able to understand and learn how to support their child specific to their mental health needs including the on-going support for their child post an intervention such as CRHS-City. Heyne et al (2005) recognise the role of parents as co-therapists responsible for the implementation of procedures requires explicit training for parents to develop behavioural and cognitive procedures effective in the treatment of childhood anxiety disorders, phobic disorders and school refusal. Evans and Meyers (2006) suggest regardless of the parents' current level of competence in family interactions, interventions designed for students with a mental health condition need to include the family and should involve instructing families how to apply these interventions.

The research indicated even though students had successfully transitioned back to school or further education they still had times when they struggled with their mental health condition. Therefore the family's ability to support their child with their mental health condition is essential for their long term ability to manage including being able to maintain their transition goals. This research further demonstrated on occasions expectations of families can be outside what CRHSCity is funded to provide. Therefore the student's mental health case manager needs to remain actively involved and available to provide support and intervention for the family. As this is not always practical as the case manager is not always available to respond to families, it may be worth considering the provision of further resource within CRHS-City to specifically support families. Further, an area for additional investigation is the types and sources of on-going support and intervention for the family once the student returns to their regular school.

\subsection{Limitations}

It is acknowledged this research is a small snap shot of the experiences of three

students and their families of the students attending CRHS-City to support a return to school or further education. There are many other students who have 
experienced attending CRHS-City to support a transition as well as many students who have a mental health condition and have not attended CRHS-City. As discussed in chapter 3 , due to the complexity of mental health conditions and how these can present, students were identified by common features of their diagnosis. The feature in common with each student was the symptoms of anxiety impacting their functioning. Therefore this research does not presume to understand either the experiences of all students with mental health conditions who have returned to school or those of their families. However for the participants in this research, attending CRHS-City was welcomed, appreciated and seen as necessary to support their return to school or further education.

This research was a snapshot in time, undertaken when students had completed their time at CHRS-City. While all three students were successful in their transition back to school or further study and then work, it is unclear the impact this intervention has on the individual long term. An area for further investigation could be a longitudinal study that follows outcomes for students over time.

\subsection{Summary}

This research found being at CRHS-City helped the participants explore different ways of managing their mental health condition and gain confidence in their abilities to do so, which in turn supported achievement of the overall goal of a return to school or further education. Both parents and students identified the supportive environment of CRHS-City enabled students to attend a school again and continue to work towards academic achievement and future goals. However returning to their regular school was not an easy process for the students, their parents, or the student's regular school. Support for the student's family and regular school is an essential part of this process.

\subsection{Recommendations}

Recommendations have arisen from this study specific to CRHS-City and to the education sector in general. These are listed separately. 


\section{Recommendations for CRHS-City.}

For each student admitted to CRHS-City the overall goal is to return to their regular school. The return to school is not easy for the students. It is often a time when students are required to put in place the strategies they have been practising while at CRHS-City to support a return. CRHS-City is aware the student's regular school needs to put in place a considerable amount of time and resource and have the skill to support the student to manage a return to school. Yet at times schools cannot provide them. It would be useful to approach a range of schools which have worked with CRHS-City to determine what type of support from CRHS-City they have found useful and if they have found any support lacking to enable the best transition outcomes for students.

- There can often be a mismatch between what a school can offer in terms of a supportive social and intellectual environment for adolescents and what students with a mental health condition actually need. This research demonstrated for two students the return or sustained return to a large mainstream school was not possible. CRHS-City's primary role is to support transition back to school or further education. If a student is not old enough to transition into further education CRHS-City may be the type of school that best meets the student's needs. But if they stay longer term, that reduces the places available for new students requiring an admission and may make it easier for other students to avoid transition. Perhaps there needs to be provision for some students to be able to complete their education within CRHS-City or a similar type of environment. However increasing the numbers of students to cater for students longer term may detract from the special character that is a feature of CRHS-City. A recommendation could be to create extra space 
and staffing within the CRHS-City context to cater for students who have longer term needs.

- When students attend CRHS-City there is intense support and intervention for the student and often the same level of support and intervention for families is required. The support for the family is often beyond the scope and ability of CRHS-City to provide. It may be useful to identify and evaluate alternative means to meet the needs of families including the possibility of a support group, education sessions for families, and possibly extra resource specific to supporting families to manage their child's mental health condition.

- While at CRHS-City the support for the student and their family provided by CRHS-City and CAMHS is an integral component of the intervention. Once the student has been withdrawn from CRHS-City and returned to school, full support from CRHS-City is no longer available. Although students are not withdrawn from CRHS-City until it is determined the student is managing successfully, it may be useful to get information from schools six months following a student's withdrawal from CRHS-City to identify any challenges that have presented for the student and school. This information may be useful to determine the type and accessibility of support required following a withdrawal from CRHS-City with a view to providing smoother transitions.

\section{Recommendations for the education sector.}

- Schools will continue to have to cope with students with mental health issues. Therefore it is important the necessary strategies and supports to assist these students are addressed using education and health agencies working together. This research has identified there is very little research base to support effective interventions within mainstream schools to 
support students who have a mental health condition. Further research into effective interventions is recommended.

- This research indicates a mental health condition is often misunderstood by schools. Schools can often label the symptoms as behavioural. For this reason it is recommended teachers are equipped with relevant knowledge in this area both at a pre-service and in-service level.

- Students with a mental health condition are likely to experience some level of alienation from school. For some, bullying is a factor that increases anxiety and school refusal. The fact that frequent exposure to bullying is related to increased risk of depression and suicide highlights the need for schools to continue to investigate how to address bullying effectively within the school and wider context.

- This research highlights the significant amount of support, resource and skill required by schools to support students who have mental health needs. A feature that enables CRHS-City to work effectively is having a mental health clinician on site working within the school to support not only the students but also staff to understand the conditions and implement interventions. Having the clinician on site enables students to have support as needed rather than waiting for a weekly or two weekly meeting with their therapist. The research confirmed on the spot support, skill development and feedback by a clinician for student and staff greatly enhances skill learning. This finding suggests there may be some merit in investigating how the education and health sectors might work together more effectively, perhaps by having health clinicians based within schools.

- Within education there is an increasing amount of pressure and expectation for academic achievement. However there are an increasing number of students who are not managing school as a result of a mental 
health condition. Within schools perhaps there needs to be the same value given to the development of the key competencies as other areas of the curriculum, including schools being able to be flexible in providing for their students. However this may require a fundamental shift in how achievement is measured.

- Provision for students with mental health needs is not covered within Special Education policy, suggesting changes are required at policy level to address the growing need for schools to cope with students who have mental health issues.

\subsection{Conclusion}

Over the last five years an increasing number of students have been admitted to Central Regional Health School as a result of a mental health condition that impacts upon their ability to attend school. However research on interventions that support young people with a mental health condition within the education system appears to be non-existent in New Zealand. CRHS-City is the first Ministry of Education funded initiative that addresses adolescent mental health and transition back to school in New Zealand. The purpose of this study was to highlight this population of students, their particular needs, and begin to document evidence around the value of this intervention. This thesis reports on the experiences of three students and their families of students attending CRHSCity and how this process supported transition back to school or further education.

The research began with one overarching question:

"What are the experiences of students returning to mainstream education who are concurrently enrolled in a specialist school for students with mental health conditions and a NZ secondary school?" 
The aim was to identify and explore the supports and challenges that the students and their families experienced in five specific areas. These were:

- Access to Education

- Mental Health \& Well-being

- Social \& Peer Relationships

- Transition Goals

- Future Plans \& Ideas

To answer this question a qualitative research design within a constructivist paradigm was used. A multiple case study was chosen as the methodology. The experiences of three students and their families were identified and explored. Data collection methods for each case study consisted of an interview with each student and their family and data collected from the student's individual plans. Interviews were analysed using inductive coding and categorised according to similarity of themes across the cases.

The research question was concerned with discovering the experiences of students and their families of students attending CRHS-City and how this process supported transition back to school or further education. Further, the research aimed to identify the successes and challenges for students to support the on-going development of CRHS-City. This research has found that being at CRHS-City helped the participants explore different ways of managing their mental health condition and gain confidence in their abilities to do so, which in turn supported the overall goal of a return to school or further education. However this was not an easy process for the students, their parents or the student's regular school.

The research identified the context, in particular the social and emotional environment of CRHS-City appeared to contribute greatly to the student's 
wellness. Further, students require support and opportunities to learn skills to manage their mental health condition. It is acknowledged social connectedness is an important part of adolescence. It includes not only making and maintaining friendships and social connections but also a connectedness to school. This research demonstrates the current focus on inclusion in education may be problematic for some students who have a mental health condition. Another key finding from this research was the importance of family participation and support for them during the planning and interventions.

From this research the recommendations specific to CRHS-City and for the education sector in general have been identified. Schools are charged with catering for all their students, including those with a mental health condition. Therefore it is essential the necessary strategies, adequate resourcing and supports to assist these students are addressed possibly by using education and health agencies working together. Further research into the effectiveness of interventions within mainstream schools which support students with mental health needs is also seen as important.

The literature search identified research specific to school transition while concurrently enrolled in a specialist school for students with mental health conditions is limited. More needs to be known about the outcome of this type of intervention for adolescents.

This research was carried out with the intention of contributing to national and international evidence in this area. It is hoped from the publication of the results from this research a more vigorous discussion is initiated in New Zealand regarding provision for and the development of services for adolescents with mental health issues. 


\section{$\underline{\text { Reference List }}$}

Adolescent Health Research Group (2003). A health profile of New Zealand youth who attend secondary school. Journal of the New Zealand Medical Association, 116:1171. Retrieved April 25, 2011 from http://www.nzma.org.nz/journal/116-1171/380/

Aggleton, P., Hill, V., Maxwell, C., Mehmedbegovic, D., Warwick, I., Yankah, E. (2008). Supporting children's emotional wellbeing and mental health in England: a review. Health education. 108, (4), p.272-286. Retrieved April 17, 2011, from ProQuest Central Document ID: 1498715061.

Ainscow, M. (1994). Special Needs in the classroom: A teacher education guide. London: Jessica Kingsley/UNESCO

Alonso, L., Angermeyer, M., Bernert, S., Brugha, T., Bruffaerts, R., de Girolamo, G., Dietrich, S., Heider, D., Matschinger, H. (2008). Adverse parenting as a risk factor in the occurrence of anxiety disorders: A study in six European countries. Social Psychiatry and Psychiatric Epidemiology, 43:4, pp. 266-72. Retrieved April 19, 2011, from ProQuest Psychology Journals. Document ID: 1456798301.

Anderson, J., Henriques, J., Jacobson, G., Riesch, S., Sawdey, L. (2008). Suicide ideation among later elementary school-aged youth. Journal of Psychiatric and Mental Health Nursing, 15, pp. 263-277. Retrieved March 17, 2011 from http://web.ebscohost.com.helicon.vuw.ac.nz/ehost/pdfviewer/ pdfviewer?sid=acbcd54e-4e98-443c-9851-deb01ec877c\%40sessionmgr13\& vid $=1 \&$ hid $=12$

Atkins, M., Hoagwood, K., Kutash, K., Seidman, E. (2010). Toward the integration of education and mental health in schools. Administration and Policy in Mental Health and Mental Health Services Research, 37, pp. 40-47. Retrieved April 20, 2011, from ProQuest Central. Document ID: 2039730241.

Beautrais, A. (2003). Suicide in New Zealand II: a review of risk factors and prevention. Journal of the New Zealand Medical Association, 116:1175. Retrieved April 25, 2011 from http://www.nzma.org.nz/journal/116-1175/461/

Bennyworth, P. (2006). Building partnerships at silverdale school. Many Voices 25, 12-15. Wellington: Ministry of Education. 
Berg, B. (2007). Qualitative research methods for the social sciences ( $6^{\text {th }}$ ed.). Boston: Pearson Education.

Bond, L., Bowes, G., Butler, H., Carlin, J., Catalona, R., Glover, S., Patton, G., Thomas, L. (2006). Promoting social inclusion in schools: A grouprandomized trial of effects on student health risk behaviour and well-being. American Journal of Public Health. 96 (9). pp. 1582-1587. Retrieved May 5, 2009 from http://www.ajph.org/

Booth, T. and Ainscow, M. (2002). The Index for Inclusion. Bristol: Centre for Studies on Inclusive Education.

Christenson, S., Eisenberg, M., Hall-Lande, J., Neumark-Sztainer, D. (2007). Social isolation, psychological health and protective factors in adolescence. Adolescence, 2:66, pp.265-286. Retrieved April 18, 2011, from ProQuest Psychology Journals. Document ID: 1318012321

Cohen, L., Manion, L., Morrison, K., (2007). Case studies. Research methods in education. (6 $6^{\text {th }}$ ed.). (pp. 253-263). New York: Routledge.

Creswell, J. (2008). Educational research: Planning, conducting, and evaluating quantitative and qualitative research. New Jersey: Pearson Education.

Cross, D., Runions, K., Waters, S. (2009). Social and ecological structures supporting adolescent connectedness to school: a theoretical model. Journal of School Health 79:11, pp.517-524. Retrieved 18 April, 2011 from http://web.ebscohost.com.helicon.vuw.ac.nz/ehost/pdfviewer/pdfviewer? sid=ad421ae1-296f-48c5-8c43-39c69f7da159\%40sessionmgr110\&vid= 3\&hid=104

Cooper, P., Hunter-Carsch, M., Sage, R., Tiknaz, Y. (Eds.). (2006). The handbook of social, emotional and behavioral difficulties. London: Continuum International Publishing Group.

Davies, T. (2000). Special Education 2000 - A national framework. Paper presented at the Internationals Special Education Congress 2000, University of Manchester, England. Retrieved May 4, 2011 from http://www.isec2000.org.uk/abstracts/papers_d/davies2_1.htm

De-Hayes, L., Grandison, K., Thambirajah, M. (2008). Understanding school refusal. Jessica Kingsley Publishers:London

Denscombe, M. (2006). The good research guide for small-scale social research 
projects $\left(2^{\text {nd }}\right.$ ed.) pp. 30-40. England: Open University Press.

Denzin, N., \& Lincoln, Y. (Eds). (2008). Collecting and interpreting qualitative materials. Thousand Oaks, CA: Sage.

Dudley, A., Gullone, E., Hughes, E., Tonge, B., (2009). A case-control study of emotion regulation and school refusal in children and adolescents. The Journal of Adolescence, 2010, 30:691. Retrieved April 12, 2011, from http://jea.sagepub.com.helicon.vuw.ac.nz/content/30/5/691.full.pdf+html

Eggleston, M., \& Watkins, W (2008). Mental health services for children and adolescents in New Zealand, outcomes, and the Health of the Nation outcomes Scale for Children and Adolescents (HoNOSCA). Journal of the New Zealand Medical Association, 121:1271. Retrieved April 25, 2011 from http://www.nzma.org.nz/journal/121-1271/2983/

Evans, I., Meyers, L. (2006). Literature Review on Intervention with Challenging Behaviour in Children and Youth with Developmental Disabilities. Victoria University for the New Zealand Ministry of Education. Retrieved May 18, 2011 from http://www.educationcounts.govt.nz/_data/assets/pdf_file /0004/15187/12014-meyerandevans.pdf

Fergusson. \& Woodward, L., (2001). Life course outcomes of young people with anxiety disorders in adolescence. Journal of the American academy of child and adolescent psychiatry, 40:9, pp.1086 - 1093. . Retrieved April 28, 2011, from http://www.otago.ac.nz/christchurch/otago014779.pdf

Fuller, A, (1998). From surviving to thriving. Promoting mental health in young people. Victoria: Australian Council for Educational Research Ltd.

Hawk, K., \& Hill, J. (2001). Troubled transition. How to ensure that educational transition points do not interrupt student learning. Set: Research information for teachers, 3, 29-32. Wellington: New Zealand council for educational research

Henderson, S., Langman, N., White, H. (2006). A school based transition programme for high-risk adolescents. Psychiatric services. 57 (8), p.1211.

Heyne, D., King, N., Ollendick, T., (2005). Cognitive-behavioral treatments for anxiety and phobic disorders in children and adolescents: A

Review. Behavioral Disorders, 30(3), pp. 241-257. Retrieved April 17, 2011, from ProQuest Central. Document ID: 938654311.

Hipkins, R. (2006). The nature of the key competencies - a background paper. New Zealand Council for Educational Research: Wellington. Retrieved May 
18, 2011 from http://keycompetencies.tki.org.nz/Resource-bank/Introducingkey-competencies/Key-resources/The-nature-of-the-key-competencies-Abackground-paper-PDF-653KB

Hornby, G \& Witte, C. (2008). Follow-up study of ex-students of a residential school for children with emotional and behavioural difficulties in New Zealand. Emotional and behavioural difficulties, 13:2, 79-93. Retrieved November 16, 2009 from http://dx.doi.org/10.1080/13632750802027598

Jones, J., Smith, C. (2004). Reducing exclusion while developing effective intervention and inclusion for pupils with behaviour difficulties. Emotional and behavioural difficulties. Vol 9 (2).

Koller, J., Svoboda, S. (2002). The application of a strengths-based mental health approach in schools. Childhood Education: Infancy through early adolescence. 78 (5), 291-294.

Loxley, A., Thomas, G. (2001). Deconstructing special education and constructing inclusion (pp.46-64). Buckingham, Philadelphia: Open University Press.

McInerney, D., \& McInerney, V. (2002). Educational psychology: Constructing learning. Australia: Pearson Education

Mertens, D. (2005). Research methods in education and psychology: Integrating diversity with quantitative, qualitative, and mixed methods ( $2^{\text {nd }}$ ed.). Thousand Oaks, CA: Sage.

Minister of Education. (2010). Review of Special Education- Recommendations for change (2010). Retrieved May 3, 2011 from http://www. minedu.govt.nz/NZ Education/EducationPolicies/SpecialEducation/ /media/MinEdu/Files/ EducationSectors/SpecialEducation/CabinetPaperSuccessForAll.pdf

Ministry of Education. (1993). The New Zealand curriculum framework. Wellington: Learning Media Ltd.

Ministry of Education. (2007). The New Zealand curriculum. Wellington: Learning Media Ltd.

Ministry of Education. (1996). Special Education 2000. Retrieved May 9, 2011 from http://www.minedu.govt.nz/NZEducation/EducationPolicies/ SpecialEducation/PolicyAndStrategy/SpecialEducationPolicy.aspx

Ministry of Education. (2011). The school high health needs fund and regional 
health schools. Crown copyright. Retrieved May 11, 2011 from http:// www. minedu.govt.nz/ /media/MinEdu/Files/EducationSectors/Special Education/ParentInformation/InfoSheetSchoolHighHealthNeedsFund.pdf

Minister of Health. (2005). Te tahuhu - Improving mental health 2005-2015: The second New Zealand mental health and addiction plan. Wellington: Ministry of Health.

Ministry of Health. (2007). What is social inclusion and why is it so important. Like Minds, Like Mine. 30 August. Retrieved May 8, 2011 from http://www.likeminds.org.nz/file/Newsletter-Archive/PDFs/lmlm_30.pdf

Ministry of Health. (2010). Suicide facts: Deaths and intentional self-harm hospitalizations 2008. Wellington Ministry of Health. Retrieved April 29, 2011 from http:// www.moh.govt.nz/moh.nsf/pagesmh/10482/\$File/suicide-facts2008-dec2010.pdf.

Moses, T (2009). Parents' conceptualization of adolescents' mental health problems: Who adopts a psychiatric perspective and does it make a difference. Community Mental Health Journal, 47, pp.67-81. Retrieved April 19, 2011 from http://www.springerlink.com.helicon.vuw.ac.nz/content 47315671m37p5327/fulltext.pdf

Murray, C. (2002). Supportive teacher-student relationships: Promoting the social and emotional health of early adolescents with high incidence disabilities. Childhood Education: Infancy through early adolescence. 78 (5), 285-290.

Nabors, L., Reynolds, M., Weist, M., (2000). Qualitative evaluation of a high school mental programme. Journal of youth and adolescence. 29 (1), pp.1-13 Retrieved May 5, 2009 from http://www.springerlink.com/content/affxw33bjOhn I?p=bcef7871a79e4291b104fdcf90bdca3\&pi=56

Oakley Brown, M.A., \& Scotts, K.M., Wells, J.E. (Eds). (2006). Te rau hinengaro: The New Zealand mental health survey. Wellington: Ministry of Health

Patton, M. Q. (2002). Qualitative research and evaluation methods ( $3^{\text {rd }}$ ed.). Thousands Oaks, CA: Sage.

Punch, K. (2005). Introduction to social research: quantitative and qualitative approaches. Second Edition. Thousand Oaks: Sage

Roberts, J., Vaughan, K. (2007). Developing a 'productive' account of young 
people's transition perspectives. Journal of Education and Work, (2007) 20:2, pp.91- 105. Retrieved April 17, 2011, from

http://dx.doi.org/10.1080/13639080701314621

Senge, P. (1990). The fifth discipline: The art and practice of the learning organisation. New York: Doubleday.

Smith, A. (1998). Understanding children's development ( $4^{\text {th }}$ ed.). Wellington: Bridget Williams Books.

Stake, R, (2005). Qualitative case studies. In Denzin, N., Lincoln, Y. (Eds.), The sage handbook of qualitative research ( $3^{\text {rd }}$ ed.) pp. 443-466. California: Sage Publications.

Timperley, H. (2005). School-based influences on teachers' learning and expectations. In Barnes, L., (Ed.). 2004). Contemporary teaching and teacher issues. New York: Nova Science Publishers, Inc.

Wearmouth, J., Glynn, T., Berryman, M. (2005). Perspectives on student behaviour. Exploring theory and developing practice. The Open University and the University of Waikato.

Yin, R. (2003). Case study research: Design and methods ( $3^{\text {rd }}$ ed.). California: Sage Publications. 
Appendix A: Parent expression of interest

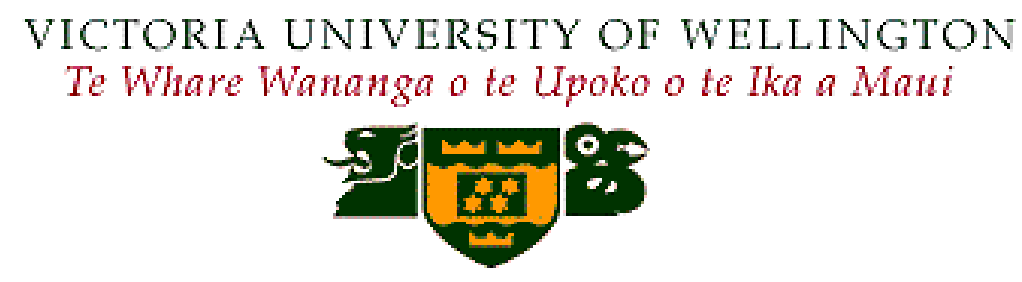

Project Title: A case study of the experience of 3 students returning to their secondary school while concurrently enrolled in a specialist school for students with mental health conditions.

Ethics Ref no: 18155

\section{Parent Expression of Interest}

Name:

$\square$ Yes I would like to participate in the above project.

$\square$ No thank you I would not like to participate in the above project.

Lisa Thompson

Team Leader Mental Health

Central Regional Health School

Lisa.thompson@centralregionalhealth.school.nz

Ph 0274314815
Supervisor Details

Dr Catherine Savage

Victoria University

Catherine.savage@vuw.ac.nz

Ph 0276036030
Chairman

HEC Committee

Victoria University 
Appendix B: Student expression of interest

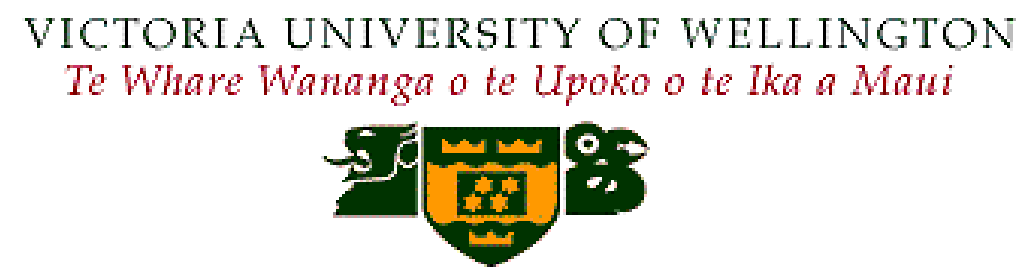

Project Title: A case study of the experience of 3 students returning to their secondary school while concurrently enrolled in a specialist school for students with mental health conditions.

Ethics Ref no: 18155

\section{Student Expression of Interest}

Name:

Yes I would like to participate in the above project.

No thank you I would not like to participate in the above project.

Lisa Thompson

Team Leader Mental Health

Central Regional Health School

Lisa.thompson@centralregionalhealth.school.nz

Ph 0274314815
Supervisor Details

Dr Catherine Savage

Victoria University

Catherine.savage@vuw.ac.nz

Ph 0276036030
Chairman

HEC Committee

Victoria University 
Appendix C: Parent information

\section{VICTORIA UNIVERSITY OF WELLINGTON \\ Te Whare Wananga o te Upoko o te Ika a Maui}

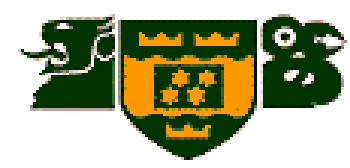

\section{Parent Information}

Project Title: A case study of the experience of 3 students returning to their secondary school while concurrently enrolled in a specialist school for students with mental health conditions.

This project has ethics approval with the New Zealand Association for Research in Education (NZARE): Ethics Ref no: 18155

As part of the requirements for my Master of Education at Victoria University I would like to conduct a case study investigating the experiences of students who have attended CRHS - City. At CRHS -City we are committed to doing our best for young people and helping them achieve. We believe that students perceptions and experiences, and yours as family, can help us to improve the service we provide.

The research will involve:

1. Interviews

This would include a $20-30$ minute interview. Interview questions will be given to students and parents before the interview. The interview is designed to support the students in telling their story about their experience at CRHS - City, steps towards transition, and possible supports and barriers that they experienced while attending CRHS-City. The interview will be typed up and given back to the person interviewed to read to check that it is accurate

\section{Document collection}

I will be collecting information from the student's education plans, therapeutic plans, review notes, transition plans and CRHS - City clinician's clinical notes. These will be analysed to look for patterns in the data in relation to the information gathered from the student and family interviews.

All students and parents involved would remain anonymous.

4. You can withdraw from participating in this research up until one week following the initial interview.

5. Your name will not be used in any written material, you can choose a pseudonym which I will use to refer to you. Particular care will be taken to ensure that the student and family remain anonymous, school names, and other identifying details will be changed to ensure confidentiality in the final written thesis.

6. Every effort will be made to ensure this research will not be harmful to you, if you feel upset you can withdraw up until one week following the initial interview. You 
will be given opportunity to tell the researcher if you would like to stop throughout the interview.

7. You will be given the opportunity to check that the interview transcript is what you said before I use them in the research.

The digital recordings used during the interview process will be destroyed at the conclusion of the thesis. If a transcriber is used as part of the research process they will be aware of and agree to all confidentiality requirements.

A summary of the major themes arising from the research will presented to Central Regional Health School - Board of Trustees, Principal and staff. The main findings may be used to inform developments with staff that work with within the Ministry of Education, and relevant services within Capital and Coast and Hutt Valley District Health Boards. You will also be provided with a summary of the research.

Yours sincerely

Lisa Thompson

Lisa Thompson

Team Leader Mental Health

Central Regional Health School

Lisa.thompson@centralregionalhealth.school.nz

Ph 0274314815
Supervisor Details

Dr Catherine Savage

Victoria University

Catherine.savage@vuw.ac.nz

Ph 0276036030
Chairman

HEC Committee

Victoria University 
Appendix D: Student information

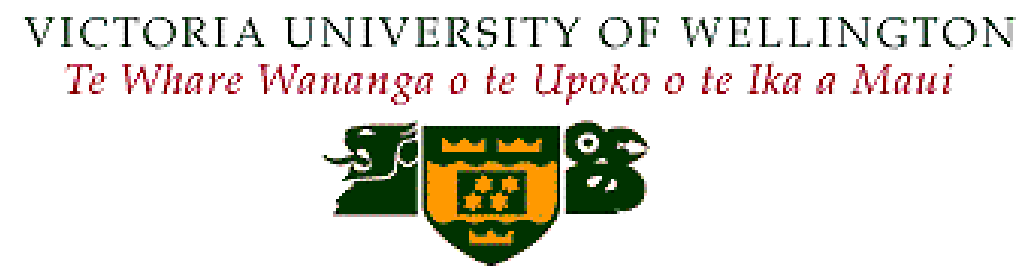

Student Information

Project Title: A case study of the experience of 3 students returning to their secondary school while concurrently enrolled in a specialist school for students with mental health conditions.

This project has ethics approval with New Zealand Association for Research in Education (NZARE): Ethics Ref no: 18155

As part of the requirements for my Master of Education at Victoria University Education I would like to conduct a case study investigating the experiences of students who have attended CRHS - City. At CRHS -City we are committed to doing our best for young people and helping them achieve. We believe that your perceptions and experiences as well as your families, can help us to improve the service we provide.

The research will involve:

1. Interviews

This would include a $20-30$ minute interview. Interview questions will be given to students before the interview. The interview is designed to support the student in telling their story about their experience at CRHS - City, steps towards transition, and possible supports and barriers will be explored in depth. The interview will be typed up and given back to you to read and check that it is accurate. I will also interview your parent/s for 20-30 minutes about their experiences and perspectives of City.

2. Document collection

I will be collecting information from your education plans, therapeutic plans, review notes, transition plans and CRHS - City clinician's clinical notes. These will be analyzed to look for patterns in the data in relation to the information gathered from the student and family interviews.

All students involved would remain anonymous.

8. You can withdraw from participating in this research up until one week following the initial interview without having to provide an explanation

9. Your name will not be used in any written material, you can choose a pseudonym which I will use to refer to you. Particular care will be taken to ensure that the student and family remain anonymous, school names, and other identifying details will be changed to ensure confidentiality in the final written thesis. 
10. Every effort will be made to ensure participation in this research will not be harmful to you, if you feel upset you can withdraw up until one week following the interview. You will be given opportunity to tell the researcher if you would like to stop throughout the interview.

11. You will be given the opportunity to check that the interview notes are what you said before I use them in the research.

The digital recordings used during the interview process will be destroyed. If a transcriber is used as part of the research process they will be aware of and agree to all confidentiality requirements.

A summary of the major themes arising from the research will presented to Central Regional Health School - Board of Trustees, Principal and staff. The main findings may be used to inform developments with staff that work with within the Ministry of Education, and relevant services within Capital and Coast and Hutt Valley District Health Boards. You will also be provided with a summary of the research.

Yours sincerely

\section{Lisa Thompson}

Lisa Thompson

Team Leader Mental Health

Central Regional Health School

Lisa.thompson@centralregionalhealth.school.nz

Ph 0274314815
Supervisor Details

Dr Catherine Savage Victoria University

Catherine.savage@vuw.ac.nz

Ph 0276036030
Chairman

HEC Committee Victoria University 
Appendix E: Invitation to parents

\section{VICTORIA UNIVERSITY OF WELLINGTON \\ Te Whare Wananga o te Upoko o te Ika a Maui}

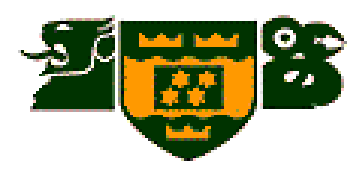

\section{Invitation to parents}

Project Title: A case study of the experience of 3 students returning to their secondary school while concurrently enrolled in a specialist school for students with mental health conditions.

This project has ethics approval with the New Zealand Association for Research in Education (NZARE): Ethics Ref no: 18155

I would like to invite you to participate in a research study that I am carrying out as part of the requirements for my Master of Education at Victoria University. Participating in this study is entirely voluntary, and if you do agree, you can withdraw up until one week following the initial interview. The purpose of this study is to further understand the experience of attending CHRS-City from the perspective of students and their families.

Participating in the research would mean consenting to be interviewed for 20-30 minutes about your experiences and perspectives of CHRS - City as the parent of a student attending. The interview would take place at a time and location that suits you. Your son/daughter would also be interviewed about their experiences of CHRS - City. I would also review the student individual plans that were written while your son/daughter was attending CHRS City to support the study.

All the information collected will be confidential. You can choose a pseudonym, and all services, people, schools referred to will have their names changed. I will keep the tapes of the interview in a locked file and will destroy them at the end of the study. If I use someone to type out the audio files they will sign a confidentiality agreement. I will keep all information confidential unless I think it is harmful to your son/daughter, where I will inform the case manager and/or parent/s.

At CHRS -City we are committed to developing our service to meet the needs of our students. The information that you provide for this study will help inform future programme and service development. Throughout the research you can: 
- Withdraw up until one week following the interview without explanation

- Be assured that your identity will be protected.

- Be able to view the interview questions before the interview so you know what I will ask

If you would like to be a part of this study please send back the expression of interest.

Yours sincerely

\section{Lisa Thompson}

Lisa Thompson

Team Leader Mental Health

Central Regional Health School

Lisa.thompson@centralregionalhealth.school.nz

Ph 0274314815
Supervisor Details

Dr Catherine Savage

Victoria University

Catherine.savage@vuw.ac.nz

Ph 0276036030
Chairman

HEC Committee

Victoria University 
Appendix F: Invitation to students

\section{VICTORIA UNIVERSITY OF WELLINGTON \\ Te Whare Wananga o te Upoko o te Ika a Mani}

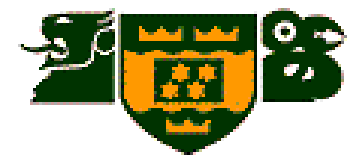

\section{Invitation to students}

Project Title: A case study of the experience of 3 students returning to their secondary school while concurrently enrolled in a specialist school for students with mental health conditions.

This project has ethics approval with New Zealand Association of Research in Education (NZARE): Ethics Ref no: 18155

I would like to invite you to participate in a research study that I am carrying out as part of the requirements for my Master of Education at Victoria University. If you agree I would like to interview you for 20-30 minutes about your experiences at City, at a place and time that suits you. I would also interview your parent/s about their experiences and perspectives of City. I would use your individual plans that we wrote with you while you were at City to also support the study. Participating in this study is entirely voluntary, however if following the interview you decide that you would like to withdraw there will be a one week time-frame which you can do this in.

All the information that I collect will be confidential. You can choose a pseudonym, and all services, people, schools referred to will have their names changed. I will keep the tapes of the interview in a locked file and will destroy them at the end of the study. If I use someone to type out the tapes they will sign a confidentiality agreement. I will keep all information confidential unless I think it is harmful to you, where I will inform your case manager and/or your parent/s.

The information from this study will help inform what we do at City, and how we might adapt our programmes and services to suit student's needs. Throughout the research you can:

- Withdraw up until one week following the initial interview.

- Be assured your identity will be protected.

- Be able to view the questions before the interview so you know what I will ask. 
If you would like to be a part of this study please send back the expression of interest.

Yours sincerely

\section{Lisa Thompson}

Lisa Thompson

Team Leader Mental Health

Central Regional Health School

Lisa.thompson@centralregionalhealth.school.nz

Ph 0274314815
Supervisor Details

Dr Catherine Savage

Victoria University

Catherine.savage@vuw.ac.nz

Ph 0276036030
Chairman

HEC Committee

Victoria University 
Appendix G: Informed consent for parents

\section{VICTORIA UNIVERSITY OF WELLINGTON \\ Te Whare Wananga o te Upoko o te Ika a Maui}

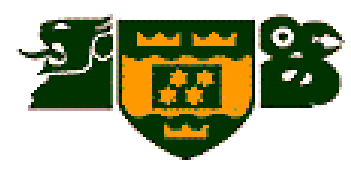

Project Title: A case study of the experience of 3 students returning to their secondary school while concurrently enrolled in a specialist school for students with mental health conditions

\section{Ethics Ref no: 18155}

\section{INFORMED CONSENT FOR PARENTS INVOLVED IN THE CASE STUDY}

I agree to take part in the above research project. I have had the project explained to me and understand that agreeing to take part means that I am willing to:

- take part in a 20 - 30 minute interview

- be interviewed by the researcher

- allow the interviews to be audiotaped and/or transcribed

- consider making time for a further interview and discussion if additional information is required.

I understand that the information from this project will be confidential and will not lead to the identification of any individual. All participants will have a code and/or pseudonyms.

I also understand that my participation is voluntary, that I can choose not to participate in the project. If I choose to participate I can withdraw up until one week following the initial interview without being penalised or disadvantaged in any way.

I would like to review my transcript (typed interview) before it is used in the study. 
Name

Signature

Date:

Lisa Thompson

Team Leader Mental Health

Central Regional Health School

Supervisor Details

Dr Catherine Savage

Victoria University

isa.thompson@centralregionalhealth.school.nz

Ph 0274314815
Catherine.savage@vuw.ac.nz

Ph 0276036030
Chairman

HEC Committee

Victoria University 
Appendix H: Informed consent for students

\section{VICTORIA UNIVERSITY OF WELLINGTON \\ Te Whare Wananga o te Upoko o te Ika a Mani}

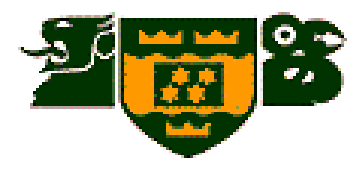

Project Title: A case study of the experience of 3 students returning to their secondary school while concurrently enrolled in a specialist school for students with mental health conditions

\section{Ethics Ref no: 18155}

\section{INFORMED CONSENT FOR STUDENTS INVOLVED IN THE CASE STUDY}

$\square$ I agree to take part in the above research project. I have had the project explained to me and understand that agreeing to take part means that I am willing to:

- take part in a 20 - 30 minute interview

- be interviewed by the researcher

- allow the interviews to be audiotaped and/or transcribed

- consider making time for a further interview and discussion if additional information is required

I understand that any information I provide is confidential, except when it is deemed harmful, in which case my case manager and/or parents will be notified.

I understand that the information from this project will be confidential and will not lead to the identification of any individual. All participants will have a code and/or pseudonyms.

I also understand that my participation is voluntary, that I can choose not to participate in the project. If I choose to participate I can withdraw up until one week following the initial interview without being penalised or disadvantaged in any way.

I would like to review my transcript (typed interview) before it is used in the study. 
Name

Lisa Thompson

Team Leader Mental Health

Central Regional Health School

Lisa.thompson@centralregionalhealth.school.nz

Ph 0274314815
Signature

Supervisor Details

Dr Catherine Savage

Victoria University

Catherine.savage@vuw.ac.nz

Ph 0276036030
Date:

Chairman

HEC Committee

Victoria University 


\section{Appendix I: Interview schedule}

\section{Interview Schedule}

\begin{tabular}{|c|c|c|}
\hline \multirow[b]{2}{*}{ Group } & Students & Family \\
\hline & $\begin{array}{l}\text { This interview round will commence with } \\
\text { letting students know that I am going to be } \\
\text { asking about different aspects of their time at } \\
\text { City. These being: Access to Education; } \\
\text { Mental Health \& Well-being; Social \& Peer } \\
\text { Relationships; Transition goals; and Future } \\
\text { plans and ideas }\end{array}$ & $\begin{array}{l}\text { This interview round will commence with } \\
\text { letting parents know that I will be asking } \\
\text { about different aspects of their experiences } \\
\text { of their sons/daughters time at City. These } \\
\text { being: Access to Education; Mental Health } \\
\text { \& Well-being; Social \& Peer Relationships; } \\
\text { Transition goals; and Future plans and } \\
\text { ideas. }\end{array}$ \\
\hline $\begin{array}{l}\text { Access to } \\
\text { Education }\end{array}$ & $\begin{array}{l}\text { The first lot of questions I will ask will be about } \\
\text { how it was for you attending CRHS - City } \\
\text { specific to meeting your educational needs } \\
\text { following a time away from school due to your } \\
\text { mental health condition. } \\
\text { I would like to understand what CRHS - City } \\
\text { was like for you specific to being able to } \\
\text { continue with your actual school work } \\
\text { (curriculum goals)? } \\
\text { - i.e. you were enrolled with The } \\
\text { Correspondence School for between 2-4 } \\
\text { subjects, was this helpful/not helpful in } \\
\text { supporting you to get back to your regular } \\
\text { school/further education? } \\
\text { Did you note any changes for you in your } \\
\text { ability to continue with your school work within } \\
\text { the CRHS - City setting specific to the key } \\
\text { competency goals that were also a focus? If } \\
\text { so what, how? } \\
\text { (will remind students of their specific KC } \\
\text { goals). } \\
\text { Are there any specific things about your time } \\
\text { at CRHS - City that impacted on you being } \\
\text { able to continue with your schooling? } \\
\text { Did the CRHS - City educational programme } \\
\text { help/not help with your ability to be able to } \\
\text { return to your regular school/further } \\
\text { education? If so what, how? } \\
\text { Is there something you feel would have been } \\
\text { useful to have included within the educational } \\
\text { programme that wasn't? }\end{array}$ & $\begin{array}{l}\text { I would like to understand what CRHS - } \\
\text { City has been like for you as a parent } \\
\text { specific to your son/daughter being able to } \\
\text { continue with their school work (curriculum } \\
\text { goals)? } \\
\text { Have you noted any changes in your } \\
\text { sons/daughters ability to continue with their } \\
\text { schooling/further education (key } \\
\text { competency goals)? If so what, how? } \\
\text { What do you feel has impacted } \\
\text { positively/negatively on their ability to } \\
\text { continue with their schooling/further } \\
\text { education? }\end{array}$ \\
\hline
\end{tabular}




\begin{tabular}{|c|c|c|}
\hline $\begin{array}{l}\text { Mental Health } \\
\text { and Well-being }\end{array}$ & $\begin{array}{l}\text { The second lot of questions I will ask about } \\
\text { are to do with the reason/s why you came to } \\
\text { City } \\
\text { I would like to understand what CRHS - City } \\
\text { was like for you specific to managing your } \\
\text { mental health? } \\
\text { I.e. was it difficult to first begin attending? } \\
\text { How about when you had settled in to the } \\
\text { routine of attending City each day? What } \\
\text { about your ability to be able to follow our } \\
\text { whole programme? What was it like when you } \\
\text { first began to transition back to school? How } \\
\text { was it for you as you began to spend more } \\
\text { time at school/less time at? } \\
\text { Have you noted any changes around how you } \\
\text { feel at school/further education? If so, what, } \\
\text { how? } \\
\text { What do you think has helped/or made it more } \\
\text { difficult for you to feel confident at your regular } \\
\text { school/further education? } \\
\text { Has the CRHS - City therapeutic programme } \\
\text { helped/not helped with your ability to be able } \\
\text { to return to your regular school? If so what, } \\
\text { how? I.e. what strategies did you find } \\
\text { useful/not useful, what were you able to } \\
\text { transfer to your regular school/further } \\
\text { educational setting; have you learnt any } \\
\text { further new skills/strategies? }\end{array}$ & $\begin{array}{l}\text { I would like to understand what CRHS - } \\
\text { City has been like for you as a parent } \\
\text { specific to your son/daughter managing } \\
\text { their mental health. } \\
\text { Have you noted any changes in their ability } \\
\text { to engage and participate within a } \\
\text { school/educational setting, what, how? } \\
\text { What elements do you feel have impacted } \\
\text { positively/negatively on their ability to be } \\
\text { able to engage and participate within a } \\
\text { school setting/further education? }\end{array}$ \\
\hline $\begin{array}{l}\text { Social and } \\
\text { Peer } \\
\text { Relationships }\end{array}$ & $\begin{array}{l}\text { The next lot of questions are about your } \\
\text { friends and relationships while you were at } \\
\text { City and transitioning to your regular } \\
\text { school/further educational setting. } \\
\\
\text { I would like to understand what CRHS - City } \\
\text { was like for you specific to making friends at } \\
\text { CRHS - City? } \\
\text { While attending CRHS - City did you find it } \\
\text { easy/difficult to maintain or develop new } \\
\text { friendships within your regular school/further } \\
\text { education? } \\
\text { If so, what, how? } \\
\text { Have you noted any changes in the } \\
\text { relationships that you have with your friends } \\
\text { at City and your regular school/further } \\
\text { educational setting. If so what, how? } \\
\text { What do you think has helped/or made it more } \\
\text { difficult to develop friendships and socialise } \\
\text { with peers within a regular school setting/ } \\
\text { further educational setting? }\end{array}$ & $\begin{array}{l}\text { I would like to understand what CRHS - } \\
\text { City has been like for you as a parent } \\
\text { specific to your son/daughter } \\
\text { developing/maintaining social and peer } \\
\text { relationships (at City and at their regular } \\
\text { school/further education). } \\
\\
\text { Have you noted any changes in their ability } \\
\text { to develop and maintain friendships, and } \\
\text { socialise with peers (at City and at their } \\
\text { regular school/further education), what, } \\
\text { how? } \\
\text { What elements have impacted } \\
\text { positively/negatively on their ability to being } \\
\text { able to develop friendships and socialise } \\
\text { with peers within a regular school } \\
\text { setting/further education? }\end{array}$ \\
\hline
\end{tabular}




\begin{tabular}{|c|c|c|}
\hline $\begin{array}{l}\text { Transition } \\
\text { goals. }\end{array}$ & $\begin{array}{l}\text { The next lot of questions are to do with your } \\
\text { transition goals from City } \\
\text { I would like to understand what CRHS - City } \\
\text { was like for you specific to you working } \\
\text { towards your transition back to mainstream } \\
\text { school/further education? } \\
\text { Did attending CRHS - City support you with } \\
\text { your transition back to school/further } \\
\text { education? If so, in what way? } \\
\text { Are there any specific things about your time } \\
\text { at CRHS-City that impacted on your return to } \\
\text { school/further education? } \\
\text { If so what, how? } \\
\text { Were there any barriers that got in the way of } \\
\text { supporting a return to school/further } \\
\text { education? If so what, how? } \\
\text { Were there services at your regular } \\
\text { school/further educational setting that } \\
\text { supported you maintaining your attendance? } \\
\text { I.e. Were these easily accessible? Were your } \\
\text { teachers/staff supportive/not supportive? }\end{array}$ & $\begin{array}{l}\text { I would like to understand what CRHS - } \\
\text { City has been like for you as a parent } \\
\text { specific to your sons/daughters transition } \\
\text { goals. } \\
\text { Can you describe how CRHS - City } \\
\text { supported/didn't support your son/daughter } \\
\text { with these goals? } \\
\text { What elements of their time at CRHS-City } \\
\text { impacted positively/negatively on these } \\
\text { goals? } \\
\text { If there were barriers to these goals what } \\
\text { were these? }\end{array}$ \\
\hline Future & $\begin{array}{l}\text { The last lot of questions are to do with where } \\
\text { you feel you are heading now. } \\
\text { I would like to understand what CRHS - City } \\
\text { has been like for you specific to your future } \\
\text { goals and plans. i.e. What did you see } \\
\text { yourself doing prior to requiring an admission } \\
\text { to CRHS - City? What are you doing now? } \\
\text { Where do you see yourself in the next } 6 \text {-12 } \\
\text { months? } \\
\text { What are your goals and plans for the future? } \\
\text { Have there been any experiences that have } \\
\text { impacted on your future plan? } \\
\text { Did your time at CRHS - City impact on your } \\
\text { plans and goals for the future? }\end{array}$ & $\begin{array}{l}\text { I would like to understand what CRHS - } \\
\text { City has been like for you as a parent } \\
\text { specific to your sons/daughters future goals } \\
\text { and plans. } \\
\text { What elements have impacted } \\
\text { positively/negatively on their goals and } \\
\text { plans for the future? } \\
\text { Can you talk about how the time at CRHS - } \\
\text { City has impacted on their plans and goals } \\
\text { for the future. }\end{array}$ \\
\hline
\end{tabular}


Appendix J: Content units of themes

Content Units of Themes

A. CRHS-City provided support for students to learn to manage their mental health, they learnt coping skills.

- Supportive environment

- Taught skills to manage mental health.

- Had opportunities in a supportive environment to practice managing mental health.

- Small steps were considered huge achievements

- Not just an academic focus

- Developed confidence

- Still struggle, but able to transfer learnt coping skills into other situations.

B. Transitions were more successful when students returned to a supportive school that included positive links with peers or to a smaller environment geared towards student interests and goals.

- Students transitioning are working hard to manage their mental health, important for schools to recognize this.

- Transitions more successful when key staff at regular school are supportive, including teachers.

- Having positive links with peers at school is important

- Difficult to return to school

- Transitions more successful when students went into a smaller setting i.e not a return to school.

- Schools sometimes didn't match the student's needs.

C. Students were able to continue with academic achievement and work towards future goals.

- Ability to work on regular school work.

- Ability to continue working towards NCEA

- Helped with learning needs.

- Future focused 
D. CRHS-City is a smaller environment set up to meet the needs of students who have similar issues.

- Environment at CRHS-City is comfortable and supportive

- CRHS-City is a smaller environment

- Fewer students

- Felt like an outcast in regular school, felt normal at CRHS-City.

- It was okay to find situations difficult, it was understood.

- Able to now attend school each day following an absence.

- Routine.

E. The time spent at CRHS-City is seen as a way to get students back on track, assisting them to maintain their education, at a time when parents feel both they and the students can't do it anymore.

- CRHS-City was a circuit breaker for students and their families.

- Provided a place where students were happy to go.

- Parents felt they could no longer manage their child's mental health and the impact of this on their education.

- Frustration as not able to continue with education prior to attending CRHS-City

F. Not only while at CRHS-City was it difficult to maintain friendships with peers at the student's regular school but also it was difficult for students to connect with them when returning to school.

- Difficult back at regular school as peers ask about where you have been.

- Felt in two camps, making friends at CRHS-City, and trying to maintain friendships at regular school.

- Didn't have positive experiences or connections with regular school.

- Had experienced bullying at regular school.

- Felt school didn't understand their needs. 
Individual to students

G. CRHS-City was difficult at times but it kept students focused on where they were going and challenged them to get there. This was good as it could become too comfortable and hard to leave.

- Transition focused, kept students moving towards the goal.

- Comfortable at CRHS-City therefore difficult to leave.

- Pushed and challenged with transition goals.

- Being pushed was difficult.

$\underline{\text { Individual to parents }}$

H. CRHS-City is a great support for parents and schools, linking them all together, including with mental health services. The focus on transition meant everyone knew the goal.

- Parents felt on their own managing their child.

- Valued the support of CRHS-City

- Parents felt supported by CRHS-City working with the base school.

- Transition goals were clear.

- Useful having the base school a part of this process so they knew that the student was coming back. 


\title{
MEMORANDUM
}

\author{
Phone 0-4-463 5676 \\ Fax 0-4-4635209 \\ Email_Allison.kirkman@vuw.ac.nz
}

\begin{tabular}{l|l}
\hline TO & Lisa Thompson \\
\hline COPY TO & Catherine Savage \\
\hline FROM & Dr Allison Kirkman, Convener, Human Ethics Committee \\
\hline DATE & 15 December 2010 \\
\hline PAGES & 1 \\
\hline
\end{tabular}

\begin{tabular}{l|l}
\hline SUBJECT & $\begin{array}{l}\text { Ethics Approval: No } 18155 \text { A case study of the experience of } 3 \\
\text { students returning to their secondary school while } \\
\text { concurrently enrolled in a specialist school for students with } \\
\text { mental health conditions }\end{array}$ \\
\hline
\end{tabular}

Thank you for your application for ethical approval, which have now been considered by the Standing Committee of the Human Ethics Committee.

Your application has been approved from the above date and this approval continues until 31 July 2011. If your data collection is not completed by this date you should apply to the Human Ethics Committee for an extension to this approval.

Best wishes with the research.

Allison Kirkman

Human Ethics Committee 


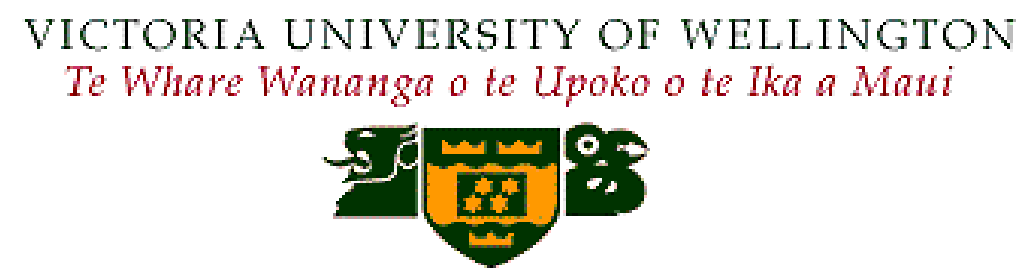

Project Title: A case study of the experience of 3 students returning to their secondary school while concurrently enrolled in a specialist school for students with mental health conditions.

This project has ethics approval with the New Zealand Association for Research in Education (NZARE): Ethics Ref no: 18155

To the Principal

As part of the requirements for my Master of Education at Victoria University I am intending to conduct a case study so that I can investigate the experiences of students who have returned to mainstream education, further education or employment following being concurrently enrolled in CRHS - City, and a NZ secondary school.

My interest in carrying out this case study comes from a desire to improve the service CRHS - City provides for students who have a mental health condition to achieve success within their regular school context. In order to do this I need to identify the supports and challenges that the students and their families encounter.

The research would involve:

1. Interviews

This would include interviews with the students and their family. The interview questions support the students to tell their story about their experience at CRHS - City. The family and student interviews will be used with other sources such as data gathered from the student's individual plans and review process when analysing data..

\section{Document collection}

This would involve a confidential collection of student information from their education plans, therapeutic plans, review notes, transition plans and CRHS - City clinician's clinical notes. These will be analysed to look for patterns in the data in relation to the information gathered from the student and family interviews.

All students involved would remain anonymous.

There are three principles that would be offered to participants of the study:

12. Participants are able to give their informed consent to participate and can terminate their involvement for any reason, up until one week following the initial interview. 
13. Participant identities will be protected by changing names in dissemination and published reports.

14. Every effort will be made to ensure this project will not harm the participants. There is no intent to draw attention to the students, their family or school personnel in the school setting so as to protect their privacy.

Participants will be identified by a code/pseudonym. Tapes used during the interview process will be destroyed. If a transcriber is used as part of the research process they will be aware of and agree to all confidentiality requirements.

A summary of the major themes arising from the research will be presented to Central Regional Health School - Board of Trustees, Principal and staff. The main findings may be used to inform developments with staff that work with within the Ministry of Education, and relevant services within Capital and Coast and Hutt Valley District Health Boards.

I would like to seek your consent to proceed with this research project. I will be happy to answer any questions you may have about this study.

Yours sincerely

Lisa Thompson

Lisa Thompson

Team Leader Mental Health

Central Regional Health School

Lisa.thompson@centralregionalhealth.school.nz

Ph 0274314815
Supervisor Details

Dr Catherine Savage Victoria University

Catherine.savage@vuw.ac.nz

Ph 0276036030
Chairman

HEC Committee Victoria University

Consent to proceed with the research

Signature:

Date:

Principal 
Appendix M: Transcriber's confidentiality agreement

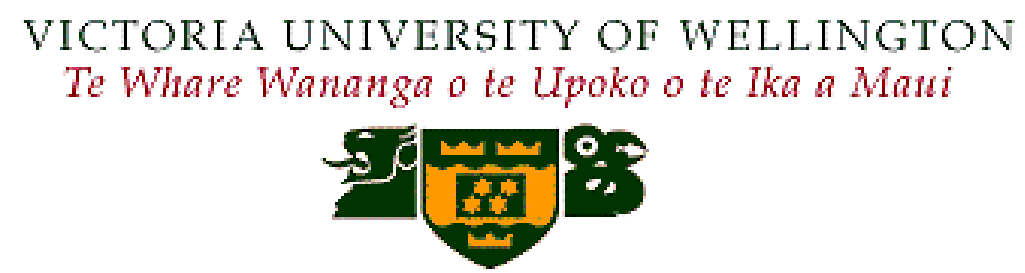

Project Title: A case study of the experience of 3 students returning to their secondary school while concurrently enrolled in a specialist school for students with mental health conditions.

This project has ethics approval with New Zealand Association for Research (NZARE): Ethics Ref no: 18155

\section{TRANSCRIBER'S CONFIDENTIALITY AGREEMENT}

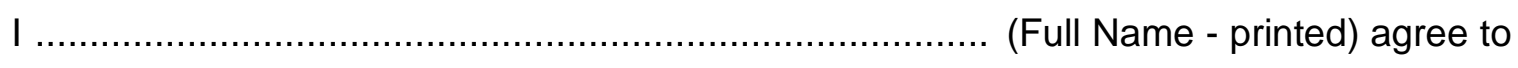
transcribe the tapes provided to me.

I agree to keep confidential all the information provided to me.

I will not make any copies of the transcripts or keep any record of them, other than those required for the project.

Signature:

Date:

Lisa Thompson

Team Leader Mental Health

Central Regional Health School

Lisa.thompson@centralregionalhealth.school.nz

Ph 0274314815
Supervisor Details Dr Catherine Savage Victoria University

Catherine.savage@vuw.ac.nz Ph 0276036030
Chairman

HEC Committee

Victoria University 
Appendix $\mathrm{N}$ : Themes that emerged from the findings

\section{Themes that emerged from the findings}

\begin{tabular}{|c|c|}
\hline & Key Themes \\
\hline A & $\begin{array}{l}\text { CRHS-City provided support for students to learn to manage their mental health, } \\
\text { they learnt coping skills. }\end{array}$ \\
\hline B & $\begin{array}{l}\text { Transitions were more successful when students returned to a supportive school } \\
\text { that included positive links with peers or to a smaller environment geared towards } \\
\text { student interests and goals. }\end{array}$ \\
\hline C & $\begin{array}{l}\text { Students were able to continue with academic achievement and working towards } \\
\text { future goals. }\end{array}$ \\
\hline D & $\begin{array}{l}\text { CRHS-City is a smaller environment set up to meet the needs of students who } \\
\text { have similar issues. }\end{array}$ \\
\hline $\mathbf{E}$ & $\begin{array}{l}\text { The time spent at CRHS-City is seen as a way to get students back on track, } \\
\text { assisting them to maintain their education, at a time when parents felt both they } \\
\text { and the students could not do it anymore. }\end{array}$ \\
\hline $\mathbf{F}$ & $\begin{array}{l}\text { Not only while at CRHS-City was it difficult to maintain friendships with peers at the } \\
\text { student's regular school but also it was difficult for students to connect with them } \\
\text { when returning to school. }\end{array}$ \\
\hline & Individual to students \\
\hline G & $\begin{array}{l}\text { CRHS-City was difficult at times but it kept students focused on where they were } \\
\text { going and challenged them to get there. This was good as it could become too } \\
\text { comfortable and hard to leave. }\end{array}$ \\
\hline & Individual to parents \\
\hline H & $\begin{array}{l}\text { CRHS-City is a great support for parents and schools, linking them all together, } \\
\text { including with mental health services. The focus on transition meant everyone } \\
\text { knew the goal. }\end{array}$ \\
\hline
\end{tabular}


Frequency of findings across cases specific to students

\begin{tabular}{|c|c|c|c|}
\hline Case & 1 & 2 & 3 \\
\hline $\begin{array}{l}\mathrm{S} \\
\mathrm{T} \\
\mathrm{U} \\
\mathrm{D} \\
\mathrm{E} \\
\mathrm{N} \\
\mathrm{T} \\
\mathrm{S}\end{array}$ & $\begin{array}{l}\text { Common themes } \\
\text { across students and } \\
\text { parents } \\
A=14 \\
B=22 \\
C=6 \\
D=9 \\
E=0 \\
F=1 \\
\text { Individual to students } \\
G=4\end{array}$ & $\begin{array}{l}\text { Common themes across } \\
\text { students and parents } \\
A=19 \\
B=14 \\
C=10 \\
D=14 \\
E=5 \\
F=1 \\
\text { Individual to students } \\
G=6\end{array}$ & $\begin{array}{l}\text { Common themes across } \\
\text { students and parents } \\
A=15 \\
B=24 \\
C=12 \\
D=7 \\
E=3 \\
F=2 \\
\text { Individual to students } \\
G=18\end{array}$ \\
\hline & $\begin{array}{l}\text { Other issues raised: } \\
\text { Took about a } \\
\text { week getting } \\
\text { used to City } \\
\text { - } \\
\text { Did return to } \\
\text { mainstream } \\
\text { school, but didn't } \\
\text { work. }\end{array}$ & 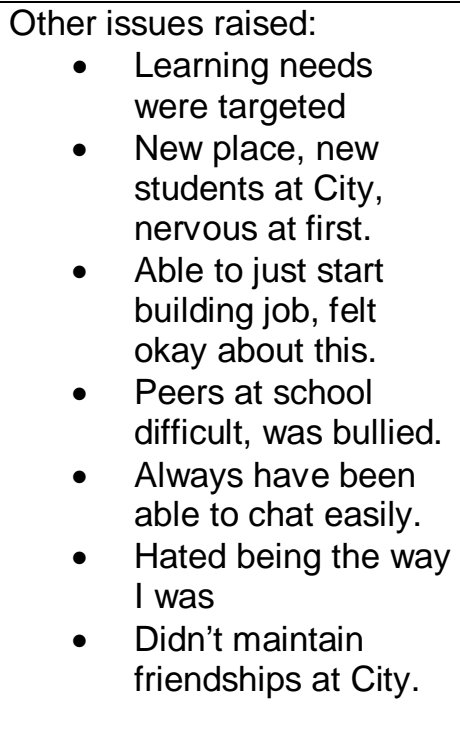 & $\begin{array}{l}\text { Other issues raised: } \\
\text { - } \quad \text { Felt in } 2 \text { camps when } \\
\text { I started transitioning } \\
\text { back to school, was } \\
\text { difficult at times } \\
\text { - } \\
\text { Didn't keep in } \\
\text { contact with peers at } \\
\text { City, only boyfriend. } \\
\text { - } \quad \text { Lost friends at } \\
\text { regular school, but } \\
\text { got new ones. } \\
\text { Generally friends } \\
\text { proud of me. } \\
\text { - Friends difficult to } \\
\text { make at school when } \\
\text { not feeling good. } \\
\text { Couldn't keep up will } \\
\text { all subjects. }\end{array}$ \\
\hline
\end{tabular}


Frequency of findings across cases specific to parents

\begin{tabular}{|c|c|c|c|}
\hline Case & 1 & 2 & 3 \\
\hline $\begin{array}{l}P \\
A \\
R \\
E \\
N \\
T \\
S\end{array}$ & $\begin{array}{l}\text { Common themes across } \\
\text { parents and students } \\
A=14 \\
B=6 \\
C=15 \\
D=4 \\
E=10 \\
F=3 \\
\text { Individual to parents } \\
H=5\end{array}$ & $\begin{array}{l}\text { Common themes across } \\
\text { parents and students } \\
A=18 \\
B=8 \\
C=18 \\
D=11 \\
E=11 \\
F=1 \\
\text { Individual to parents } \\
H=1\end{array}$ & $\begin{array}{l}\text { Common themes across } \\
\text { parents and students } \\
A=18 \\
B=0 \\
C=13 \\
D=12 \\
E=9 \\
F=1 \\
\text { Individual to parents } \\
H=10\end{array}$ \\
\hline & $\begin{array}{ll}\text { Other issues raised } \\
\text { - } & \text { Happier now } \\
& \text { Difficult for } \\
& \text { students when } \\
& \text { others at regular } \\
& \text { school don't } \\
\text { understand } & \text { Talking about } \\
& \text { where she had } \\
& \text { been i.e at City } \\
& \text { was difficult } \\
\text { - } & \text { Parent felt out on } \\
\text { own with situation } \\
\text { Counsellor at } \\
\text { school tried her } \\
\text { best to support } \\
\text { transition } \\
\text { Is more mature } \\
\text { than other students } \\
\text { at school due to } \\
\text { experiences. }\end{array}$ & $\begin{array}{l}\text { Other issues raised } \\
\text { - } \\
\text { Student able to } \\
\text { decisions with } \\
\text { peers from course } \\
\text { i.e not getting into } \\
\text { drugs } \\
\text { - } \quad \text { More mature now } \\
\text { Parents were at } \\
\text { end point, felt they } \\
\text { couldn't do it } \\
\text { anymore with him. } \\
\text { Parents had } \\
\text { concerns about his } \\
\text { choice of a music } \\
\text { course, but has } \\
\text { worked out well, } \\
\text { seen as a stepping } \\
\text { stone. } \\
\text { Issues with } \\
\text { bullying at regular } \\
\text { school } \\
\text { Still no real peers } \\
\text { in his life } \\
\text { He has been } \\
\text { employed by step- } \\
\text { dad so has helped } \\
\text { employment } \\
\text { process } \\
\text { Timing of year } \\
\text { difficult for } \\
\text { transition with } \\
\text { course starting in } \\
\text { Feb, and finishing } \\
\text { in Dec but } \\
\text { managed. } \\
\text { Could have been a } \\
\text { suicide risk or in } \\
\text { prison if things } \\
\text { hadn't changed. }\end{array}$ & $\begin{array}{l}\text { Other issues raised } \\
\text { - } \quad \text { Took a while to get } \\
\text { her confidence back } \\
\text { Was a low point for } \\
\text { parents felt they } \\
\text { couldn't do it } \\
\text { anymore. } \\
\text { - Timing of year } \\
\text { difficult for transition } \\
\text { with being Dec and } \\
\text { starting school in } \\
\text { Feb, but managed. } \\
\text { Made friends at City, } \\
\text { including boy-friend. } \\
\text { Able to connect with } \\
\text { peers at regular } \\
\text { school } \\
\text { Been back to speak } \\
\text { at City was positive } \\
\text { for her } \\
\text { City became very } \\
\text { comfortable/cocoon } \\
\text { however clear about } \\
\text { transition focus } \\
\text { which kept student } \\
\text { moving forward. } \\
\text { Could have been a } \\
\text { suicide risk if things } \\
\text { hadn't changed. }\end{array}$ \\
\hline
\end{tabular}




\section{Frequency of Themes A - F}

\section{Common Themes Across Students and Parents}

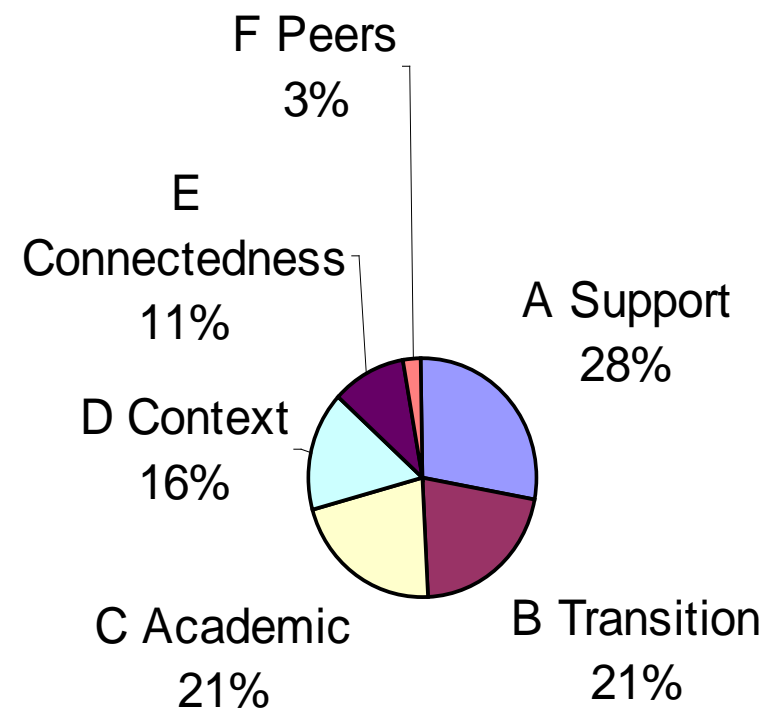

$\square$ A Support

$\square$ B Transition

$\square$ C Academic

$\square \mathrm{D}$ Context

$\square$ E Connectedness

$\square$ F Peers 